\title{
Functional food components and cardiovascular risk markers: effects of plant stanols, B-glucan and conjugated linoleic acid
}

Citation for published version (APA):

Naumann, E. (2006). Functional food components and cardiovascular risk markers: effects of plant stanols, B-glucan and conjugated linoleic acid. [Doctoral Thesis, Maastricht University]. Maastricht University. https://doi.org/10.26481/dis.20060531en

Document status and date:

Published: 01/01/2006

DOI:

10.26481/dis.20060531en

Document Version:

Publisher's PDF, also known as Version of record

Please check the document version of this publication:

- A submitted manuscript is the version of the article upon submission and before peer-review. There can be important differences between the submitted version and the official published version of record.

People interested in the research are advised to contact the author for the final version of the publication, or visit the DOI to the publisher's website.

- The final author version and the galley proof are versions of the publication after peer review.

- The final published version features the final layout of the paper including the volume, issue and page numbers.

Link to publication

\footnotetext{
General rights rights.

- You may freely distribute the URL identifying the publication in the public portal. please follow below link for the End User Agreement:

www.umlib.nl/taverne-license

Take down policy

If you believe that this document breaches copyright please contact us at:

repository@maastrichtuniversity.nl

providing details and we will investigate your claim.
}

Copyright and moral rights for the publications made accessible in the public portal are retained by the authors and/or other copyright owners and it is a condition of accessing publications that users recognise and abide by the legal requirements associated with these

- Users may download and print one copy of any publication from the public portal for the purpose of private study or research.

- You may not further distribute the material or use it for any profit-making activity or commercial gain

If the publication is distributed under the terms of Article $25 \mathrm{fa}$ of the Dutch Copyright Act, indicated by the "Taverne" license above, 
Functional food components and cardiovascular risk markers: effects of plant stanols, $\beta$-glucan and conjugated linoleic acid 

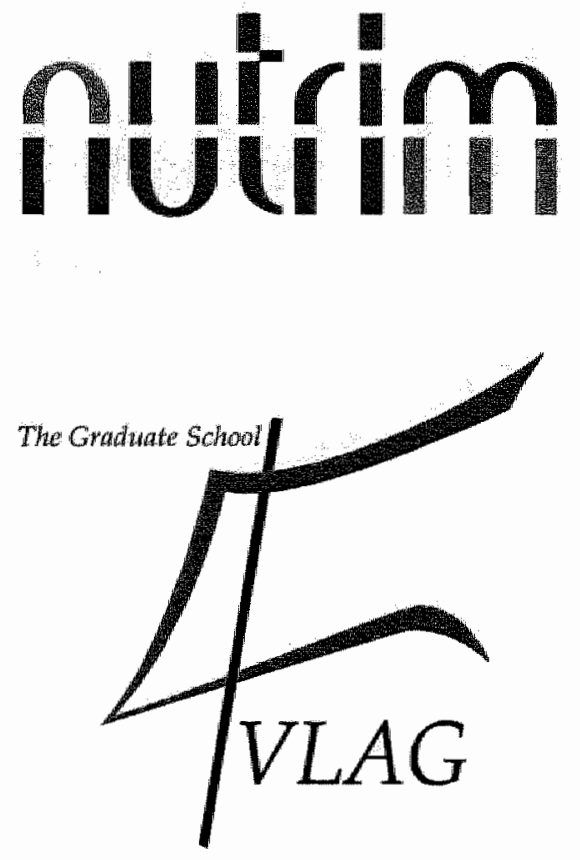

The studies presented in this thesis was performed within the Nutrition and Toxicollogy Research Institute Maastricht (NUTRIM) which participates in the Graduate School VLAG (Food Technology, Agrobiotechnology, Nutrition and Health Sciences), accredited by the Royal Netherlandis Academy of Arts and Sciences.

Production: Ponsen \& Looijen BV, Wageningen Cover Design: Mario Dijsselbloem

(C) Elke Naumann, Nijmegen, 2006

ISBN-10: 90-6464-007-6

ISBN-13: 978-90-6464-007-0 


\title{
Functional food components and cardiovascular risk markers: effects of plant stanols, $\beta$-glucan and conjugated linoleic acid
}

\author{
Proefschrift \\ ter verkrijging van de graad van doctor \\ aan de Universiteit van Maastricht, \\ op gezag van de Rector Magnificus, \\ Prof. Mr. G.P.M.F. Mols \\ volgens het besluit van het College van Decanen, \\ in het openbaar te verdedigen \\ op woensdag 31 mei 2006 om 14.00 uur
}

door

\section{Elke Naumann}

geboren op 7 juli 1976 te Tegelen 


\section{Promotor:}

Prof. Dr. Ir. R.P. Mensink

\section{Co-promotor:}

Dr. J.Plat

\section{Beoordelingscommissie:}

Prof. Dr. Ir. W.H.M. Saris (voorzitter)

Prof. Dr. M.H. Hofker

Prof. Dr. Em. G. Hornstra

Prof. Dr. A.M.W.J. Schols

Dr. Ir. P. Zock (Unilever Health Institute, Vlaardingen)

Financial support by the Netherlands Heart Foundation for the publication of this thesis is gratefully acknowledged. 


\section{Contents}

\section{Chapter 1}

General introduction

\section{Chapter 2}

Plant sterols and plant stanols, lipoprotein metabolism, and cardiovascullar disease

\section{Chapter 3}

Changes in serum concentrations of non-cholesteral sterols and lipoproteins in healthy subjects do not depend on the ratio of plant sterols to stanols in the diet

\section{Chapter 4}

The baseline serum lipoprotein profile is related to plant stanol induced changes in serum lipids and lipoproteins

\section{Chapter 5}

$\beta$-Glucan incorporated into a fruit drink effectively lowers serum LDL cholesterol concentrations

\section{Chapter 6}

Cis-9, trans- 11 and trans-10, cis- 12 conjugated linoleilc acid (CLA) do not affect the plasma lipoprotein profile in moderately overweight subjects with LDL phenotype $B$

\section{Chapter 7}

General discussion

\section{Summary}

Samenvatting

Dankwoord 

Chapter 1

General introduction 


\section{General introduction}

In $200334 \%$ of the total mortality in the Netherlands, about 48000 people, was due to cardiovascular disease, which is thereby the most important cause of death, not only in the Netherlands but also in other western countries [1]. Several risk factors are known, such as obesity, diabetes, high blood pressure, high serum concentrations of total and LDL cholesterol and of triacylglyceral, and low serum concentrations of HDL cholesterol. These risk factors can be positively affected by the composition of the diet. To support the effect of diet, functional foods can be helpful.

\section{Serum lipids and lipoproteins and coronary heart disease risk}

High serum concentrations of total cholesterol are an important risk factor for mortality of coronary heart disease. This was for example demonstrated in a prospective cohort study of about 350000 men, who were divided into quintiles according to total cholesterol concentrations in serum. Compared to the lowest quintile (serum concentrations of total cholesterol $<4.70 \mathrm{mmol} / \mathrm{L}$ ), the relative risk of mortality of coronary heart disease increased from 1.3 in the second to 3.4 in the fifth quintile (serum concentration of total cholesterol $>6.40 \mathrm{mmol} / \mathrm{L}$ ). The risk increased steadily between the $20^{\text {th }}$ to $85^{\text {th }}$ percentile, which indicates that about four-fifth of the population will have a decreased risk of mortality of coronary heart disease when they lower their cholesterol concentrations [2]. The association between tolal cholesterol concentrations and coronary heart disease risk is mainly explained by serum concentrations of LDL cholesterol. High serum concentrations of LDL cholesterol are related to the risk of coronary heart disease [3]. In the USA, the recommended goal for LDL cholesterol concentrations is $<2.60 \mathrm{mmol} / \mathrm{L}$ in people who are at risk (10-year risk $>20 \%$ ) for coronary heart disease [4]. More aggressive lowering of serum LDL cholesterol might even further reduce coronary heart disease risk in very high risk patients [5]. The detrimental effect of increased serum concentrations of LDL cholesterol on coronary heart disease risk has been demonstrated in studies with statins, the most commonly used cholesterol-lowering drugs. They reduce serum concentrations of LDL cholesterol and triacylglycerol and increase serum concentrations of HDL cholesterol [6]. The reduction in serum LDL cholesterol is about $30 \%$, which decreases mortality of coronary heart disease by $25-42 \%[7-10]$. Further, low serum concentrations of HDL cholesterol are associated with the risk for coronary heart disease $[3,11,12]$. A $10 \%$ reduction in $\mathrm{HDL}$ cholesterol for example. was associated with a $13 \%$ increase in ischemic heart disease [12]. The ratio of total to HDL cholesterol is also commonly used to predict the risk of coronary heart disease. In the Netherlands, this ratio is regarded as the most important predictor for cardiovascular risk and, along with the presence of other risk factors (age "gender diabetes mellitus, smoking and hypertension), determines if medication with cholesterol-lowering drugs is 
indicated [13, 14]. In addition, high serum concentrations of triacylglycerol are associated with an increasied risk for coronary heart disease [15].

\section{Effect of nutrition on serum lipids and lipoproteins}

In addition to medication, the composition of the diet affects serum lipids and lipoproteins and consequently the risk of coronary heart disease [16]. Replacing carbohydrates isoenergetically by saturated fatty acids (lauric acid, myristic acid and palmitic acid) or trans fatty acids increases serum concentrations of total and LDL cholesterol, whereas replacing carbohydrates iso-energetically by mono- or poly-unsaturated fatty acids has the opposite effects. Lauric acid however decreases the ratio of total to HDL cholesterol when used instead of carbohydrates. The total to $\mathrm{HDL}$ cholesterol ratio was not affected by myristic acid and palmitic acid [17]. Several campaigns have been carried out during the last years to increase the knowledge of Dutch consumers about saturated as unhealthy and unsaturated as more healthy fatty acids and to make them aware of their own fat intake. However, intake of saturated fatty acids is still 14-15\% of energy for men and women between 22 and 65 years of age and $13 \%$ of energy in a recent study in people between 19 and 30 years of age, while an intake as low as possible is recommended and $10 \%$ of energy intake is the tolerable upper intake level $[14,18,19]$. It seems therefore that people do not easily change their diets. The intake of trans fatty acids has decreased during the last years, mainly due to changes in fats and oils used for food processing. Although a diet in accordance with the dietary reference intakes should always be recommended, functional foods are helpfull to further improve a favourable serum lipoprotein profile.

\section{Functional foods}

One of the definitions of a functional food is: "A food can be regarded as functional if it is satisfactory demonstrated to affect beneficially one or more target functions in the body, beyond adequate nutritional effects, in a way that is relevant to either improved stage of health and well-being and/ or reduction of risk of disease. A functional food must remain food and it must demonstrate its effects in amounts that can normally be expected to be consumed in the diet: it is not a pill or a capsule "but part of the normal food pattern" [20]. Therefiore, a food to which a component has been added to affect serum concentrations of lipids and lipoproteins is a functional food. In this thesis the possibilities of plant sterols and stanols, the soluble fibre $\beta$-glucan and conjugated linoleic acid (CLA) as functional ingredients to improve an atherogenic lipoprotein profile will be presented. 


\section{Plant sterols and stanols}

Plant sterols and stanols are present naturally in the diet in amounts of $160-450 \mathrm{mg}$ per day. An increase in daily intake with $2-2.5 \mathrm{~g}$ through the use of functional foods lowers serum concentrations of LDL cholesterol on average by $8.9 \%$ [21]. Therefore, margarines enriched with plant sterols are sold in the Netherlands for several years now, whereas also plant sterol eniriched yogurts and plant sterol enriched milk have been introduced. Plant stanol enriched food products have been on the market for some years. Safety studies have indicated no adverse effects of plant sterols and stanols, but the Joint FAONWO Expert Committee on Food Additives recommends that the daily intake of plant sterols and stanols should not exceed $137 \mathrm{mg} / \mathrm{kg} /$ day, which is equivalent to $9.6 \mathrm{~g}$ per day for a $70 \mathrm{~kg}$ adult. A higher intake of plant sterols however is not very likely. also due to the limited number of plant sterol containing functional food products in the Netherlands. If more plant sterol enriched products would be avallable, the risk of over-consumption may increase [22]. On the other hand, because functional foods are more expensive than their non-enriched counterparts, people might not easily consume more of these functional foods than the $2-3 \mathrm{~g}$ per day necessary to achieve a maximum cholesterol-lowering effect. For some people in the Netherlands, higher prices of food products enriched with plant sterols may however not longer be a reason for not buying these products, since some Dutch health insurance companies decided to pay back the difference in price of the functional food compared with the regular food product. It is however necessary that consumers are well informed about the optimall dose of $2-3 \mathrm{~g}$ per day and about the ineffectiveness of increasing this dose any further. Further, plant sterols and stanols should be consumed as part of a recommended diet, and should not be used to counterbalance the effects of an unhealthy diet. Therefore, for people with slightly elevated serum concentrations of LDL cholesterol, dietary changes alone might already sufficiently decrease serum concentrations of LDL cholesterol. Thus, when consumed as part of a healthy diet and in amounts recommended, functional foods containing plant sterols and stanols might be useful for people with elevated serum LDL chollesterol concentrations. Effects of plant sterols and plant stanols on lipoprotein metabolism, and cardiovascular disease risk will be presented in more detail in Chapter 2 of this thesis and will therefore not be discussed here.

Consumption of plant sterol and stanol enriched products is considered safe, except for people with sitosterolemia, who should not consume plant sterol enriched products. Sitosterolemia is a rare inherited disease characterized by extremely high serum plant sterol concentrations. These patients have a wery high risk of coronary heart disease, although it is not known whether this is caused by their high serum plant sterol concentrations [23, 24]. Although consumption of plant sterol enriched products increases their respective serum concentrations, concentrations always remain much lower than in sitosterolemic patients. It has been suggested that plant stanols reduce serum concentrations of plant sterols. To examine the effects of plant stanols on plant sterol metabolism, we decided to study the effects of mixtures of plant sterols and stanols on their respective serum concentrations 
(Chapter 3). Although a daily intake of $2-2.5 \mathrm{~g}$ decreases serum concentrations of $\mathrm{LDL}$ cholesterol on average by $8.9 \%$, reductions between studies varied from $4-19 \%$. These differences might be explained by differences in baseline characteristics of the subjects. To examine the effects of subjects' characteristics on the effects of plant stanols on the serum lipid and lipoprotein profile more systematically we decided to carry out a meta-analyses. using the individual data of five studies performed at our Department (Chapter 4).

\section{Dietary fibre}

Dietary fibres are plant compounds that are resistant to digestion by enzymes in the small intestine. They can, however, be fermented into short chain fatty acids by bacteria in the colon. Dietary fibres are often classified into soluble and insoluble fibres. Insoluble fibres are structural or matrix fibres, such as cellulose, lignins and some hemicelluloses and are present in plants. Soluble fibres are gel-forming fibres, such as $\beta$-glucan, pectin, gums, mucilages and other hemicelluloses and are present for example in oats, barley, rye, vegetables and citrus fruits. An increased intake of dietary fibre, especially soluble fibre by 10 $\mathrm{g}$ per day is associated with a reduction in risk of coronary heart disease by $10-30 \%$ [25]. This reduction in risk might be caused by decreases in serum concentrations of LDL cholesterol, lowering of blood pressure, improvement of insulin sensitivity or a combination of these factors. The NCEP guideline recommends a daily intake of 5-10 $\mathrm{g}$ of soluble fibre to reduce serum LDL cholesterol concentrations by $3-5 \%$ [4]. It is however difficult to estimate daily intake of soluble fibre, as procedures to measure the soluble fibre content in foods are not standardized. Thus, only few studies reported median daily intakes of soluble fibres, which were $5.4 \mathrm{~g}$ in adult male smokers in Finland [26] and $2.4 \mathrm{~g} / 1735 \mathrm{kcal}$ in adult men and women in the United States [27]. In the latter study, daily intakes of soluble fibre were about $1 \mathrm{~g}$ the lowest and $7 \mathrm{~g}$ in the highest quartile [27]. When daily soluble fibre intake in American women was grouped into quintiles, daily intakes were $3 \mathrm{~g}$ in the lowest and $7 \mathrm{~g}$ in the highest quintile [28, 29]. These results suggest that daily intakes are often less than 5-10 g per day. When it is assumed that about $20 \%$ of total dietary fibre intake is soluble fibre [27], it can be estimated that soluble fibre intake in the Netherlands is approximately $4 \mathrm{~g}$ at a total dietary fibre intake of $20 \mathrm{~g}$. The use of functional foods enriched with soluble fibre might be helpful to increase the daily intake of soluble fibre, which might favourably affect the lipoprotein profile. The soluble fibre $\beta$-glucan might be suitable for incorporation into these products.

\section{B-glucian}

$\beta$-glucan consists of several molecules of glucose, connected to each other by $\beta-(1 \rightarrow 4)$ and $\beta-(1 \rightarrow 3)$ bounds (Figure 1.1). It is present in relatively high amounts in oats and barley (about $7 \%$ in oat bran, $4 \%$ in oatmeal and $5 \%$ in barley bran). In 1963, de Groot et al. discovered the cholesterol-lowering effects of rolled oats [30]. In 1994, $\beta$-glucan was idientified as the cholesterol-lowering compound of rolled oats [31]. 


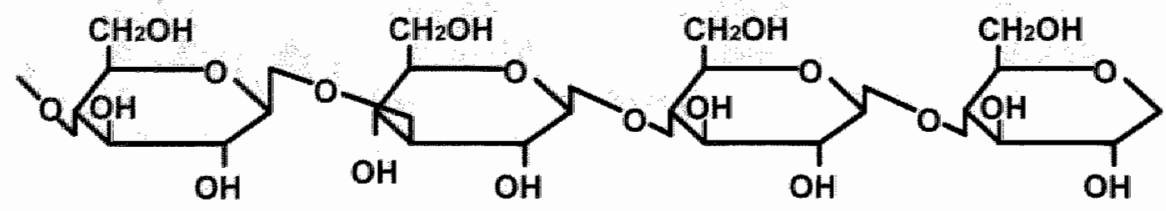

Figure 1.1: The molecular structure of $\beta$-glucan.

\section{Effects of $\beta$-glucan on serum cholesterol}

Several meta-analyses have been carried out to evaluate the cholesterol-lowering effects of $\beta$-glucan. A recent meta-analysis found a decrease of $0.04 \mathrm{mmol} / \mathrm{L}$ in serum concentrations of total cholesterol and of $0.03 \mathrm{mmol} / \mathrm{L}$ in serum concentrations of $\mathrm{LDL}$ cholesterol per $\mathrm{g}$ of soluble fibre from oat [32]. However, results of individual studies on cholesterol-lowering effects of $\beta$-glucan are conflicting. One review reported decreases in serum total cholesterol ranging from 0 to $18 \%$ [33]. These differences between studies might be explained by the food matrix and food processing of the $\beta$-glucan enriched product. Evidence for this comes from a study in which daily consumption of $5.9 \mathrm{~g}$ of $\beta$-glucan from oat bran incorporated into bread and cookies did not affect serum cholesterol concentrations, whille incorporation of the same amount of $\beta$-glucan into orange juice lowered serum total cholesterol by $3.8 \%$ and serum LDL cholesterol by 6.7\% [34]. In 1997, the American Food and Drug Administration allowed a health claim for whale oat foods on reducing the risk of heart disease. To qualify for the health claim, these foods must provide at least 0.75 grams of soluble fibre per serving and total intake should be $3 \mathrm{~g}$ of soluble fibre per day to reach a cholesterol-lowering effect [35]. However, as there are several studies that did not find cholesterol-lowering effects of $\beta$ glucan [36], the FDA claim might not be suitable for every product that provides 0.75 grams of soluble fibre from whole oats per serving. Since it is difficult to predict the cholesterollowering effect of individual food products enriched with $\beta$-glucan and to better understand the mechanism of action, we examined the effects of a $\beta$-glucan enriched fruit juice on the serum lipoprotein profile (Chapter 5).

\section{Mechanism of action of $\beta$-glucan}

Although the exact mechanism of action of $\beta$-glucan has not been elucidated, several hypotheses exist to explain its cholesterol-lowering properties. One hypothesis concerns changes in bile acid metabolism. Lia et al. studied the effects of a wheat test meal and an oat 
bran test meal in six ileostomy subjects. In the 24-hour period after the test meal $\mathrm{s}_{\text {" }}$ excretion of bile acids was significantly higher after the oat bran test meal than after the wheat test meal [37]. In another study, bille acid excretion was significantly increased in illeostomy subjects after a diet rich in oat bran compared with both a wheat based diet and a diet enriched with oat bran plus $\beta$-glucanase, an enzyme that degrades $\beta$-glucan, indicating that the increase in bile acid excretion after oat bran was indeed due to $\beta$-glucan [38]. Marlett et al. also explained the cholesterol-lowering effects of $\beta$-glucan at least partly by an increase in bile acid synthesis and a decrease in bile acid re-absorption, although results should be interpreted carefully because a control group was missing [39]. The increase in bile acid synthesis might be explained by a decreased re-absorption of bile acids from the intestine, due to a greater intestinal viscosity, resulting in an enlarged thickness of the unstirred water layer in the intestine [40]. This also suggests that $\beta$-glucan affects absorption of lipids and other nutrients as well. Indeed, excretion of fatty acids was higher after oat bran than after wheat consumption and chylomicron cholesterol concentrations were lower in illeostomy patients after an oat bran rich diet compared with a wheat bran diet [37]. Effects of different fibres on intestinal viscosity were tested in ileostomy patients, who consumed four different types of bread. The breads contained high amounts of oat bran, barley, wheat and aat bran plus B-glucanase incorporated into bread. Oat bran bread developed the highest intestinal viscosity and resulted in the highest excretion of $\beta$-glucan $(87 \%)$. Consumption of barley bread resulted in a slightly lower viscosity and an excretion of $\beta$-glucan of $81 \%$. Consumption of wheat bread and oat bread plus $\beta$-glucanase resulted in a low viscosity and an excretion of $\beta$-glucan of only $36 \%$ and $58 \%$ of intake, respectively [41]. Together these studies provide evidence that $\beta$-glucan affects the entero-hepatic circulation. It increases intestinal viscosity, which lowers absorption of bile acids, cholesterol and fatty acids. A decrease in re-absorption of bile acids increases bille acid synthesis, resulting in an increased utilization of cholesterol for bile acid synthesis. This will decrease serum concentrations of LDL cholesterol and increase bile acid excretion (Figure 1.2). 


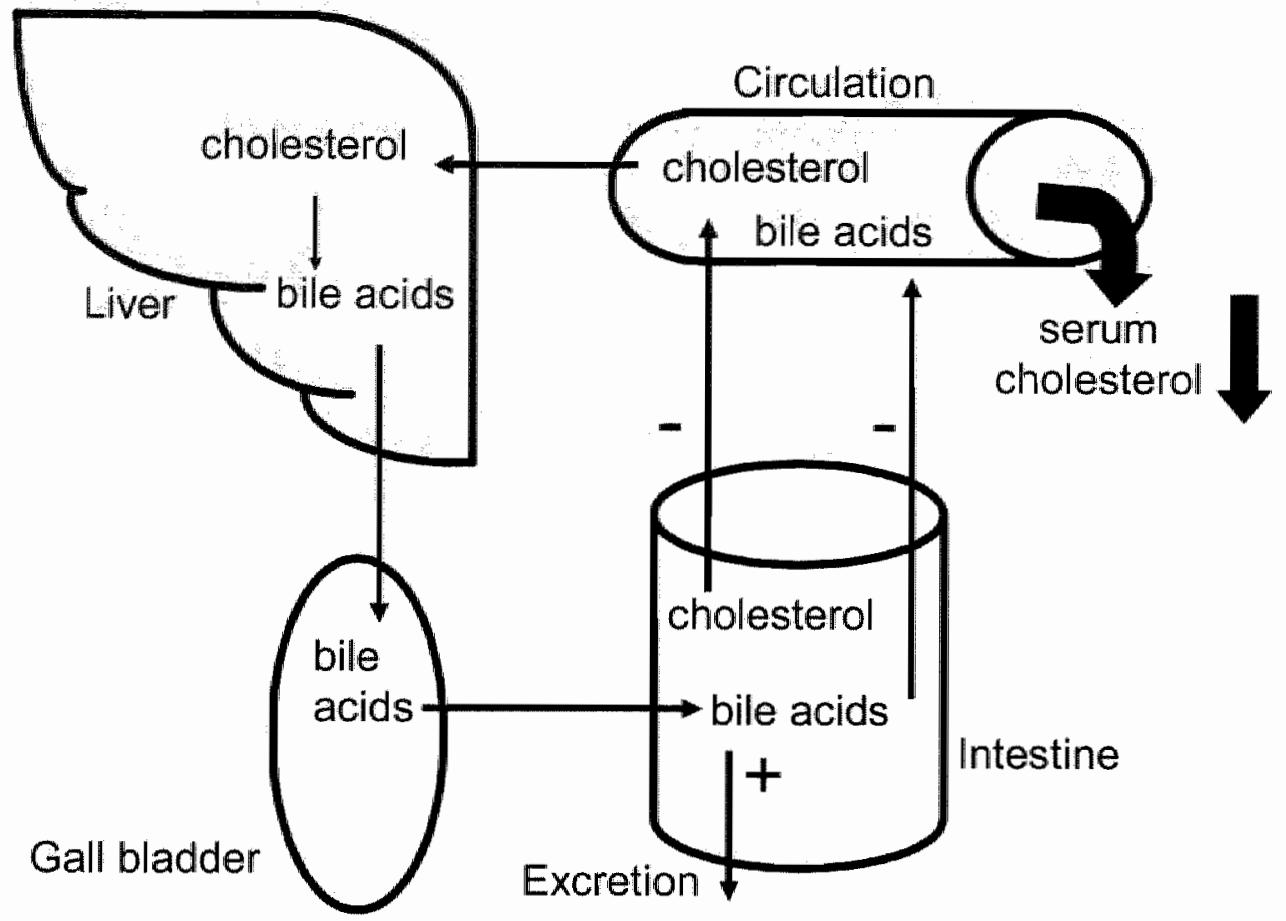

Figure 1.2: Schematic overview of the entero-hepatic circulation and possible effects of $\beta$-glucan. $\beta$ glucan might decrease (re-)absorption of bile acids and cholesterol (indicated by -) and increase their excretion (indicated by +). Consequently, less cholesterol and bile acids enter the circulation. This might increase bile acid synthesis, which requires cholesterol. The cholesterol-lowering effect of $\beta$ glucan might therefore be explained by increased utilization for bile acid synthesis, along with reduced absorption of cholesterol.

Besides effects on re-absorption of bile acids from the intestine, either by influencing intestinal viscosity or intestinal binding of bille acids, $\beta$-glucan might affect colonic production of short-chain fatty acids. Oat bran increased postprandial serum concentrations of acetate, which could have contributed to the cholesterol-lowering effect of this study [42]. Contrary to these findings, rectally infused acetate increased serum concentrations of total and LDL cholesterol in another study [43] or had no effect on serum lipids [44]. Further, it has been suggested that it takes 6 months before soluble dietary fibres increase serum concentrations of acetate [45]. This observation does not support the hypothesis that $\beta$-glucan lowers serum 
concentrations of cholesterol by affecting acetate concentrations, because effects on cholesterol concentrations are usually seen within a few weeks [31, 34, 46, 47]. Finally, negative correlation was observed between serum cholesterol concentrations and acetate concentrations in women and propionate concentrations in men. while an increase in the ratio of acetate to propionate was positively correlated with serum cholesterol concentrations in men and non-significantly in women [48]. Together, these results do not support the hypothesis that oat bran reduces serum concentrations of cholesterol by affecting short-chain fatty acid production.

Besides possible effects of $\beta$-glucan on bile acid metabolism and colonic short chain fatty acid production, a third hypothesis involves effects of $\beta$-glucan on serum concentration of insulin and glucose [36]. High cholesterol synthesis is associated with increased serum concentrations of insulin [49-51] and glucose [52]. Therefore, reducing serum glucose and insulin might decrease cholesterol synthesis and subsequently serum cholesterol levels. Although several studies found smaller postprandial increases in blood glucose or insulin concentrations after consumption of meals containing B-glucan compared to placebo [53-56]" other trials could not confirm these results $[37,57]$.

To summarize, of the suggested mechanisms of action of B-glucan, the most likely effect of $\beta$-glucan is an increased excretion of bile acids, resulting form a decreased absorption of bile acids. It can be suggested that this would also affect absorption and synthesis of cholesterol. To better understand the underlying mechanism, we determined markers of cholesterol absorption (serum concentrations of plant sterols) and cholesterol synthesis (serum concentrations of lathosterol) during consumption of a $\beta$-glucan enriched fruit drink (Chapter 5).

\section{Conjugated Linoleic Acid}

Conjugated linoleic acid (CLA) refers to a group of positional and geometric isomers of linoleic acid. Contrary to linoleic acid, in which the double bonds are separated by two single bonds in the cis configuration. CLA has only one single bond between two double bonds. Since the double bonds in the CLA molecule can be present at different sites in the molecule. several CLA isomers occur. Cis-9, trans-11 CLA $(c 9,111$ CLA) is the most common CLA isomer in the western diet, followed by the trans-10, cis-12 CLA ( $110, c 12 C L A)$ isomer (Figure 1.3) [58]. CLA is formed in the rumen gut as a result of microbial isomerisation of dietary linoleic acid and desaturation of oleic acid derivatives [58]. The main sources of dietary CLA are dairy products and meat. Daily intake of CLA is estimated to be about 150 mg per day for women and $200 \mathrm{mg}$ per day for men [59]. Several health effects have been ascribed to CLA, including anti-carcinogenic properties, decreases in adiposity, improvement of immune function, and anti-atherogenic properties [60]. The latter effect will be discussed in short bellow. 


\section{Linoleic acid $(18: 2 \operatorname{cis} 9, \operatorname{cis} 12)$}

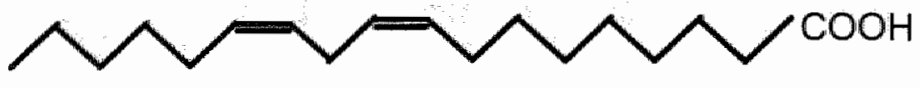

cis9, trans11-CLA

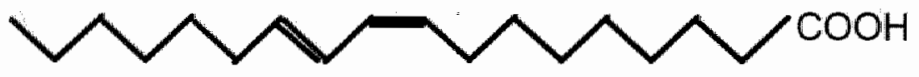

trans10, cis12-CLA

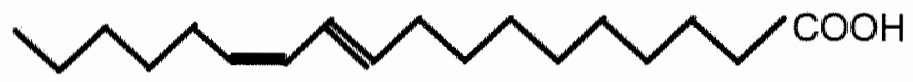

Figure 1.3: The molecular structures of linoleic acid, $c 9, t 11 \mathrm{CLA}$ and $\$ 10,012 \mathrm{CLA}$.

\section{Anti-atherogenic effect of CLA}

Evidence for anti-atherosclerotic properties of CLA mainly comes from animal studies. CLA may decrease serum concentrations of total cholesterol and reduce aortic fatty streak areas in rabbits [61] and hamsters [62-64]. In humans, no favourable effects of the two most investigated isomers, $c 9, t 11 \mathrm{CLA}$ and $t 10, c 12 \mathrm{CLA}$, have been found on serum concentrations of lipids and lipoproteins [65-68], except for decreased VLDL-triacylglycerol concentrations [69]. Most studies used mixtures of $c 9, t 11$ CLA and $t 10, c 12$ CLA and therefore effects of these isomers separately are less clear. In the study of Noone et al [69], two different mixtures were used. The mixture containing equal amounts of both isomers decreased serum concentrations of triacylglycerol, while the mixture containing $80 \% c 9, t 11$ CLA and $20 \% t 10, C 12$ CLA did not. Contrary to this finding, serum triacylglycerol concentrations were higher during $t 10, c \| 2$ CLA than during $c 9,111$ CLA treatment in healthy imen in a study of Tricon et al [70]. Despite these opposite findings, it supports the suggestion that the two isomers have different effects in the human body [71-73]. In addition, serum concentrations of total cholesterol, LDL cholesterol and the ratio of total to HDL cholesteral were higher during consumption of $t 10, c 12$ CLA than of $c 9,111 \mathrm{CLA}$ in healthy subjects [70]. A pilot study at our Department indicated that $c 9, t 11$ CLA, but not $t 10, c 12$ CLA, reduced the proportion of small dense LDL cholesterol. It has been estimated that people carrying $>35 \%$ of $L D L$ cholesterol in small dense $L D L$ cholesterol $(L D L \geq 1.0409 \mathrm{~g} / \mathrm{ml})$, a phenomenon called $L D L$ phenotype $B$, have a more than three times higher risk for coronary heart disease [74]. Since the LDL phenotype $B$ is rather common in western countries, a functional food 
component that could decrease the proportion of small dense LDL cholesterol could be of benefit for a lot of people. Therefore, to test the findings from the pilot study, we investigated in a larger group of subjects the effects of CLA on proportions of small dense LDL cholesterol (Chapter 6).

\section{Mechanism of action of CLA}

Effects of CLA on the serum lipid profile are still not clear. Therefore, it is difficult to speculate on possible mechanisms of action. Nevertheless, there are some suggestions. CLA, especially the 110,612 CLA isomer, may reduce the number of VLDL particles by inhibition of hepatic synthesis of apoB-containing lipoproteins $[73,75-78]$, which might explain the decrease in VLDL-triacylglycerol concentrations found in a study by Noone et al. [69]. In addition, it has been suggested that $110, c 12$ CLA decreases stearoyl-CoA desaturase activity. This enzyme is involved in the desaluration of stearic acid into oleic acid, the preferred substrate for the synthesis of triacylglycerols. A decrease in stearoyl-CoA desaturase activity may therefore result in a decrease in triacylglycerol concentrations $[79,80]$. In adidition, CLA may increase LDL receptor activity [81] . Further, CLA may displace cholesterol form LDL particles or may decrease cholesterol absorption by inhibiting intestinal acyl-coenzyme A: cholesterol acyltransferase (ACAT) activity [64].

\section{Outline of the thesis}

This thesis focuses on effects of nutritional components that might be suitable for incorporation into functional foods to positively affect serum lipoprotein and lipid profiles. Chapter 2 gives an overview of effects of plant sterols and plant stanols, lipoprotein metabolism, and cardiovascular disease. Although the cholesterol-lowering properties of plant sterols and stanols are widely accepted, less is known about their concentrations in serum after consumption of plant steral and stanol enriched food products. This will be discussed in chapter 3. In addition, cholesterol-lowering effects are not the same for everyone. In chapter 4 we therefore analyzed subject characteristics that might affect the cholesterol-lowering properties of plant stanols. In addition to plant stanols, fo-glucan might be suitable for incorporation into functional foods because of its cholesterol-lowering characteristics. Effects of a $\beta$-glucan enriched fruit drink on serum cholesteral concentrations and cholesterol metabolism are presented in Chapter 5 . Chapter 6 describes the results of a study on the effects of CLA on the serum lipoprotein profile. Finally, the main outcomes of the studies are discussed in the General Discussion in Chapter 7. 


\section{References}

1. Nederlandse Hartstichting. Internet: http:/www hartstichting.nl.

2. Martin MJ, Hulley SB, Browner WS, Kuller LH and Wentworth D. Serum cholesterol, blood pressure, and mortality: implications from a cohort of 361662 men. The Lancet 1986; oktober:932-36.

3. Pekkanen J. Linn $S$, Heiss $G$, et al. Ten-year mortality from cardiovascular disease in relation to cholesterol levell among men with and without preexisting cardiovascular disease. $N$ Engl J Med 1990; $322: 1700-7$.

4. National Cholesterol Education Program (NCEP) Expert Panel on Detection, Evaluation, and Treatment of High Blood Cholesterol in Adults (Adult Treatment Panel III). Third Report of the National Cholesterol Education Program (NCEP) Expert Panel on Detection, Evaluation, and Treatment of High Blood Cholesterol in Adults (Adult Treatment Panel III). Final Report. September 2002, National Heart, Lung, and Blood Institute. National Institute of Health.

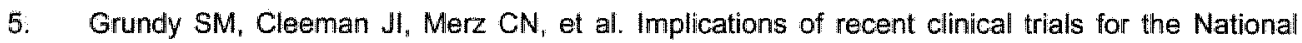
Cholesterol Education Program Adult Treatment Panel lil guidelines. Circulation 2004; 110:22739.

6. LaRosa JC, He $J$ and Vupputuri $S$. Effect of statins on risk of coronary disease: a meta-analysis of randomized controlled trials. Jama 1999; 282:2340-6.

7. Sacks FM, Pfeffer MA Moye LA, et at. The effect of pravastatin on coronary events after myocardial infarction in patients with average cholesterol levels. N Engl J Med 1996; 335:100109 .

8. Shepherd $\mathrm{J}$ Cobbe $\mathrm{S}$, Ford $\mathrm{I}$, et al. Prevention of coronary heart disease with pravastatin in men with hypercholesterolemia. N Engl J Med 1995; 333:1301-07.

9. The long-term intervention with pravastatin in ischeamic diseases (LIPID) study group. Prevention of cardiovascular events and death with pravastatin in patients with coronary heart disease and a broad range of initial cholesterol levels. N Engl J Med 1998; 339:1349-57.

10. Scandinavian Simvastatin Survival Study Group. Randomised trial of cholesterol lowering in 4444 patients with coronary heart disease: the Scandinavian Simvastatin Survival Study (4S). Lancet 1994: 344:1383-89.

11. NIH Consensus Development Panel on triglyceride high-density lipoprotein, and coronary heart disease. Triglyceride, high-density lipoprotein, and coronary heart disease. JAMA 1993; 269:505-10.

12. Despres J-P, Lemieux I, Dagenais $G-R$, Cantin $B$ and Lamarche B. HDL-cholesterol as a marker of coronary heart disease risk: the Quebec cardiovascular study. Atherosclerosis 2000; 153:263-72.

13. Centraal begeleidingsorgaan voor de intercollegiale toetsing, in samenwerking met Nederlandse Hartstichting, et al. Behandeling en preventie van coronaire hartziekten door verlaging van de plasma cholesterolconcentratie. Utrecht: CBO, 1998. 
14. Gezondheidsraad. Voedingsnormen. Energie, eiwitten, vetten en verteerbare koothydraten. Ih publicatie $\mathrm{nr}$ 2001/19R (gecorrigeerde editie: juni 2002): Den Haag: Gezondheidsraad, 2001.

15. Cullen $P$. Evidence that triglycerides are an independent coronary heart disease risk factor. Am J Cardiol 2000; 86:943-49.

16. Hu FB, Manson JE and Willett WC. Types of dietary fat and risk of coronary heart disease: $a$ critical review. J Am Coll Nutr 2001; 20:5-19.

17. Mensink RP, Zock PL, Kester AD and Katan MB. Effects of dietary fatty acids and carbohydrates on the ratio of serum total to HDL cholesterol and on serum lipids and apolipoproteins: a meta-analysis of 60 controlled trials. Am J Clin Nutr 2003; 77:1146-55.

18. Voedingscentrum. Zo eet Nederland 1998. Resultaten van de Voedselconsumptiepeiling 1998. Den Haag: Voedingscentrum, 1998

19. Voedingscentrum. Zo eten jongvolwassenen in Nederland. Resultaten van de Voedselconsumptiepeiling 2003. Den Haag: Voedingscentrum 2004.

20. Roberfroid MB. Global view on functional foods: European perspectives. $\mathrm{Br} \mathrm{J}$ Nutr 2002; $8 \mathrm{~B}$ Suppl 2:S133-8.

21. Katan MB, Grundy SM, Jones P, Law M, Miettinen T and Paoletti R. Efficacy and safety of plant stanols and sterols in the management of blood cholesterol levels. Mayo Clin Proc 2003; 78:965-78.

22. De Jong N, Pijpers L, Bleeker JK and Ocke MC. Potential intake of phytosterols/-stanols: results of a simulation study. Eur J Clin Nutr 2004; 58:907-19.

23. Salen G, Shefer S, Nguyen L, Ness GC, Tint GS and Shore V. Sitosterolemia. J Lipid Res 1992: $33: 945-55$.

24. Salen $G$, Horak I, Rothkopf $M_{n}$ et al. Lethal atherosclerosis associated with abnormal plasma and tissue sterol composition in sitosterolemia with xanthomatosis. J Lipid Res 1985; 26:112633.

25. Pereira MA, O'Reilly $E$, Augustsson $K_{\text {, }}$ et al. Dietary fiber and risk of coronary heart disease: a pooled analysis of cohort studies. Arch Intern Med 2004: 164:370-6.

26. Pietinen $P$, Rimm $E B$, Korhonen $P$, et al. Intake of dietary fiber and risk of coronary heart disease in a cohort of Finnish men. The Alpha-Tocopherol, Beta-Carotene Cancer Prevention Study. Circulation 1996; $94: 2720$-7.

27. Bazzano LA, He J, Ogden LG, Loria CM and Whelton PK. Dietary fiber intake and reduced risk of coronary heart disease in US men and women: the National Health and Nutrition Examination Survey I Epidemiologic Follow-up Study. Arch Intern Med 2003; 163:1897-904.

28. Liu S, Buring JE, Sesso HD, Rimm EB, Willett WC and Manson JE. A prospective study of dietary fiber intake and risk of cardiovascular disease among women. J Am Coll Cardiol 2002 39:49-56.

29. Wolk $A_{*}$ Manson JE, Stampfer M.J, et al, Long-term intake of dietary fiber and decreased risk of coronary heart disease among women. Jama 1999; 281:1998-2004.

30. Groot A de, Luyken R and Pikaar NA. Cholesterol-lowering effect of rolled oats. Lancet 1963; 2:303-4. 
31. Braaten JT, Wood Pdi Scott FW, et al: Oat beta-glucan reduces blood cholesterol concentration in thypercholesterolemic subjects. Eur J Clin Nutr 1994; 48:465-74.

32. Brown $L_{\text {. }}$ Rosner $B$, Willett WW and Sacks FM. Cholesterol-lowering effects of dietary fiber: a meta-analysis. Am J Clin Nutr 1999; 69:30 42.

33. Truswell AS. Cereal grains and coronary heart disease. Eur J Clin Nutr 2002; 56:1-14.

34. Kerckhoffs DA, Hornistra $G$ and Mensink RP. Cholesteroll-lowering effect of beta-glucan from oat bran in mildly hypercholesterolemic subjects may decrease when beta-glucan is incorporated into bread and cookies. Am J Clin Nutr 2003; 78:221-7.

35. FDA Talk Paper. FDA allows whole oat foods to make health claim on reducing the risk of heart disease. 1997: Avallable at: http/www.cfsan.fda.gov/-lrd/tpoats.html. Accessed April 27, 2001.

36. Kerckhoffs DA, Brouns F, Hornstra $G$ and Mensink RP. Effects on the human serum lipoprotein profile of beta-glucan, soy protein and isoflavones, plant sterols and stanols, garlic and tocotrienols. J Nutr 2002; 132:2494-505.

37. Lia A, Andersson H, Mekki N, Juhel C, Senft M and Lairon D. Postprandial lipemia in relation to sterol and fat excretion in ileostomy subjects given oat-bran and wheat test meals. Am J Clin Nutr $1997 ; 66: 357-65$.

38. Lia A, Hallmans $G$, Sandberg AS, Sundberg B, Aman P and Andersson H. Oat beta-glucan increases bile acid excretion and a fiber-rich barley fraction increases cholesterol excretion in ileostomy subjects. Am $\Downarrow$ Clin Nutr 1995; 62:1245-51.

39. Marlett JA, Hosig KB, Vollendorf NW, Shinnick FL, Haack VS and Story JA. Mechanism of serum cholesterol reduction by oat bran. Hepatology 1994; 20:1450-7.

40. Johnson IT and Gee JM. Effect of gel-forming gums on the intestinal unstirred layer and sugar transport in vitro. Gut 1981; 22:398-403.

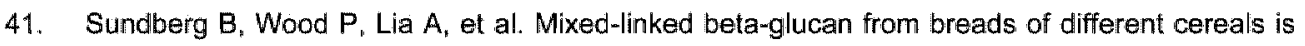
partly degraded in the human ileostomy model. Am J Clin Nutr 1996;64:878-85.

42. Bridges SR, Anderson JW, Deakins DA, Dillon DW and Wood CL. Oat bran increases serum acetate of hypercholesterolemic men. Am J Clin Nutr 1992; 56:455-9.

43. Wolever $\mathrm{TM}_{1}$ Spadafora $\mathrm{P}$ and Eshuis $\mathrm{H}$. Interaction between colonic acetate and propionate in humans. Am J Clin Nutr 1991; 53:681-7.

44. Wolever TM. Spadafora PJ "Cunnane SC and Pencharz PB. Propionate inhibits incorporation of colonic [1,2-13C]acetate into plasma lipids in humans. Am J Clin Nutr 1995; 61:1241-7.

45. Wolever TM, Schrade KB, Vogt JA, Tsihlias EB and McBurney MI. Do colonic short-chain fatty acids contribute to the long-term adaptation of blood lipids in subjects with type 2 diabetes consuming a high-fiber diet? Am J Clin Nutr 2002; 75:1023-30.

46. Behall KM, Scholfield DJ and Hallfrisch J. Effect of beta-glucan level in oat fiber extracts on blood lipids in men and women. J Am Coll Nutr 1997; 16:46-51.

47. Önning G, Wallmark A, Persson M, Ákesson B, Elmståhll S and Öste R. Consumption of aat milk for 5 weeks lowers serum cholesterol and LDL cholesterol in free-living men with moderate hypercholesterolemia. Ann Nutr Metab 1999; 43:301-9. 
48. Wolever TM, Fernandes $J$ and Rao AV. Serum acetateppopionate ratio is related to serum cholesterol in men but not women. J Nutr 1996; 126:2790-7.

49. Griffin M, Frazer A, Johnson A, Collins $P$, Owens D and Tomkin GH. Cellular cholesterol synthesis-the relationship to post-prandial glucose and insulin following weight loss. Atherosclerosis 1998; 138:313-8.

50. Naoumova RP, Cummings MH, Watts GF, et al. Acute hyperinsulinaemia decreases cholesterol synthesis less in subjects with non-insulin-dependent diabetes melitus than in non-diabetic subjects. Eur J Clin Invest 1996; 26:332-40,

51. Feillet $\mathrm{C}$, Monnier $\mathrm{LH}_{*}$ Barjon $\mathrm{JN}$, Perrin $\mathrm{M}$, Descomps $\mathrm{B}$ and Crastes de Paulet A. Evidence for a short-term stimulatory effect of insulin on cholesterol symthesis in newly insulin-treated diabetic patients. Metabolism 1994; 43:1233-40.

52. Strandberg TE, Salomaa V, Vanhamen $H$ and Miettinen TA. Associations of fasting blood glucose with cholesterol absorption and synthesis in nondiabetic middle-aged men. Diabetes $1996 ; 45: 755-61$.

53. Braaten JT, Wood PJ, Scott FW, Riedel KD, Poste LM and Collins MW, Oat gum lowers glucose and insulin after an oral glucose load. Am J Clin Nutr 1991; 53:1425-30.

54. Braaten JT, Scott FW, Wood PJ, et al. High beta-glucan oat bran and oat gum reduce postprandial blood glucose and insulin in subjects with and without type 2 diabetes. Diabet Med $1994 ; 11: 312-8$.

55. Battilana $P$, Ornstein $K$, Minehira $K$, et al. Mechanisms of action of beta-glucan in postprandial glucose metabolism in healthy men. Eur $\mathrm{J}$ Clin Nutr 2001; 55:327-33.

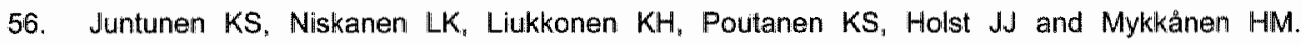
Postprandial glucose, insulin, and incretin responses to grain products in healthy subjects. Am J Clin Nutr 2002; 75:254-62.

57. Lovegrove JA, Clohessy A, Milon $H$ and Williams CM. Modest doses of beta-glucan do not reduce concentrations of potentially atherogenic lipoproteins. Am J Clin Nutr 2000; 72:49-55.

58. Kelly GS. Conjugated linoleic acid: a review. Altern Med Rev 2001; 6:367-82.

59. Ritzenthaler $K \mathbb{L}$. McGuire MK, Falen $\mathrm{R}$, Shultz TD, Dasgupta $\mathrm{N}$ and McGuire MA. Estimatton of conjugated linoleic acid intake by written dietary assessment methodologies underestimates actual intake evaluated by food duplicate methadology. J Nutr 2001: 131:1548-54.

60. Belury MA. Dietary conjugated linoleic acid in health: physiological effects and mechanisms of action. Annu Rev Nutr 2002; 22:505-31.

61. Lee $K N$, Kritchevsky $D$ and Pariza MW. Conjugated linoleic acid and atherosclerosis in rabbits. Alherosclerosis $1994 ; 108: 19-25$.

62. Wilson T, Nicolosi R.J, Chrysam M and Kritchevsky D. Conjugated linoleic acid reduces early aortic atherosclerosis greater than linleic acid in hypercholesterolemic hamsters. Nutrition Research 2000; 20:1795-805.

63. Nicolosi RJ, Rogers EJ, Kritchevsky D, Scimeca JA and Huth PJ. Dietary conjugated linoleic acid reduces plasma lipoproteins and early aortic atherosclerosis in hypercholesterolemic hamsters. Artery 1997; 22:266-77. 
64. Thornas Yeung $\mathrm{CH}_{\text {, Yang }} \mathrm{L}_{\text {, Huang }} \mathrm{Y}$, Wang $J$ and Chen $Z \mathrm{Y}$. Dietary conjuglated linoleic acid mixture affects the activity of intestinal acyl coenzyme A: cholesterol acyltransfierase in hamsters. Br J Nutr 2000; 84:935-41.

65. Smedman $A$ and Vessby B. Conjugated linoleic acid supplementation in humans-metabolic effects. Lipids 2001; 36:773-81.

66. Benito P, Nelson GJ, Kelley DS, Bartolini G, Schmidt PC and Simon V. The effect of conjugated linoleic acid on plasma lipoproteins and tissue fatty acid composition in humans. Lipids 2001; 36:229-36.

67. Mougios W, Matsakas A, Petridou A, et al. Effect of supplementation with conjugated linoleic acid on human serum lipids and body fat. J Nutr Blochem 2001; 12:585-94.

68. Riserus $U_{2}$ Berglund $L$ and Vessby $B$. Conjugated linoleic acid (CLA) reduced abdominal adipose tissue in obese middle-aged men with signs of the metabolic syndrome: a randomised controlled trial. Int $\downarrow$ U Obes Relat Metab Disord 2001; 25:1129-35.

69. Noone EJ, Roche HM, Nugent AP and Gibney MJ. The effect of dietary supplementation using isomeric blends of conjugated linoleic acid on lipid metabolism in healthy human subjects. $\mathrm{Br} J$ Nutr 2002; 88:243-51.

70. Tricon $S$, Burdge $G$, Kew $S$, et al. Opposing effects of cis-9, trans-11 and trans-10, cis-12 conjugated linoleic acid on blood lipids in healthy hurnans. Am J Clin Nutr 2004; B0:614-20.

71. Riserus U, Smedman A, Basu S and Vessby B. Metabolic effects of conjugated limoleic acid in humans: the Swedish experience. Am J Clin Nutr 2004; 79:1146S-48S.

72. Pariza MW, Park $Y$ and Cook ME. Mechanisms of action of conjugated linoleic acid: evidence and speculation. Proc Soc Exp Biol Med 2000; 223:8-13.

73. Pariza MW, Park $Y$ and Cook ME. The biologically active isomers of conjugated linoleic acid. Prog Lipid Res 2001; 40:283-98.

74. Krauss RM. Atherogenic lipoprotein phenotype and diet-gene interactions. I Nutr 2001: 131:340S-3S.

75. Pall S. Takechi $R$ and Ho SS. Conjugated linoleic acid suppresses the secretion of atherogenic lipoproteins from human HepG2 liver cells. Clin Chem Lab Med 2005; 43:269-74.

76. Yotsumoto H. Hara E, Naka $S_{v}$ Adlof $O$, Emken A, Yanagita T. 10trans, 12cis-Linoleic acid reduces apolipoprotein B secretion in HepG2 cells. Food Res Int 1999; 31:403-9.

77. Mc Lead $R_{*}$ LeBlanc AM, Langille MA, Mitchell PL, Currie DL. Conjugated linoleilc acids, atherosclerosis, and hepatic very-low-density lipoprotein metabolism. Am J Clin Nutr 2004; 79: 1169S-74S.

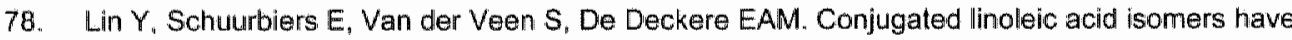
differential effects on triglyceride secretion in Hep G2 cells. Biochim. Biophys. Acta 2001; 1533: $38-46$.

79. Choi Y. Kim Y-C, Han Y-B, Park Y, Pariza MW, Ntambi JM. The trans-10, cis-12 isomer of conjugated linoleic acid downregulates stearoyl-CoA desaturase 1 gene expression in 3T3-L1 adipocytes. J Nutr 2000; 130: 1920-4. 
80. Terpstra AHM. Effect of conjugated linoleic acid on body composition and plasma lipids in humans: an overview of the literature. Am $\rfloor \mathrm{Clin}$ Nutr 2004: 79: 352-61.

81. Yu-Poth $S$, Yin $D$, Zhao $G$, Kris-Etherton PM and Etherton TD. Conjugated linoleic acid upregulated LDL receptor gene expression in Hep G2 cells. J Nutr 2004; 134: 68-71. 


\section{Chapter 2}

Plant sterols and plant stanols, lipoprotein metabolism, and cardiovascular disease

Elke Naumann, Jogchum Plat and Ronald P. Mensink

Maastricht University, Department of Human Biology,

Maastricht, The Netherlands

Based on: Nutrition and Heart disease. Causation and prevention. Chapter 15.

Editors R.R. Watson and V.R. Preedy. CRC Press LLC, Florida, USA, 2004. 


\section{Introduction}

Several risk factors for cardiovascular disease - still the most important cause of death in the Western world - are known. Certain factors such as age, gender, and a family history of coronary heart disease cannot be modified, but other factors like high blood pressure, diabetes mellitus and smoking can be changed. This chapter will focus on another important modifiable risk factor: high serum concentration of cholesterol.

It is well established that the mortality of coronary heart disease increases continuously and progressively with increasing serum cholesterol concentrations [1]. From this finding, we can predict that lowering serum cholesterol concentrations is especially beneficial for mildly cholesterolemic and hypercholesterolemic subjects. In addition to drugs, serum cholesterol concentrations can be lowered by diet. A decrease in intakes of saturated and trans fatty acids and cholesteral, and an increase in intakes of unsaturated fatty acids and fiber have been advacated [2]. Another successful way to lower serum cholesteral concentrations is through the consumption of plant sterols and stanols. Their cholesterol-lowering effect is widely accepted and functional foods enriched with plant sterols and stanols are currently on the market to help people lower their cholesterol levels.

\section{What are plant sterols and stanols?}

Plant sterols are structurally related to cholesterol, but differ in having a methyl group (campesterol) or ethyl group (sitosterol) at position 24 or an additional double bond at position 22 (stigmasterol). The structures of plant stanols resemble those of plant sterols, but lack the double bonds (Figure 2.1). Since humans cannot synthesize these compounds, all plant sterols and stanols in the body originate from diet. Western diets provide $160-437 \mathrm{mg}$ plant sterols a day, which is approximately similar to the amount of cholesterol in the diet [3]. A recent survey from the Netherlands found that important sources of plant sterol and stanol intake are brown bread, vegietable fats and oils, vegetables and fruits. Plant stanols are present in these products in onlly very small amounts and estimated daily intake is less than $30 \mathrm{mg}$ [4]. It should be noted that it is difficult to estimate plant sterol and stanol intake accurately due to a wide variations in the compositions of comparable products, differences in harvesting periods, and geographic locations [5]. 

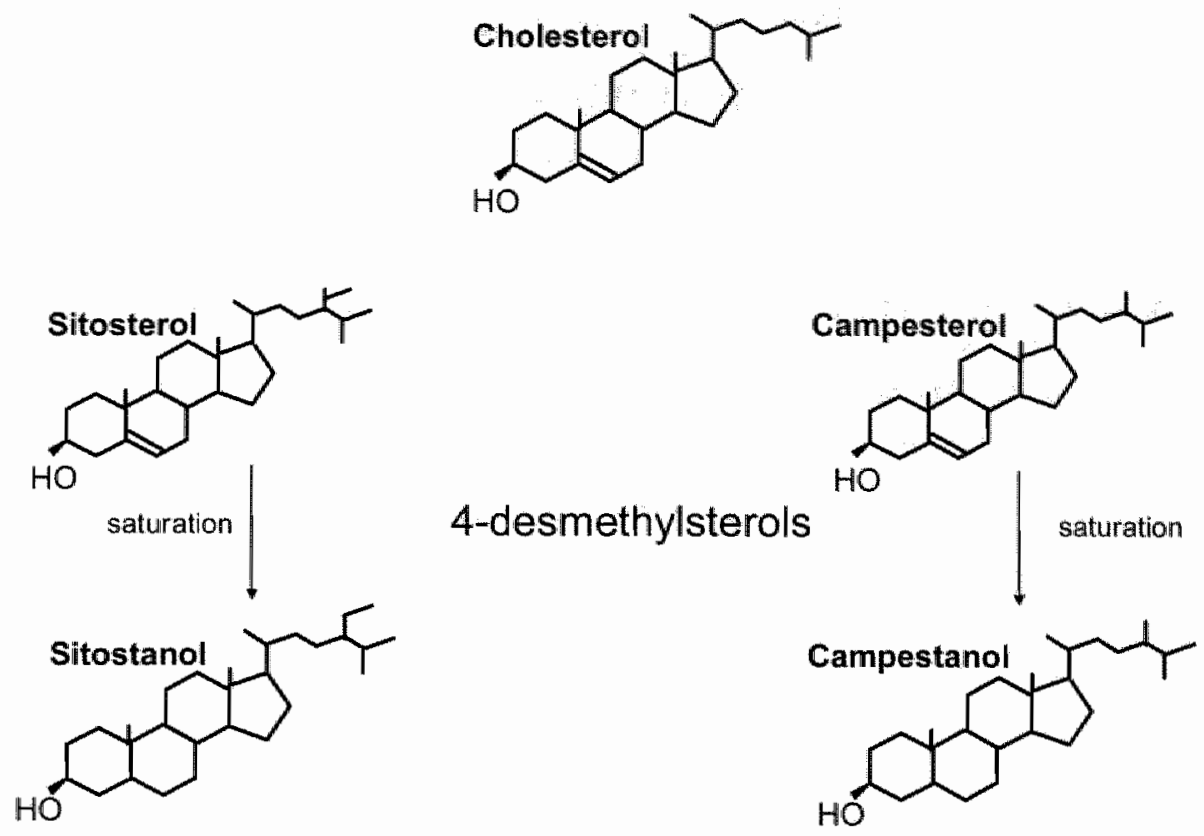

Figure 2.1: The molecular structures of cholesterol and two 4-desmethylsterols (sitosterol and campesterol). Saturation of the double bond in sitosterol and campesterol results in the formation of sitostanol and campestanol respectively.

The most common plant sterol in the Western diet is sitosterol, which contributes about $65 \%$ to total daily plant sterol and stanol intake. For campesterol and stigmasterol these values are about $20 \%$ and $10 \%$, respectively. Sitostanol and campestanol contribute about $5 \%$ to daily plant sterol and stanol intake [4].

Sitosterol, campesterol and stigmasterol are 4-desmethylsterols. Their cholesterol-lowering effect, as well as that of plant stanols, has been proven in many trials [3]. In contrast, 4,4dimethylsterols, like lupeol, $\alpha$-amyrin and cycloartenol (Figure 2.2) present in ricebran and shea nut oil, hardly lower serum cholesterol [6]. The structures of 4-desmethyl sterols resemble the structures of cholesterol more than 4,4-dimethyl sterols, which might be the reason for the difference in cholesterol-lowering effect. 


\section{4,4-dimethylsterols}

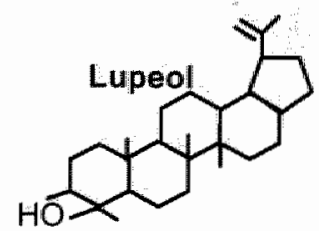

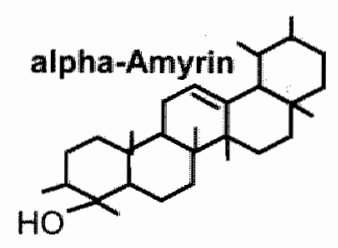

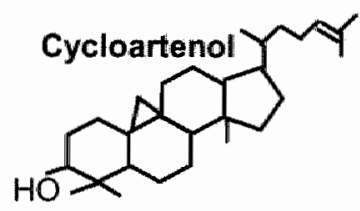

Filgure 2.2: The molecular structure of three 4,4-dimetylsterals.

Plant sterols and stanols are nowadays added to a wide variety of products such as margarines, yogurts, cream cheese, milk and snack bars. The plant stanols present in these products are mainly produced by hydrogenation of plant sterols. Hydrogenation of sitosterol and carmpesterol results in the formation of sitostanol and campestanol respectively. Stigmasterol is converted into sitostanol.

As mentioned, plant sterols and stanols effectively lower serum cholesterol concentrations. To understand (1) why these effects are beneficial with respect to the development of cardiovascular disease and (2) the mechanisms of action of plant sterols and stanols, it is necessary to be familiar with some basic principles of cholesterol metabolism and the relation between cholesterol concentrations and cardiovascular disease. This will now first be discussed before the discussion of the effects of plant sterols and stanols on lipid and lipoprotein metabolism. 


\section{Cholesterol metabolism}

Cholesterol is an essential component for the human body. It is one of the building blocks for cell membranes and serves as a precursor for a number of compounds such as steroid hormones and bile acids. Because of the low solubility of cholesterol in the hydrophylic environment of the circulation, cholesterol is transported through the blood stream in lipoproteins. A lipoprotein consists of a hydrophilic coat, which contains free cholesterol, phospholipids, and apolipoproteins and a hydrophobic core consisting of cholesterol esters and triacylglycerols. There are several lipoproteins, differing in their amounts of cholesterol and triacylglycerol (Table 2.1). The cholesterol the lipopiroteins contain is derived from two pathways: dietary cholesterol (exogenous route) and endogenous synthesis.

Table 2.1 Mean composition of lipoproteins (\% of totall mass)

\begin{tabular}{lcrrrr}
\hline & Chylomicron & VLDL & IDL & LDL & HDL \\
\hline Triacylglycerol & 87 & 52 & 26 & 6 & 6 \\
Cholesterol ester & 3 & 9 & 28 & 40 & 21 \\
Free cholesterol & 2 & 6 & 7 & 9 & 3 \\
Phospholipids & 6 & 23 & 22 & 22 & 24 \\
Apolipoprotein & 2 & 10 & 14 & 23 & 46 \\
\hline
\end{tabular}

VLDL: Very Low Density Lipoprotein

IDL: Intermediate Density Lipoprotein

LDL: Low Density Lipoprotein

HIDL: High Density Lipoprotein

\section{Exogenous route}

Cholesterol esters and triacylglycerol from the diet are first hydrolyzed within the small intestine. This results in the formation of free cholesterol fatty acids, monoglycerides; diglycerides, and glycerol. These components along with phospholipids and bile acids are incorporated into mixed micelles. The individual components of the micelles can be taken up by the enterocytes. Within the intestinal cells the free cholesterol is re-esterified by an enzyme called ACAT (acyl-coenzyme A: cholesterol acyltransferase). Monoglycerides and diglycerides, however, are first hydrolyzed into free fatty acids and glycerol and then used for the formation of new triacylglycerols. These triacylglycerols and the cholesterol esters are, together with apolipoproteins and phospholipids, used for the synthesis of chylomicrons. The lipoproteins are secreted into the lymph and reach the circulation in the venia subclavia. The triacylglycerols from the chylomicrons are taken up by various peripheral tissues (for 
example, the adipose tissue and muscle cells) after hydrolysis into free fatty acids and glycerol through the action of lipoprotein lipase, an enzyme.

The particles formed by the gradual delipidation are relatively rich in cholesterol and are now called chylomicron remnants. They are taken up by the liver, which can store cholesterol as cholesterol esters through the action of ACAT or resecrete it along with endogenously synthesized cholesterol into the circulation in very low density lipoprotein (VLDL) particles (Figure 2.3, see Endogenous route).

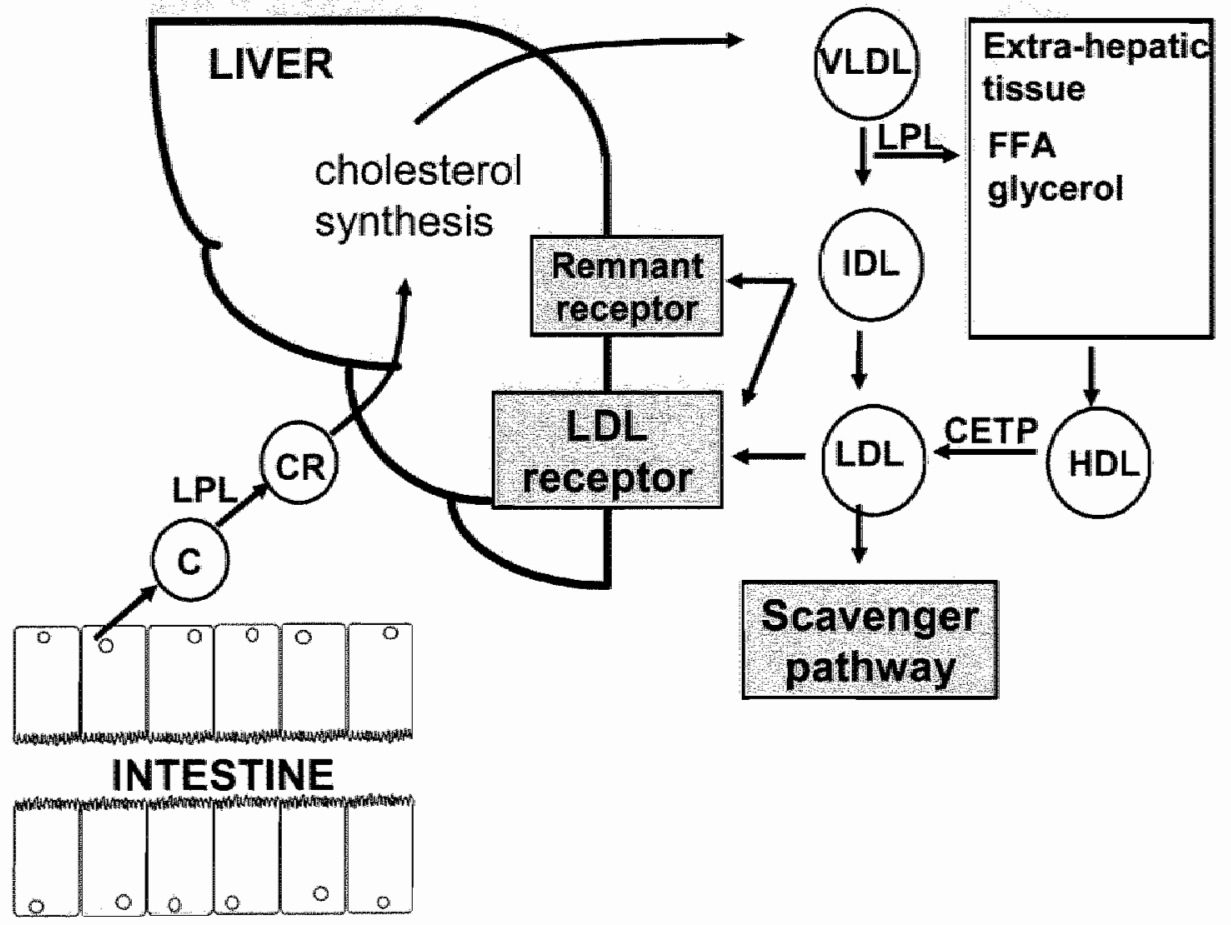

Figure 2.3: Scheme of metabolism cholesterol.

Dietary cholesterol enters the circulation in chylomicrons (C). After removal of triacylglycerols from the chylamicrons through the action of the enzyme lipoprotein lipase (LPL), chylomicron remnants (CR) are taken up by the liver. The liver can re-secrete cholesterol, together with endogenously synthesized cholesteral, into the circulation in very low density lipoproteins (VLDL). Like for chylomicrons, most of the triacylglycerol is hydrolyzed into free fatty acids (FFA) and glycerol and taken up by peripheral tissues. The remaining particles are intermediate density lipoproteins ( $(\mathrm{DL})$, which can be taken up by the liver. IDL particles that are not taken up are converted into cholesterol-rich low density lipoproteins (LDL). LDL particles are also cleared from the circulation by the LDL receptor. A part of the LDL is also removed by the scavenger pathway. Cholesterol from extra-hepatic tissues can be removed via high density lipoproteins (HDL), which transfers cholesteral to the liver, or with the help of cholesterol ester transfer protein (CETP) to LDL and VLDL particles. 


\section{Endogenous route}

The liver produces and secretes VLDL particles that contain mainly triacylglycerol and cholesteral. As described for chylomicrons, most of the triacylglycerol is taken up by peripheral tissues. The remaining particle, now called an intermediate density lipoprotein (IDL) " can be taken up through hepatic low density lipoprotein (LDL) receptors. IDL particles not takem up are converted into cholesterol-rich LDL particles that are also cleared from the circulation by $L D L$ receptors. Some of the $L D L$, however, is also removed by the scavenger pathway (Figure 2.3). The higher the LDL cholesterol concentration in the blood the more LDL cholesterol is removed from the circulation via this pathway. It is this scavenger pathway that is mainly involved in the development of atherosclerosis.

\section{Lipoproteins and the risk for coronary heart disease}

\section{LDL cholesterol}

High serum concentrations of LDL cholesterol are positively and causally related to the risk of coronary heart disease [7]. Reducing serum LDL cholesterol concentrations will decrease the risk of coronary heart disease. Serum LDL cholesterol concentrations can be lowered by drugs that inhibit HMG-CoA-reductase, the rate limiting enzyme for endogenous cholesterol synthesis. These drugs are called statins and they reduce serum concentrations of total cholesterol by approximately $20 \%$ and of LDL cholesterol by approximately $30 \%$ [8-11]. These decreases are associated with reductions in the relative risk of death from coronary heart disease of $24-42 \%[8-11]$.

One reason why LDL cholesterol is atherogenic, is the presence of several components in the LDL that are easily oxidized like the unsaturated fatty acids from phospholipids. The formation of oxidized LDL is an important step in the development of atherosclerosis. $O$ xidized $L D L$ is not recognized by the $L D L$ receptor, but is instead efficiently cleared by scavenger receptors on macrophages found in the arterial walls. The macrophages then develop into foam cells. Many of these foam cells together form a fatty streak that can ultimately turn into an atherosclerotic plaque. As a consequence, the diameter and olasticity of the vessel wall diminish and endothelial function is impaired. If a plaque ruptures, a part may loosen from the vessel wall. This embolus enters the circulation and may obstruct an artery, and this can lead to a myocardial infarction or a cerebrovascular accident.

\section{HDL cholesterol}

In contrast to high serum LDL cholesterol concentrations, high HDL cholesterol levels are negatively associated with the risk for cardiovascular disease. The reason for this protective effect of $\mathrm{HDL}$ is its role in reverse cholesterol transport. Cholesterol from extrahepatic tissues, including the vessel wall, is taken up by an HDL particle that transfers cholesterol directly or via LDL and VLDL particles to the liver for secretion (Figure 2.3). 


\section{Plant sterols and stanols and their effects on cholesterol metabolism}

\section{Effects of plant sterols and stanols on serum lipid and lipoprotein concentrations}

Already in the 1950 s it was found that plant sterols from soybeans lowered serum cholesterol concentrations in chickens [12][13], rabbits [14] and humans [15]. However, the plant sterols could not easily be incorporated into food products and intakes of large amounts in the forms of capsules or syrups were necessary to achieve substantial reductions in plasma cholesterol concentrations. Therefore, interest in the cholesterol-lowering properties of plant sterols decreased until the discovery in the 1970s that esterification of plant sterols facilitated their incorporation into various food products.

Since then, many studies have shown that both plant sterol and stanol esters lower serum LDL cholesterol concentrations without effects on serum HDL cholesterol concentrations. In one study of patients with type II diabetes, consumption of plant stanoll esters even increased serum HDL cholesterol concentrations by $11 \%$ [16], but thils could not be confirmed in another study [17]. In recent years, also free plant sterols and stanols have been incorporated into food products by improved techniques. Their effects on serum lipoprotein concentrations are the same as those of esterified plant sterols and stanols.

Heinemann et al. [18] studied the effects of plant sterols and stanols on cholesterol absorption over a $40-\mathrm{cm}$ segment of the small intestine during passage of a liquid diet containing sitosterol or sitostanol. Cholesterol absorption decreased by $50 \%$ after sitosterol infusion and by almost $85 \%$ after sitostanol infusion. This suggested that plant stanols might be more effective than plant sterols. However, recent studies demonstrated that plant sterols and stanols, either free or esterified ${ }_{n}$ are equally effective in reducing serum LDL cholesterol concentrations [19-23].

Daily intakes of 2 to $3 \mathrm{~g}$ of plant sterols and stanols result in decreases in LDL cholesterol concentrations of $10-15 \%$ (Figure 2.4) [24]. Increasing the daily intake to more than $3 \mathrm{~g}$ hardly reduces $L D L$ cholesterol any further. Plant sterols as present naturally in vegetable oils also reduce $\mathrm{LDL}$ cholesterof concentrations. This has been known for more than 40 years [25] and was confirmed recently in an elegant study. Cholesterol absorption was measured after consumption of a commercial corn oil containing $270 \mathrm{mg}$ of plant sterols per treatment, purified corn oil from which the plant sterols were removed, or purified corn oil to which the plant sterols were added back at two different amounts (150 and $300 \mathrm{mg}$ per treatment). Compared with corn oil without plant sterols, cholesterol absorption was decreased by $27.5 \%$ after consumption of the commercial corn oil. A similar decrease was observed when plant sterols were added to the plant sterol-free corn cil to a nearly equal amount as that in the commercial oil. The decrease was $12 \%$ when only $150 \mathrm{mg}$ of plant sterols were added back to the purified corn oil [26]. 


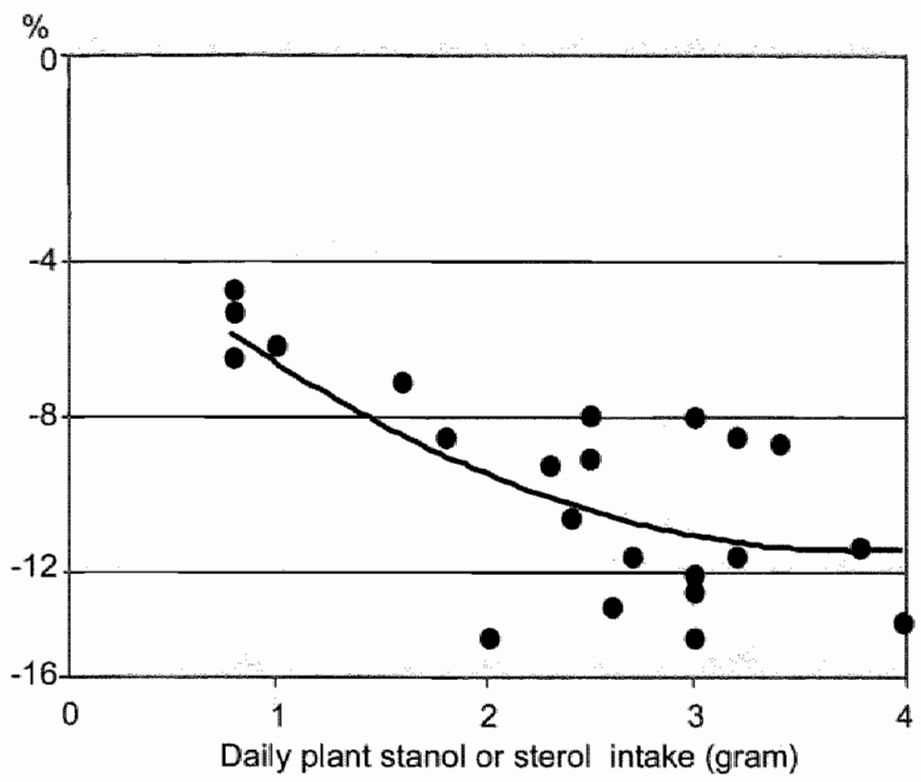

Figure 2.4: Relative changes in serum LDL cholesterol during different intakes of plant sterols or stanols. Daily intakes of $2-3 \mathrm{~g}$ of plant sterols and stanols decrease serum LDL cholesterol concentrations by $10-15 \%$ (based on reference 24 ).

Plant sterols and stanols lower LDL cholesterol in people with elevated as well as with normal serum cholesterol concentrations, in people with diabetes mellitus, and in children. Furthermore, effects of plant sterols and stanols do not depend on the amount of fat or cholesterol in the diet, which means that they are also effective when consumed as part of a recommended diet [27]. In subjects receiving statin therapy, the LDL cholesterol-lowering effect of plant sterols and stanols is still present and is additive to the LDL cholesterollowering effect of statins alone [28]. Although plant sterols and stanols are often esterified to improve their fat solubility, they need not be incorporated into high-fat food products. Plant stanol esters incorporated into low-fat yogurt also effectively decreased serum LDL concentrations [29].

\section{Effects of plant sterols and stanols on the development of atherosclerosis}

Although plant sterols and stanols lower serum LDL cholesterol levels, this does not mean that consumption of plant sterols and stanols lowers the risk for atherosclerosis. 
Theoretically, it is possible that plant sterols and stanals have unfavourable effects on other risk factors for atherosclerosis. Effects of diet on atherosclerosis are not easy to study in humans. Biomarkers for atherosclerosis such as flow mediated vasodilatation or ultra-sound techniques can be used to examine effects of plant sterols and stanols on the condition of vessel walls, but such studies have not yet been carried out. Several animal studies have evaluated effects of plant sterols and stanols on plaque formation. Transgenic and knock-out mouse models such as the apoE knock-out and the apoE3-Leiden, which are validated models for studying the effects of diet on plaque formation, have been used.

In studies of Moghadasian et al. [30-32] a diet enriched with a mixture of plant sterols and stanols resulted in smaller lesions in the aortic roots and sinuses of male apoE-knock-out mice as compared to those in control animals that received a diet without added plant sterols and stanols. Plant stanol esters also reduced atherosclerotic lesion area in female apoE*3Leiden transgenic mice [33]. In vitro studies suggest anti-atherogenic effects of plant sterols not directly related to effects on LDL cholesterol. Plant sterols, especially sitosterol, inhibited vascular smooth muscle cell growth and proliferation without cytotoxic effects or reduction in cell viability. Further, sitosterol increased prostacyclin release, which may improve endothelial function. Taken together, these animal and cell studies indicate that plant sterols and stanols exert favourable effects on the development and progression of atherosclerosis [34]. Only long-term human intervention studies can actually prove whether consumption of plant sterols and stanols truly affects atherosclerotic risk.

\section{Mechanism of action}

Plant sterols and stanols have a higher affinity for incorporation into micelles and occupy more space in micelles than cholesterol. These effects will result in a decreased incorporation of cholesterol into micelles, a consequent reduced availability of cholesterol for absorption, and lower serum LDL cholesteroll concentrations. However, if effect on micellar composition is the only mechanism, plant sterols and stanols should be most effective when consumed with cholesterol. A study reported in 2000 that a daily intake of $2.5 \mathrm{~g}$ of plant stanols once a day is as effective as consumption of the same amount of plant stanols divided over three meals (Figure 2.5) [35]. This indicates that replacement of plant sterols and stanols for cholesterol in the micelles is not the only mechanism causing a reduction in serum LDL cholesterol. 
$\mathrm{mmol} / \mathrm{L}$

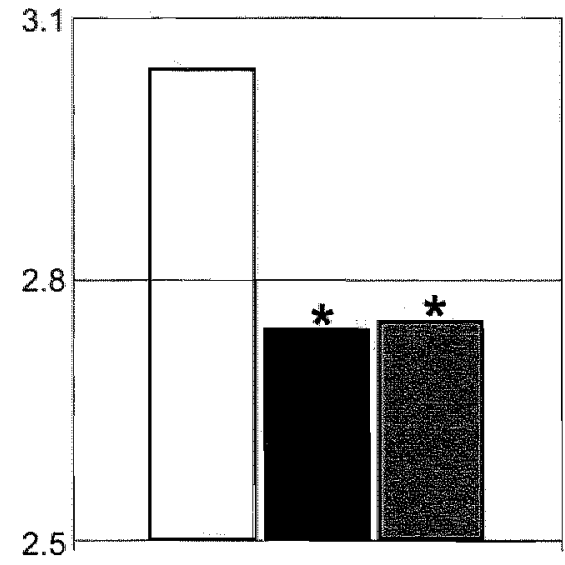

LDL cholesterol

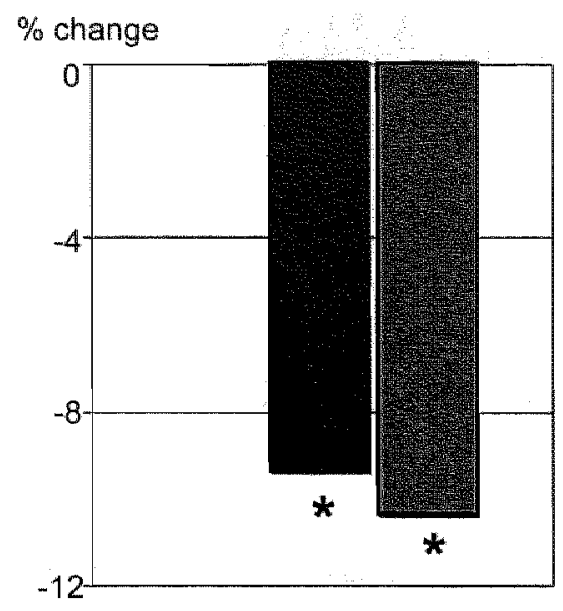

LDL cholesterol

$\square$ Control $\quad$ Once a day $2.5 \mathrm{~g}$ stanols * $P<0.001$ vs control group

Figure 2.5: Effect of consumption frequency of plant stanols on their serum LDL cholesterol-1owering properties. Consumption of $2.5 \mathrm{~g}$ of plant stanols once a day is as effective as consumption of $2.5 \mathrm{~g}$ of plant stanols three times a day (based on reference 35 ).

It was suggested that plant sterols and stanols produce effects in the lumen of the small intestine and also inside the enterocytes. In a caco-2 cell line - an accepted model to study human intestinal lipoprotein metabolism - sitostanol increased the expression of ABCA1. ABCA1 transfers cholesterol from the enterocyte back into the intestinal lumen. This suggests that plant sterols and stanols also lower the absorption of cholesterol by transporting cholesterol out of enterocytes (Figure 2.6). 
Without consumption of products enriched with plant sterols or stanols

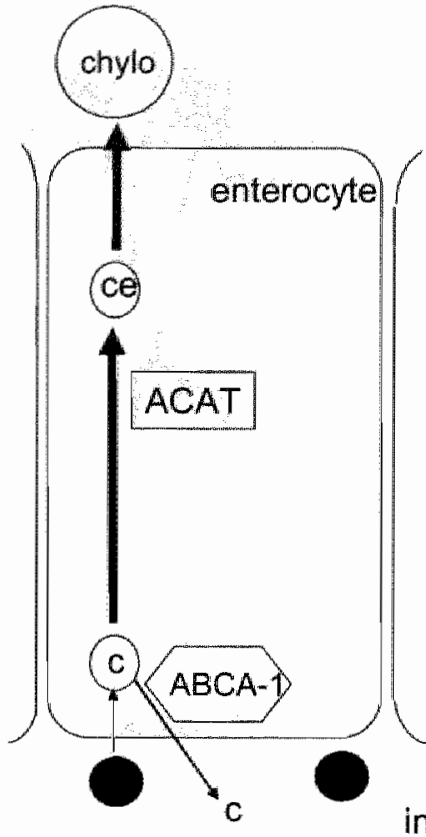

During consumption of products enriched with plant sterols or stanols

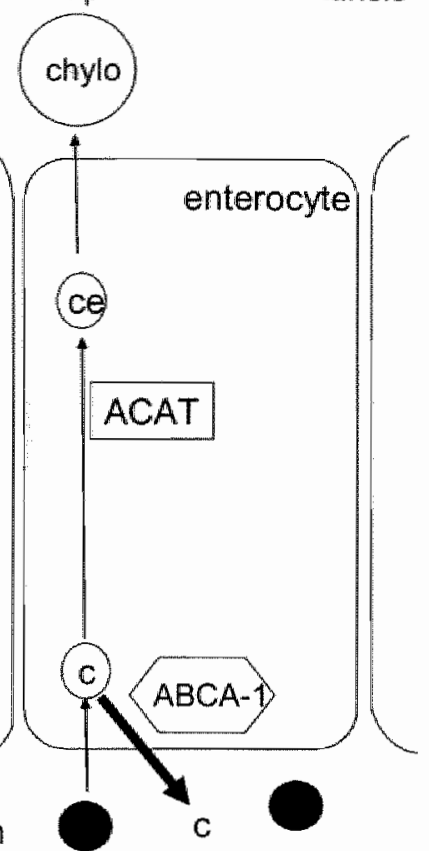

Figure 2.6: Suggested effects of plant sterols and stanols on cholesterol metabolism. Besides a reduced incorporation of cholesterol into mixed micelles $(\bullet)$ in the intestinal lumen, plant sterois and stanols might also have an effect in the intestinal wall. Inside enterocytes cholesterol can be esterified into cholesterol esters (ce) by ACAT (acyl-coenzyme A: cholesterol acyltransferase) and then incorporated into chylomicrons (chylo). Part of the cholesterol can also be re-secreted back into the intestinal lumen through $A B C A-1$. It is suggested that plant sterols and stanols increase the expression of $A B C A-1$, which shuttles cholesterol out of the enterocyte back into the intestinal lumen, and thus decrease cholesterol absorption.

Thus, the cholesterol-lowering properties of plant sterols and stanols can be explained by reduced incorporation of cholesterol into mixed micelles along with increased transport of cholesterol from enterocyte back into the intestinal lumen. As a result of decreased cholesterol absorption, endogenous cholesterol synthesis increases. Despite this increase, the net result will be reduced $L D L$ cholesterol concentration after plant sterol or stanol consumption. 


\section{Metabolism of plant sterols and stanols}

After consumption, about $80 \%$ of campesterol and $50-60 \%$ of the sitosterol campestanol and sitostanol esters are hydrolyzed in the upper part of the small intestine by intestinal sterol ester hydrolase [36]. As $90 \%$ of plant sterols and stanols are in the unesterified form in faeces [37], further hydrolysis should occur in other parts of the intestine. The free plant sterols and stanols are incorporated into mixed micelles and taken up by enterocytes. As compared to cholesterol, of which approximately $30-80 \%$ is absorbed, plant sterols and stanols are poorly absorbed. Estimated uptake of campesterol $(1.89 \%)$ is higher than that of sitosterol $(0.51 \%)$, while campestanol absorption $(0.16 \%)$ is higher than sitostanol absorption $(0.04 \%)[38]$.

Saturation of the plant sterol lowers absorption. Absorption efficiency decreases when the length of the side-chain at position 24 of the molecule increases. Thus, absorption of sitosterol, with an ethyl group at position 24, is lower than that of campesterol, which contains a methyl group. Similarly, absorption of sitostanol is lower than of campestanol. Cholesterol only contains a hydrogen atom at position 24 and has the highest absorption (Figure 2.1).

Plant sterols and stanols are poor substrates for ACAT and after absorption only a very small part of the plant sterols and stanols is esterified. Since free plant sterols and stanols are poorly incorporated into chylomicrons, their absorption is very low as compared to cholesterol. In analogy with cholesterol, which is resecreted from enterocytes into the intestinal lumen via $A B C A 1$, other $A B C$-transporters ( $A B C G 5$ and $A B C G 8$ ) may be involved in the resecretion of free plant sterols and stano's from the enterocyte back into the intestinal lumen $[39,40]$.

Once taken up by the liver through lipoproteins, plant sterols and stanols are incorporated into VLDL or secreted via bile. ABCG5 and $A B C G 8$ are involved in secretion of free plant sterols and stanols from the liver into the bile [37, 41]. Due to a lower affinity of ACAT for sitosterol in the liver, biliary excretion is faster for sitosterol than for campesterol [42]. This, along with higher absorption of campesterol from the gut, explains the higher serum concentrations of campesterol than of sitosterol. Serum concentrations of plant stanols are lower as compared with plant sterol concentrations, which can at least partly be explained by a lower absorption of plant stanols than of plant sterols from the gut. Consumption of products enriched with plant sterols or stanols increases their respective serum concentrations, but they are still less than $1 \%$ of serum cholesterol concentrations.

\section{Sitosterolemia}

Sitosterolemia is a rare inherited disease characterized by xanthomas in skin, tendons and coronary arteries and early development of atherosclerosis. It often results in an early myocardial infarction, sometimes before the age of $20[43,44]$. These patients have extremely high serum concentrations of plant sterols and stanols. Sitosterol in particular is extremely elevated and plasma concentrations in these patients are about $0.48 \mathrm{mmol} / \mathrm{L}$. In 
nonsitosterolemic people, concentrations are more than 40 times lower. The high serum plant sterol and stanol concentrations are due to an increased absorption of plant sterols and stanols in combination with a slow elimination.

Patients with sitosterolemia have mutations $\mathrm{An} A B C G 5$ and $\mathrm{ABCG} 8$ that may result in reduced transport of plant sterols and stanols from enterocytes back into the intestinal lumen and in reduced secretion into bile [45-47]. Mice overexpressing ABCG5 and ABCG8 showed clear reductions in plasma sitosterol and campesterol concentrations as compared with wildtype mice [40], while an increase in plasma plant sterol concentrations was found in ABCG5 and $\mathrm{ABCG} 8$ knock-out mice [39]. Whether the high plant sterol concentrations cause the high risk of coronary heart disease in sitosterolemic patients is not known.

\section{Sidle effects}

Safety studies have shown that consumption of plant sterols and stanols is non-toxic and does not cause any adverse effects on liver, kidney, and gastrointestinal function, or on hematological, coagulation, and fibrinolytic parameters [48-52]. One aspect related to plant sterol and stanol consumption that may need attention is the lowered serum concentrations of fat-solublle anti-oxidants.

Since plant sterols and stanols interfere with the absorption of cholesterol, they may also influence the absorption of other lipophylic substances. Most studies have found decreases in plasma concentrations of $\alpha$-carotene, $\beta$-carotene, lycopene, lutein/zeaxanthin, $\beta$ cryptoxanthin, and tocopherols after plant sterol or stanol consumption [53]. These lipophylic substances are transported in lipoproteins and the observed decrease may be simply due to a decrease in serum LDL cholesterol. Therefore, plasma concentrations are usually standardized for plasma LDL cholesterol concentrations. In general, LDL cholesterol standardized changes were negative for the hydrocarbon carotenoids ( $\alpha$ - carotene, $\beta$ carotene and lycopene), about zero for oxygenated carotenoids (lutein/zeaxanthin and $\beta$ cryptoxanthin), and positive for tocopherols [54]. Results of several studies of $\alpha$-carotene plus $\beta$-carotene and $\alpha$-tocopherol are shown in figures 2.7 and 2.8 .

For LDL cholesterol standardized concentrations effects are most pronounced at daily intakes above $2 \mathrm{~g}$; effects are hardly evident below this level. Whether the lowered serum hydrocarbon carotenoid concentrations at higher intakes have any functional consequences is unknown. However, all plasma concentrations remained within normall ranges. Plasma concentrations of fat-soluble vitamin $A$, vitamin $D$ and vitamin $K$ are not affected by plant sterols and stanols. 
Intake of plant sterols or stanols (g/day)
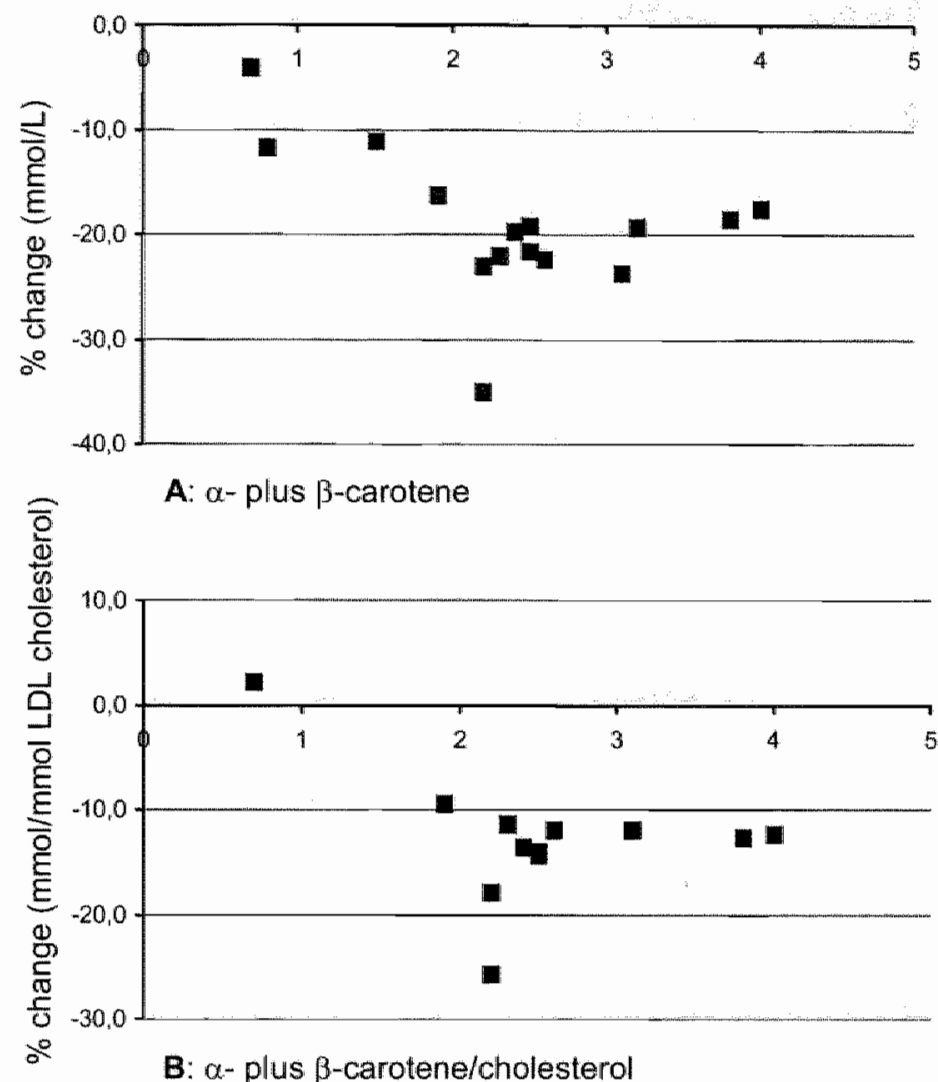

B: $\alpha$ - plus $\beta$-carotene/cholesterol

Figure 2.7: \% changes in absolute (upper panel) and LDL cholesterol-standardized (bottom panel) plasma concentrations of $\alpha$ - plus $\beta$-carotene at different intakes of plant sterols or stanols. 
Intake of plant sterols or stanols ( $g /$ day)
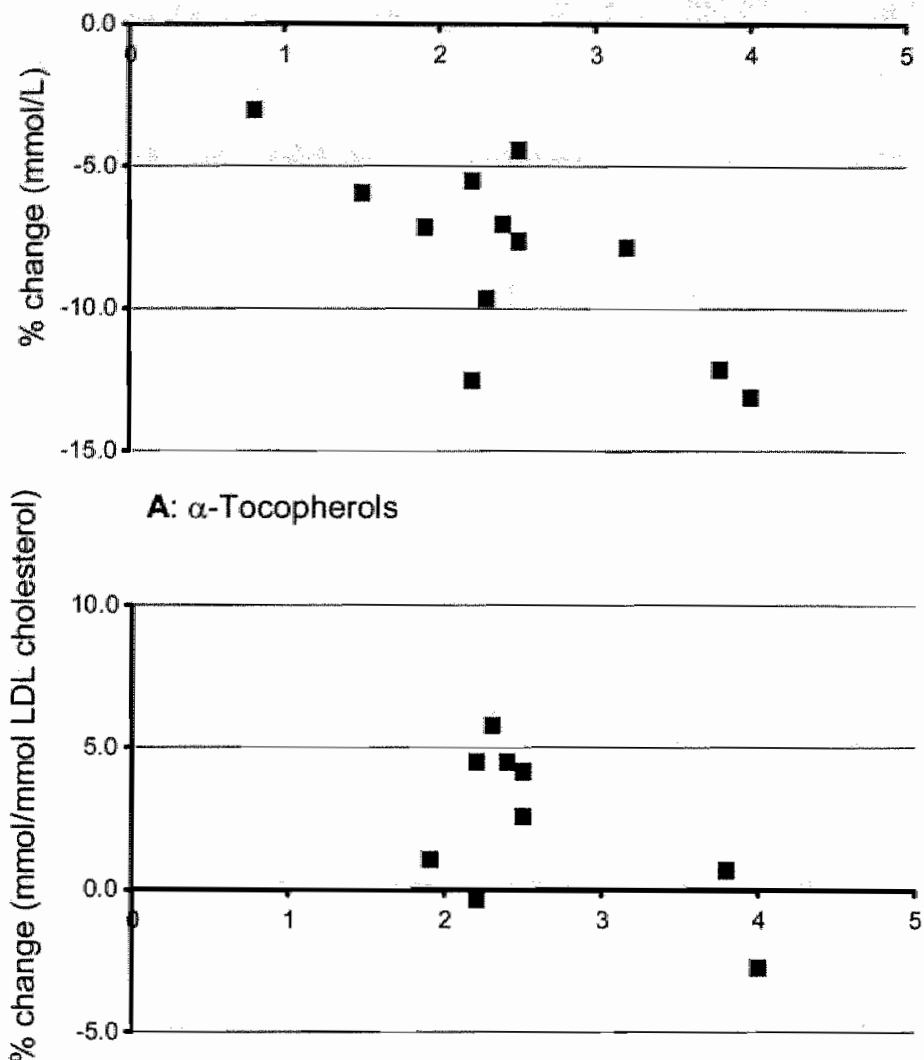

B: $\alpha$-Tocopherols/LDL cholesterol

Figure 2.8: \% changes in absolute (upper panel) and LDL cholesterol-standardized (bottom panel) plasma concentrations of $\alpha$-tocopherol at different intakes of plant sterols or stanols.

\section{Conclusion}

Many studies have shown that a wide variety of functional foods enriched with plant sterols and stanols reduce absorption of cholesterol. Daily intakes of 2 to $3 \mathrm{~g}$ of these components reduce serum LDL cholesterol concentrations by 10 to $15 \%$. As high serum LDL cholesterol concentrations increase the risk for coronary heart disease, decreases in serum LDL cholesterol through consumption of plant sterols and stanols may be beneficial with regard to 
the development of atherasclerosis. Reductions in atherosclerotic lesion sizes were found in animals after plant sterol and stanol consumption and in vitro plant sterols reduced smooth muscle cell growth and proliferation.

Consumption of plant sterols and stanols is considered safe. The only possible relevant side effect reported is a reduction in serum cholesteral-standardized hydrocarbon carotenoid concentrations, although they remained within normall ranges. Thus, functional foods enriched with plant sterols and stanols as components of a prudent diet are helpful for lowering serum LDL chollesterol concentrations. 


\section{References}

1. Martin MJ, Hulley SB, Browner WS, Kuller LH and Wentworth D. Serum cholesterol, blood pressure, and mortality: implications from a cohort of 361662 men. The Lancet 1986; 932-6.

2. National Cholesterol Education Program (NCEP) Expert Panel on Detection, Evaluation, and Treatment of High Blood Cholesterol in Adults (Adult Treatment Panel III). Third Report of the National Cholesterol Education Program (NCEP) Expert Panel on Detection, Evaluation, and Treatment of High Blood Cholesterol in Adults (Adult Treatment Panel III). Final Report. September 2002, National Heart, Lung, and Blood Institute. National Institute of Health.

3. Ostlund RE Jr. Phytosterols in human nutrition. Annu Rev Nutr 2002; 22:533-49.

4. Normen AL, Brants HA, Voorrips LE, Andersson $H A$ s van den Brandt PA and Goldbohm RA. et al. Plant sterol intakes and colorectal cancer risk in the Netherlands Cohort Study on Diet and Cancer. Am J Clin Nutr 2001; 74:141-8.

5. Weihrauch JL and Gardner JM. Sterol content of foods of plant origin. JADA 1978; 73:39-47.

6. Sierksma A, Weststrate JA and Meljer GW. Spreads enriched with plant sterols, either esterified 4,4-dimethylsterols or free 4-desmethylsterols, and plasma total- and LDL-cholesteroll concentrations. Br J Nutr 1999; B2:273-82.

7. Pekkanen J, Linn S, Heiss G, Suchindran CM, Leon A, Rifkind BM and Tyraler HA. Ten-year mortality from cardiovascular disease in relation to cholesterol level among men with and without preexisting cardiovascular disease. N Engl J Med 1990; 322:1700-7.

8. Sacks FM, Pfeffer MA, Moye LA, et al. The effect of pravastatin on coronary events after myocardial infarction in patients with average cholesterol levels. N Engl J Med 1996; 335:10019.

9. Shepherd J, Cobbe S, Ford I, et al. Prevention of coronary heart disease with pravastatin in men with hypercholesterolemia. N Engl I Med 1995; 333, 1301-7.

10. The long-term intervention with pravastatin in ischeamic diseases (LIPID) study group. Prevention of cardiovascullar events and death with pravastatin in patients with coronary heart disease and a broad range of inithal cholesterol levels. N Engl J Med 1998; 339:1349-57.

11. Scandinavian Simvastatin Survival Study Group. Randomised trial of cholesterol lowering in 4444 patients with coronary heart disease: the Scandinavian Simvastatin Survival Study (4S). Lancet 1994; 344:1383-9.

12. Peterson DW, Shneour EA, Peek NF and Gaffey HW. Dietary constituents affecting plasma and Ilver cholesterol in cholesterol-fed chikcs. J Nutr 1952; 50:191-201.

13. Peterson DW. Effect of soybean sterols in the diet on plasma and liver cholesterol in chicks. Proc Exp Bial Med.1951; 78:143-7.

14. Pollak OJ. Successful prevention of experimental hyperchalesterolemia and cholesterol atherosclerosis in the rabbit. Circulation 1953" 696-701.

15. Peterson DW, Nichols LW, and Peck NF. Depression of plasma chollesteral in human subjects consuming butter containing soy sterols. Fed Proc 1956; 65:569. 
16. Gylling $H$ and Miettinen TA. Serum cholesterol and cholesterol and lipoprotein metabolism in hypercholesterolaemic NIDDM patients before and during sitostanol ester-margarine treatment. Diabetologia 1994; $37: 773-80$.

17. Gylling $H$ and Miettinen TA. Effects of inhibiting cholesterol absorption and synthesis on cholesterol and lipoprotein metabolism in hypercholesterolemic non- insulin-dependent diabetic men. J Lipid Res 1996; 37, 1776-85.

18. Heinemann $T$, Pietruck $B$, Kullak Ublick $G$ and von Bergmann $K$. Comparison of sitosterol and sitostanol on inhibition of intestinal cholesterol absorption. Agents Actions Suppl 1988; 26:11722.

19. Weststrate JA and Meijer GW. Plant sterol-enriched margarines and reduction of plasma totaland LDL-cholesterol concentrations in normocholesterolaemic and mildly hypercholesterolaemic subjects. Eur J Clin Nutr 1998; 52:334-43.

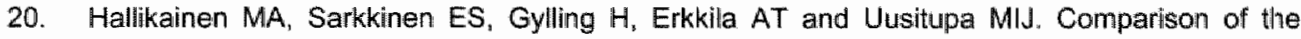
effects of plant sterol ester and plant stanol esters-enriched margarines in lowering serum cholesterol concentrations in hypercholesterolaemic subjects on a low-fat diet. Eur J Clin Nutr $2000 ; 54,715-25$.

21. Normen L, Dutta P, Lia A and Andersson H. Soy sterol esters and beta-sitostanol ester as inhibitors of cholesterol absorption in human small bowel. Am J Clin Nutr 2000; 71:908-13.

22. Noakes $M$, Clifton $P$, Ntanios $F$, Shrapnel $W$, Record I and Mclnerney J. An increase in dietary carotenoids when consuming plant sterols or stanols is effective in maintaining plasma carotenoid concentrations. Am J Clin Nutr 2002; 75:79-86.

23. Vanstone $\mathrm{C}$. Raeini-Sarjaz M, Parsons $W E$ and Jones $P J H$. Unesterified plant sterols and stanols lower LDL-cholesterol concentrations equivalently in hypercholesterolemic persons. Am J Clin Nutr 2002; 76:1272-8.

24. Law MR. Plant sterol and stanol margarines and health. West J Med 2000; 173:43-7.

25. Keys A, Anderson JT and Grande F. Serum cholesteral response to change in the diet. II. ladine value of dietary fat versus 2S-P. Metabolism 1965; 14:747-58.

26. Ostlund RE Jr, Racette SB, Okeke A and Stenson WF. Phytosterols that are naturally present in commercial corn oil significantly reduce cholesterol absorption in humans. Am d Clin Nutr 2002; $75: 1000-4$

27. Hallikainen MA and Uusitupa MI. Effects of 2 low-fat stanol ester-containing margarines on serum cholesterol concentrations as part of a low-fat diet in hypercholesterolemic subjects. Am J Clin Nutr 1999: 69, 403-10.

28. Simons LA. Additive effect of plant sterol-ester margarine and cerivastatin in lowering lowdensity lipoprotein cholesterol in primary hypercholesterolemia. Arn J Cardiol 2002; 90;737-40.

29. Mensink RP, Ebbing $S$, Lindhout M, Plat $J$ and van Heugten MM. Effects of plant stanol esters supplied in low-fat yoghurt on serum lipids and lipoproteins, non-cholesterol sterols and fat soluble antioxidant concentrations. Atherosclerosis 2002; 160:205-13.

30. Moghadasian MH, Godin DV, McManus BM and Frohllich JJ. Lack of regression of atherosclerotic lesions in phytosterol-treated apo E-deficient mice. Life Sci 1999; 64:1029-36. 
31. Moghadasian MH, McManus BM, Godin DV, Rodrigues B and Frohlich Jj. Proatherogenic and antiatherogenic effects of probucol and phytosterols in apolipoprotein E-deficient mice: possible mecharisms of action. Circulation 1999; 99:1733-9.

32. Moghadasian MH, MCManus BM, Pritchard PH and Frohlich JJ: "Tall oll"-derived phytosterols reduce atherosclerosis in ApoE- deficient mice. Arteriascler Thromb Vasc Biol 1997; 17:119-26.

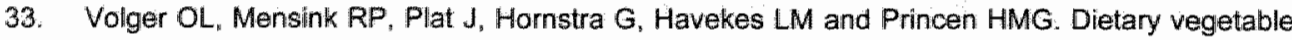
oll and wood derived plant stanol esters reduce atherosclerotic lesion size and severity in apoE*3-Leiden transgenic mice. Atherosclerosis 2001; 157:375-81.

34. Awad $A B$, Smith $A J$ and Fink $C S$. Plant sterols regulate rat vascular smooth muscle cell growth and prostacyclin release in culture. Prostaglandins Leukot Essent Fatty Acids 2001; 64:323-30.

35. Plat J, van Onselen ENM, van Heugten MMA and Mensink RP. Effects on serum lipids, lipoproteins and fat soluble antioxidant concentrations of consumption frequency of margarines and shortenings enriched with plant stanol esters. Eur J Clin Nutr 2000; 54:671-7.

36. Nissinen $M$, Gylling $H_{4}$ Vuoristo $M$ and Miettinen TA. Micellar distribution of cholesterol and phytosterols after duodenal plant stanol ester infusion. Am J Physiol Gastrointest Liver Physiol 2002; 282;G1009-15.

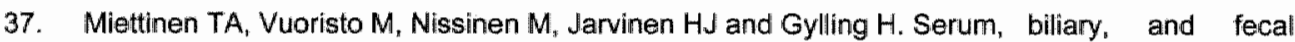
cholesterol and plant sterols in colectomized patients before and during consumption of stanol ester margarine. Am J Clin Nutr 2000; 71:1095-102.

38. Ostlund RE Jr, McGill JB, Zeng $\mathrm{CM}_{r}$ Covey DF, Stearns J, Stenson WF and Spilburg CA. Gastrointestinal absorption and plasma kinetics of soy Delta(5)-phytosterols and phytostanols in humans. Am $\Downarrow$ Physiol Endocrinol Metal 2002; 282: E911-6.

39. Yu L, Hammer RE, Li-Hawkins $J_{\text {w }}$ von Bergmann $K$, Lutjohann $D$, Cohen JC and Hobbs HH. Disruption of $\mathrm{Abcg} 5$ and $\mathrm{Abcg} 8$ in mice reveals their crucial role in biliary cholesterol secretion. Proc Natl Acad Sci 2002; 99:16237-42.

40. Yu L, Lî-Hawkins J, Hammer RE, Berge KE, Horton JD, Cohen JC and Hobbs HH. Overexpression of $\mathrm{ABCG} 5$ and $\mathrm{ABCG} 8$ promotes biliary cholesterol secretion and reduces fractional absorption of dietary cholesterol. J Clin Invest 2002; 110:671-80.

41. Salen G, Ahrens EH and Grundy SM. Metabolism of beta-sitosterol in Man. J Clin Invest 1970; 49:952-67.

42. Tavani DM, Nes WR and Billheimer JT. The sterol substrate specificity of acyl CoA: cholesterol acyltransferase from rat liver. J Lipid Res 1982; 23:774-81.

43. Salen G, Shefer S, Nguyen L, Ness GC, Tint GS and Shore V. Sitosterolemia. J Lipid Res 1992; $33,945-55$.

44. Salen $G$, Horak $I$, Rothkopf $M$, et al. Lethal atherosclerosis associated with abnormal plasma and tissue sterol composition in sitosterolemia with xanthomatosis. J Lipid Res $1985 ; 26: 1126-$ 33.

45. Berge KE, Tian $\mathrm{H}$, Graf GA, et al. Accumulation of dietary cholesterol in sitosterolemia caused by mutations in adjacent $A B C$ transporters. Science 2000; 290:1771-5.

46. Chen HC. Molecular mechanisms of sterol absorption. J Nutr 2001; 31:2603-5. 
47. Hubacek JA Berge $K E_{\text {, }}$ Cohen JC and Hobbs HH Mutations In ATP-cassette binding proteins G5 (ABCG5) and G8 (ABCG8) causing sitosterolemia. Hum Mutat 2001; 18.359-60.

48. Plat J, van Onselen ENM and Mensink RP. Dietary plant stanol ester mixtures. Effects on safely parameters and erythrocyte membrane fatty acid composition in non-hypercholesteroternic subjects. Eur Heart J 1999:1 (supplement S) S58-63.

49. Hepburn PA, Horner SA and Smith M. Safety evaluation of phytosterol asters. Part 2. Subchronic 90-day oral toxicity study on phytosterol esters-a novel functional food. Food Chem Toxicol 1999; 37:521-32.

50. Sanders DJ, Minter $H \downarrow$, Howes D and Hepburn PA. The safety evaluation of phytosterol esters. Part 6. The comparative absorption and tissue distribution of phytosterols in the rat. Food Chem Toxicol 2000; 38:485-91

51. Davidson $\mathrm{MH}_{3}$ Maki $\mathrm{KC}_{n} \mathrm{Umporowicz}_{\mathrm{DM}}$ et al. Safety and tolerability of esterified phytosterots administered in reduced-fat spread and salad dressing to healthy adult men and women. J Am Colli Nutr 2001; 20:307-19.

52. Turnbull D, Whittaker MH, Frankos VH and Jonker D. 13-week oral toxicity study with stanol esters in rats. Regul Toxicol Pharmacol 1999; 29:2 $16-26$.

53. Plat J, Kerckhoffs DA and Mensink RP. Therapeutic potential of plant sterols and stanols. Curr Opin Lipidol 2000; 11:571-6.

54. Plat $J$ and Mensink RP. Effects of diets enriched with two different plant stanol ester mixtures on plasma ubiquinol-110 and fat-soluble antioxidant concentrations. Metabolism 2001; 50:520-9. 


\section{Chapter 3}

Changes in serum concentrations of non-cholesterol sterols and lipoproteins in healthy subjects do not depend on the ratio of plant sterols to stanols in the diet

Elke Naumann, Jogchum Plat and Ronald P. Mensink

Maastricht University, Department of Human Biology, Maastricht, The Netherlands

Based on: Journal of Nutrition 133: 2741-2747, 2003 


\section{Abstract}

Consumption of plant sterols or stanols increases their respective serum concentrations, whereas plant sterols might reduce serum concentrations of plant stanols and vice versa. This suggests that changes in serum plant sterol and stanol concentrations depend on the ratio of plant sterols to stanols in the diet. To examine this in more detail, healthy men $(n=15)$ and women $(n=29)$ daily consumed in random order for three weeks $1.5 \mathrm{~g}$ of plant sterols plus $0.5 \mathrm{~g}$ of plant stanols (high sterol margarine), $1 \mathrm{~g}$ of each (low sterol margarine), or control margarine. Sterols and stanols were provided as fatty acid esters. Compared with the control period, serum cholesterol-standardized campesterol and sitosterol concentrations increased by $33 \%(p<0.001)$ and $19 \%(p<0.002)$, respectively, during the high sterol period, but by only $20 \%(p<0.001)$ and $11 \%(p=0.001)$, respectively, during the low sterol period. During the high sterol period, these values for campestanol and sitostanol were $18 \%$ $(p=0.063)$ and $1 \% \quad(p=0.630)$, and during the low sterol period $25 \% \quad(p=0.105)$ and $7 \%$ $(p=0.163)$, respectively. Effects on LDL cholesterol were similar. We therefore conclude that changes in serum plant sterol and stanol concentrations are not greatly affected by the simultaneous consumption of plant sterols and plant stanols, but are proportional to intakes. Furthermore, both mixtures were equally effective in lowering serum LDL cholesterol concentrations. 


\section{Introduction}

Plant sterols and stanols, which effectively lower serum LDL cholesterol by reducing the absorption of both dietary and biliary cholesterol [1], are not well absorbed. Using a dual stable isotope method, it was estimated that cholesterol absorption was 30- $80 \%$ [2], whereas the absorption of campesterol, sitosterol "campestanol and sitostanol was only 1.89 , $0.51,0.16$, and $0.04 \%$, respectively [3]. Because of this low uptake in combination with rapid biliary elimination $[4,5]$, serum concentrations of campesterol, sitosterol and plant stanols (campestanol and sitostanol) are only $0.3 \%, 0.1 \%$ and $\leq 0.01 \%$, respectively, of serum cholesterol concentrations [6-8].

Consumption of plant sterols and stanols at recommended intakes of 2 to $2.5 \mathrm{~g}$ per day doubled their respective serum concentrations; however, they remained much lower than those of cholesterol [6-8]. Further, several [6,9-13], but not all [14], studies have suggested that plant stanols not only reduced serum concentrations of cholesterol "but also those of plant sterols. Similarly, plant sterols may lower the serum concentration of plant stanols [15]. If plant sterols and stanols indeed influence each other's serum concentrations, then the increase in serum plant sterol and stanol concentrations may depend on the ratio of plant sterols to stanols in the diet. To examine this, we provided in the present study healthy subjects with three different margarines containing either no added plant sterols and stanols (control) or $2 \mathrm{~g}$ of plant sterols plus stanols at two different ratios. Effects of these mixtures on serum lipid and lipoprotein concentrations were also studied.

\section{Materials and methods}

\section{Subjects}

Subjects were recruited via posters in the university building, and by advertisements in the weekly journall for employees of the academic hospital Maastricht, in local newspapers and on local television. Ninety-one subjects expressed interest and received an information brochure about the purpose of the study. Fifty subjects, who met our first selection criterla, were willing to participate and were invited for two screening visits. These subjects were between 18 and 65 years of age , had a body mass index below $30 \mathrm{~kg} / \mathrm{m}^{2}$ and a stable body weight (weight gain or loss of not more than $3 \mathrm{~kg}$ in the past three months); did not use medication or a diet known to affect serum lipid levels, had no history of coronary heart disease, diabetes mellitus or liver disease; were not pregnant or breast-feeding; had not participated in another biochemical trial or donated blood within the previous 30 days; and did not use commercially available products enriched with plant sterol or stanol esters. The screening visit consisted of two blood samples from fasting subjects taken with at least three days in between for lipid and lipoprotein analysis, measurement of blood pressure and collection of a urine sample for determination of glucose. All subjects had to fill in a medical 
questionnaire. Forty-five subjects met our selection criteria and had mean serum total cholesteral concentrations below $8.0 \mathrm{mmol} / \mathrm{L}$, mean serum triacylglycerol concentrations below $4.0 \mathrm{mmol} / \mathrm{L}$, and no indication for treatment with cholesterol-lowering drugs according to the Dutch Cholesterol Consensus [16]. Further, all subjects had blood pressures below $160 / 95 \mathrm{~mm} \mathrm{Hg}$, no glucosuria, and no abuse of drugs or alcohol.

In the end, 44 subjects, 29 women and 15 men, started the study. During the study two women dropped out, because of illness $(n=1)$ or of personal reasons $(n=1)$. Therefore, data of 42 subjects were used for analyses.

The women were $32 \pm 14$ years of age (mean \pm SD) and had a body mass index of $23 \pm 3$ $\mathrm{kg} / \mathrm{m}^{2}$. Their mean serum concentration of total cholesterol was $4.69 \pm 1.05 \mathrm{mmol} / \mathrm{L}$, of $\mathrm{LDL}$ cholesterol $2.69 \pm 0.95 \mathrm{mmol} / \mathrm{L}$, of HDL cholesterol

$1.36 \pm 0.44 \mathrm{mmal} / \mathrm{L}$ and of triacylglycerol $1.22 \pm 0.57 \mathrm{mmol} / \mathrm{L}$. Four women smoked cigarettes, 16 used oral contraceptives and 4 were menopausal. The men were $37 \pm 16$ years of age and had a body mass index of $24 \pm 3 \mathrm{~kg} / \mathrm{m}^{2}$. Their mean serum concentrations of total cholesterol was $4.64 \pm 1.25 \mathrm{mmol} / \mathrm{L}$, of $\mathrm{LDL}$ cholesterol $2.93 \pm 1.25 \mathrm{mmol} / \mathrm{L}$, of $\mathrm{HDL}$ cholesterol $1.16 \pm 0.42 \mathrm{mmol} / L$ and of triacylglycerol $1.16 \pm 0.54 \mathrm{mmol} / \mathrm{L}$. Two men were smokers.

\section{Diet and design}

The study had a multiple cross over design with three experimental margarines and three successive periods of three weeks. (Figure 3.1). Subjects were divided into six groups of seven or eight subjects. Each group received the three margarines in one of the six possible treatment ordlers and daily consumption was $25 \mathrm{~g}$. During the study, subjects were not allowed to use any other margarine. The control margarine contained natural levels of sterols and stanols, whereas $25 \mathrm{~g}$ of the low sterol margarine provided $1 \mathrm{~g}$ plant sterols plus $1 \mathrm{~g}$ plant stanols per day. The high sterol margarine provided $1.5 \mathrm{~g}$ plant sterols plus $0.5 \mathrm{~g}$ plant stanols per day.

Stanols were produced by hydrogenation of plant sterols; fifty percent of the plant sterol batch was used for the production of one batch of plant stanols. The free plant sterols and stanols were esterified with rapeseed oil fatty acids and subsequently mixed with the margarine. The fatty acid composition of the three margarines was similar; they contained the same amounts of absorbable fats, because sterols and stanols were exchanged for water. Before the start of the study, thirty subjects selected a light margarine with $38 \%$ absorbable fats and twelve subjects selected a regular margarine with $62 \%$ absorbable fats. Switching between the two types of margarines during the study was not allowed. All margarines were based on sunflower oil and prepared especially for this study. To standiardize fatty acid intake as much as possible, subjects were also prowided with a sunflower-oil based shortening for baking. This shortening contained $98 \%$ absorbable fats and natural levels of plant sterols or plant stanols. The detailed composition of the 
experimental products is shown in Table 3.1. All products were prepared, packaged and color-coded by RAISIO GROUP (Raisio. Finland). Subjects as well as the investigators had no knowledge of treatment assignment.

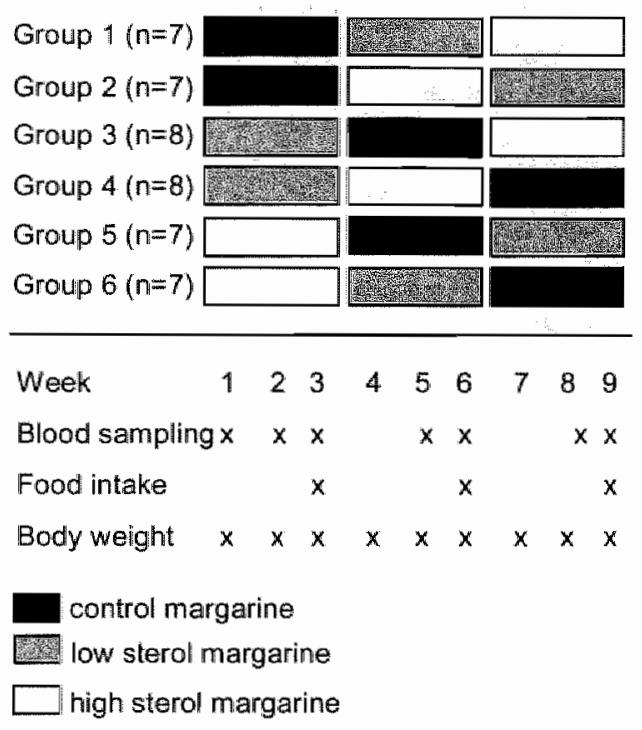

Figure 3.1: Study design

Subjects received new tubs of margarine and shortening every week and had to hand in the used tubes. Each tub of margarine contained about $200 \mathrm{~g}$ of margarine and subjects were instructed to consume one eighth of the tub every day. The tubs of shortening contained about $220 \mathrm{~g}$ of margarine. The new and used tubs of margarine and shortening were weighed. In this way, mean daily intakes of the experimental products could be calculated and these values were used to calculate mean daily plant sterol and stanol intake for each subject. To estimate energy and nutrient intakes, subjects were asked to fill in food frequency lists at the end of every dietary period as described elsewhere [17].

Subjects were weighed every week to determine whether body weight remained constant. They were asked not to change their habitulal diet, level of physical exercise. smoking habits or use of alcohol or oral contraceptives during the study. They were also asked to record 
Illness and use of medication, amount of alcohol consumed, the phase of the menstrua: cycle, and any deviatons from the protocol in a diary.

The study protocol was approwed by the medical ethical committee of the Maastricht University. All subjecis gawe their written informed consent before the start of the study.

\section{Blood sampling}

Blood samples were taken after an ovemight fast and after abstinence from drinking alcohol the day preceding and smoking on the morning of blood sampling. All blood samples from fasting subjects were taken by venipuncture at the same location and at about the same time of the day.

Blood samples were taken once at the start of the study (day 0 ) and twice at the end of every dietary period (weeks 3,6 and 9. Figure 3.1). The interval between the two blood samples was three days. On each occasion a $10 \mathrm{~mL}$ serum tube (Becton Dickinson Vacutainer Systems, Franklin Lakes, NJ) was used. To obtain serum, the tube was left for at least one hour after venipuncture at room temperature. Then, serum was prepared by centrifuging at $2000 \times \mathrm{g}$ for $30 \mathrm{~min}$ at 4 " $\mathrm{C}$. Serum samples were stored at $-80^{\circ} \mathrm{C}$ until the end of the study. At day 0 and once at the end of every dietary period, blood was also sampled in a $10 \mathrm{~mL}$ EDTA tube (Becton Dickinson Vacutainer Systems Franklin Lakes, NJ).

\section{Measurements}

In all serum samples, total cholesterol, HDL-cholesterol and triacylglycerol with correction for free glycerol were analyzed enzymatically as described [17]. Serum LDL cholesterol levels were calculated using the Friedewald equation [18]. Samples from one subject were always analyzed in one rum. Within run variance coefficients were $1.4 \%$ for total cholesterol, $6.8 \%$ for HDL cholesterol and $2.6 \%$ for triacylglycerol.

Before analyses of serum sterols and stanols (sitosterol, sitostanol, campesterol, and campestanol), and a cholesterol precursoir sterol (lathosterol), sera from the two blood samples at the end of every dietary period were pooled. Anallyses were performed in duplicate as described elsewhere [8]. Values of plant sterols, plant stanols and lathosterol were corrected for serum total cholesterol concentrations.

In serum samples taken at the start of the study and at the end of each dietary period, alanine aminotransferase (ALAT), aspartate aminotransferase (ASAT), totall bilirubin, $\gamma$ glutamyl transpeptidase $(\gamma-G T)$, creatinine and $C$-reactive protein were analyzed using a Beckman Synchron CX7 System (Beckman Instruments, Inc, Palo Alto, CA). Hematological variables (number of white blood cells, number and \% of lymphocytes, number and $\%$ of monocytes, number and $\%$ of granulocytes, number of red bload cells, hemoglobin, hematocrit, mean cell volume, mean cell hemoglobin, mean cell hemoglobin concentration, number of platelets and mean platelet volume) were analyzed in EDTA blood on a Coulter Microdiff 18 (Coulter Corporation, Miami, FI). 


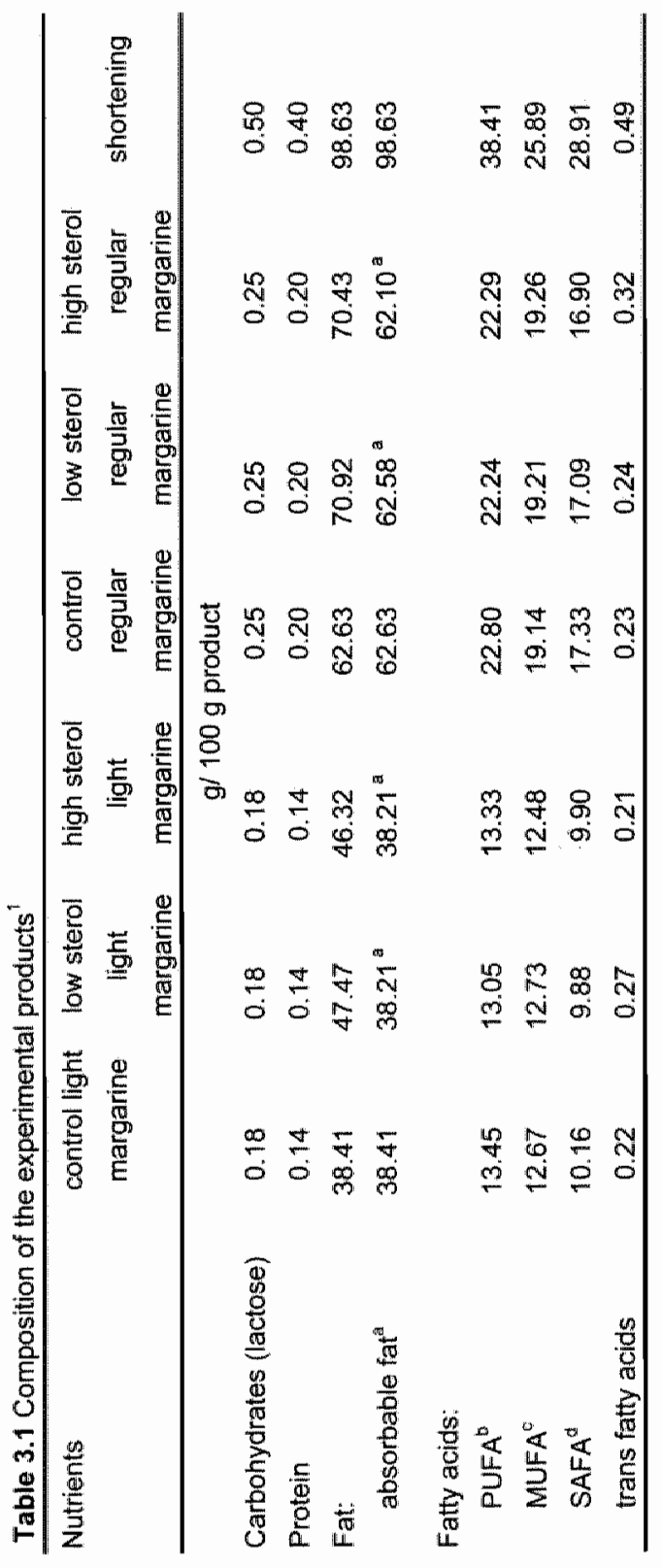




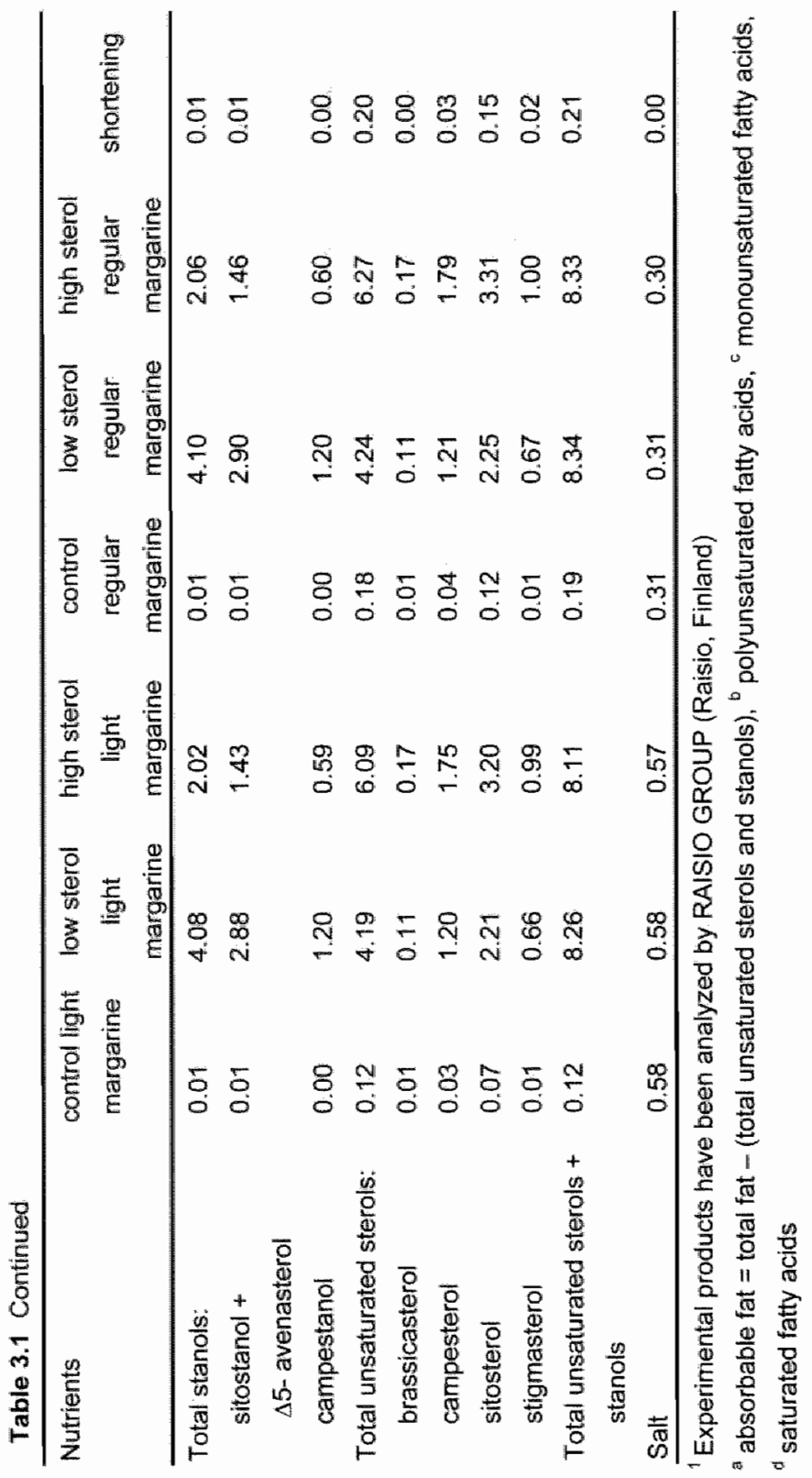




\section{Statistics}

For lipids and lipoproteins, results of the two serum samples taken at the end of each period were averaged before statisticall analyses. Effects of the experimental products were evaluated by analyses of variance (ANOVA). If these effects were significant, the Tukey method was used to compare the three treatments pairwise. For ANOVA, a model that included margarine, period, carny-over effects and subject number as independent variables was used. Because period and carry-over effects were not significant, they were excluded from the model. The $95 \%$ confidence interval for the differences in effects between the margarines was corrected for multiple comparisons. Serum total cholesterol-standardized sterol and stanol concentrations as well as liver, kidney and inflammatory variables were not normally distributed, and differences among the dietary periods were therefore analyzed using the Friedman test. If there were differences between the three dietary periods, the Wilcoxon test was used to compare two interventions pairwise. Differences were considered statistically significant at $p \leq 0.017$. Statistical analyses were performed using SAS version 5 (SAS Intitute INC, Cary, NC) and SPSS for Macintosh 6.1 (SPSS, Chicago, IL). All values are means $\pm S D$.

\section{Results}

\section{Dietary intakes, margarine consumption, body weight and safety variables}

Daily intakes of energy, and the percentages of energy from fat, saturated fatty acids, monounsaturated fatty acids, polyunsaturated fatty acids, linoleic acid, $\alpha$-linolenic acid, protein and carbohydrates as well as daily intake of cholesterol, fibre and alcohol, did not differ during the three dietary periods (data not shown). Mean daily intake of the control margarine was $25.7 \pm 4.1 \mathrm{~g}$, of the low sterol margarine $23.4 \pm 3.9 \mathrm{~g}$, and of the high sterol margarine $24.2 \pm 3.5 \mathrm{~g}$. Consequently, daily intakes of plant stanols and sterols were close to the targeted intakes (Table 3.2).

Compared with the start of the study (day 0), body weight decreased on average by $0.50 \pm$ $0.83 \mathrm{~kg}$ during the control period, by $0.42 \pm 0.88 \mathrm{~kg}$ during the low sterol period and by $0.37 \pm$ $1.19 \mathrm{~kg}$ during the high sterol period, changes that did not differ $(p=0.803)$.

The diets did not affect the hematological variables, ALAT, ASAT, total bilirubin, $\gamma$-GT, creatinine and $C$-reactive protein. Inspection of the diaries revealed no serious deviations from the protocol. 
Table 3.2 Daily irtake of plant sterols and stanols derived from the experimental margarines and shortaning during consumption for 3 weeks of two margarines enriched with plant sterols plus stanols at two different ratios ${ }^{\text {i.2 }}$

\begin{tabular}{lcc}
\hline & $\begin{array}{c}\text { low sterol } \\
\text { period }\end{array}$ & $\begin{array}{c}\text { high sterol } \\
\text { period }\end{array}$ \\
\hline & & $g /$ day \\
Total plant sterols & $1.00 \pm 0.16$ & $1.50 \pm 0.72$ \\
$\quad$ campesterol & $0.28 \pm 0.05$ & $0.43 \pm 0.21$ \\
sitosterol & $0.55 \pm 0.09$ & $0.79 \pm 0.38$ \\
other sterols & $0.18 \pm 0.03$ & $0.28 \pm 0.14$ \\
& & \\
Total plant stanols & $0.96 \pm 0.16$ & $0.49 \pm 0.24$ \\
$\quad$ campestanol & $0.28 \pm 0.05$ & $0.14 \pm 0.07$ \\
sitostanol & $0.68 \pm 0.11$ & $0.35 \pm 0.17$ \\
Total plant sterols + stanols & $1.96 \pm 0.32$ & $1.99 \pm 0.96$ \\
\hline
\end{tabular}

Values are means $\pm S D, n=42$

${ }^{2}$ Intake of plant sterols plus stanols during the control period $0.05 \pm 0.01 \mathrm{~g}$

\section{Serum lipids and lipoproteins}

Compared with the control period, serum total cholesterol was $0.15 \mathrm{mmol} / \mathrm{L}(-3.4 \%)$ lower during the low sterol period $(\mathrm{p}=0.014,95 \%$ confidence interval $(\mathrm{Cl})$ for the difference between the dietary periods -0.30 to $-0.01 \mathrm{mmol} / \mathrm{L})$ and $0.12 \mathrm{mmol} / \mathrm{L}(-2.7 \%)$ during the high sterol period $(p=0.037,95 \% \mathrm{Cl}$ for the difference -0.27 to $0.02 \mathrm{mmol} / \mathrm{L}$, Table 3.3 ). The low and high sterol periods did not differ in serum total cholesterol concentrations $(p=0.705,95 \% \mathrm{Cl}$ for the difference -0.12 to $0.17 \mathrm{mmol} / \mathrm{L}$ ).

Serum LDL cholesterol decreased by $0.17 \mathrm{mmol} / \mathrm{L}(-6.0 \%)$ during the low sterol period $(p=0.010,95 \% \mathrm{Cl}$ for the difference -0.37 to $-0.02 \mathrm{mmol} / \mathrm{L}$ ) and by $0.19 \mathrm{mmol} / \mathrm{L}(-6.7 \%)$ during the high sterol period $(p=0.003,95 \% \mathrm{Cl}$ for the difference -0.40 to $-0.05 \mathrm{mmol} / \mathrm{L})$. The low and high sterol periods did not differ in serum LDL cholesterol concentrations $(p=0.692$, $95 \% \mathrm{Cl}$ for the difference -0.21 to $0.15 \mathrm{mmol} / \mathrm{L}$ ).

The three margarines did not change serum concentrations of HDL cholesterol $(p=0.714)$ and triacylglycerol $(p=0.068)$. However, triacylglycerol concentrations tended to be higher at the end of the high sterol period as compared to the control period $(p=0.024)$. The total to HDL cholesterol ratio was $3.78 \pm 1.22$ during the control period, $3.61 \pm 1.16$ during the low sterol period ( $p=0.074$ versus contral) and $3.60 \pm 1.02$ during the high sterol period $(p=0.054$ 
versus control). The LDL to HDL cholesterol ratio was $2.43 \pm 1.08$ at the end of the control period; $2.24 \pm 0.92$ at the end of the low sterol period ( $p=0.017$ versus control) and $2.21 \pm$ 0.85 at the end of the high sterol period $(p=0.007$ wersus control). There were no differences in effect between the llow and high fat margarines on any of the serum lipid or lipoprotein concentrations (data not shown).

Table 3.3 Serum concentrations of total cholesterol, LDL cholesterol, HDL cholesterol and triacylglycerol during consumption for 3 weeks of two margarines enriched with plant sterols plus stanols at two different ratios 1.2

\begin{tabular}{llcl}
\hline & $\begin{array}{c}\text { control } \\
\text { period }\end{array}$ & $\begin{array}{c}\text { low steral } \\
\text { period }\end{array}$ & $\begin{array}{c}\text { high sterol } \\
\text { periodl }\end{array}$ \\
\hline & & mmol/L \\
Total cholesterol & $4.47 \pm 1.06^{\mathrm{a}}$ & $4.32 \pm 0.98^{\mathrm{b}}$ & $4.35 \pm 0.94^{\mathrm{ab}}$ \\
LDL cholesterol & $2.82 \pm 0.97^{\text {a }}$ & $2.65 \pm 0.84^{\mathrm{b}}$ & $2.63 \pm 0.77^{\mathrm{b}}$ \\
HDL cholesteral & $1.25 \pm 0.32$ & $1.25 \pm 0.28$ & $1.26 \pm 0.30$ \\
Triacylglycerol & $0.89 \pm 0.38$ & $0.92 \pm 0.45$ & $0.98 \pm 0.45$ \\
\hline
\end{tabular}

\footnotetext{
"Values are means $\pm S D, n=42$

${ }^{2}$ Values on the same row not sharing a common superscript differ significantly $p<0.017$
}

\section{Serum plant sterol and stanol concentrations}

Consumption of the low and high sterol margarine increased serum cholesterol-standardized concentrations of campesterol and sitosterol compared with the control margarine (Table 3.4). Serum cholesterol-standardized campesterol concentrations increased by $58 \times 10^{2}$ $\mu \mathrm{mol} / \mathrm{mmol}$ cholesterol $(20 \%)$ during consumption of the low sterol margarine $(p<0,001)$ and by $84 \times 10^{2} \mu \mathrm{mol} / \mathrm{mm}$ ol cholesterol $(33 \%)$ during consumption of the high sterol margarine $(p<0.001)$. The serum cholesterol-standardized campesterol concentrations between the low and high sterol period tended to be different $(p=0.020 \%$. Serum cholesterol-standardized sitosterol concentrations increased by $9 \times 10^{2}$ umol $/ \mathrm{mmol}$ cholesterol $(11 \%)$ during consumption of the low sterol margarine $(p=0.001)$ and by $23 \times 10^{2}$ umol/mmol cholesterol $(19 \%)$ during consumption of the high sterol margarine $(p=0.002)$. Serum cholesterolstandardized sitosterol concentrations at the end of the low sterol period did not differ from those of the high sterol period $(p=0.069)$. 
Table 3.4 Serum cholesterol-standardized levels of plant sterols, plant stanols and lathosterol during consumption for 3 weeks of margarine enriched with plant sterols plus stanols at two different ratios ${ }^{1,2}$

\begin{tabular}{lccc}
\hline & & $10^{2} \times \mu$ mol/mmol cholesteral & \\
Campesterol & $339^{\mathrm{a}}$ & $397^{\mathrm{b}}$ & $423^{\mathrm{b}}$ \\
& $(142-751)$ & $(177-1043)$ & $(174-856)$ \\
Sitosterol & $118^{\mathrm{a}}$ & $127^{\mathrm{b}}$ & $141^{\mathrm{b}}$ \\
& $(18-257)$ & $(29-304)$ & $(31-255)$ \\
Campestanol & 6.9 & 8.7 & 8.3 \\
Sitostanol & $(0.7-32.6)$ & $(0.0-50.9)$ & $(2.01-65.6)$ \\
& 3.0 & 3.7 & 2.9 \\
Lathosterol & $(1.2-15.6)$ & $(1.0-14.7)$ & $(1.3-14.7)$ \\
& $120^{\mathrm{a}}$ & $131^{\mathrm{bb}}$ & $138^{\mathrm{b}}$ \\
& $(52-343)$. & $(77-244)$ & $(72-272)$ \\
\hline
\end{tabular}

${ }^{1}$ Values are medians (ranges), $n=42$

${ }^{2}$ Values on the same row not sharing a common supersicript differ significantly, $p<0.017$

The increase in serum cholesterol-standardized sterol concentrations were proportional to intakes; when expressed per gram of daily plant steral intake, they did not differ during the low sterol ( $20 \%$ for serum campesterol ${ }_{n} 11 \%$ for serum sitosteral) and high sterol ( $22 \%$ for serum campesterol, $13 \%$ for serum sitosterol) periods. To compare the increases in serum cholesterol-standardized plant sterol concentrations from the present study with those from previous studies, we plotted the intakes of campesterol and sitosterol (Figure 3.2) against the relative changes in serum cholesterol-standardized plant sterol concentrations in the present study and other studies. In the other studies, products enriched with only plant sterol esters were provided. Only studies that lasted at least two weeks were included. As can be seen, the relative changes in cholesterol-standardized serum concentrations of campesterol and sitosterol from the present study did not deviate from those of other studies.

Although serum cholesterol-standardized campestanol concentrations increased by $25 \%$ during consumption of the low sterol margarine $(p=0.105)$ and by $18 \%$ during consumption of high sterol margarine $(p=0.063)$, these changes were not significant. Serum cholesterolstandardized sitostanol concentrations did not change during the low and high sterol periods. Per gram of plant stanol intake, the relative changes in serum cholesterol-standardized campestanol concentrations were $25 \%$ during the low sterol period and $36 \%$ during the high sterol period; for sitostanol, the changes were $7 \%$ and $-2 \%$, respectively. As for plant sterols, 
the relative changes in serum plant stanol concentrations agreed with those of other studies (Figure 3.3).

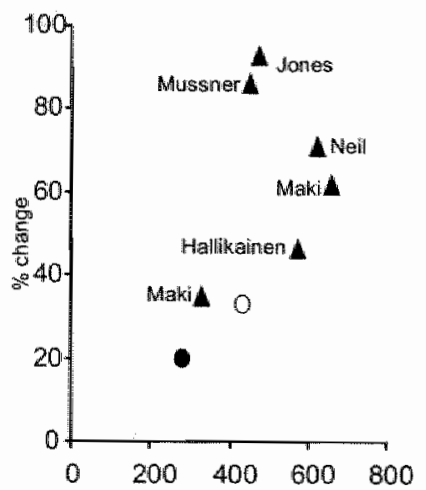

Inerease in intake of campestorol (ngyday)

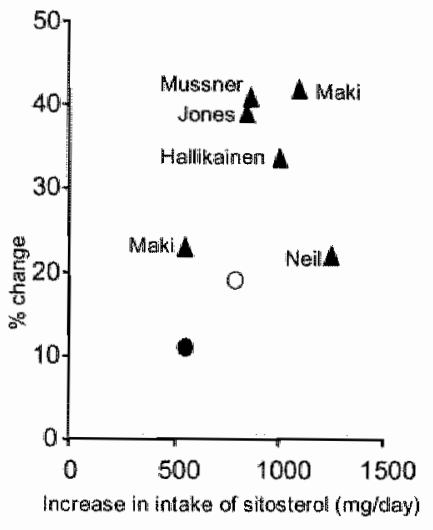

A Prowticts enriched will gillant stands O High sterol margarine (present study)

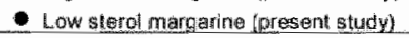

Figure 3.2: increase in daily intake of plant sterols (mg) versus relative changes in serum cholesterolstandardized plant sterol concentrations (upper panel: campesterol bottom panel: sitosterol) after consumption of products enriched with only plant sterols $[7,14,15,19-21]$ or with two mixtures of plant sterols plus plant stanols (present study). The first author of a study is indicated near the symbol. If serum concentrations of plant sterols and stanols were reported in absolute values only [14, 21], mean serum cholesterol concentrations were used to calculate serum cholestenol-standardized values. Values have been corrected for changes in the control group in case a parallel design was used. 

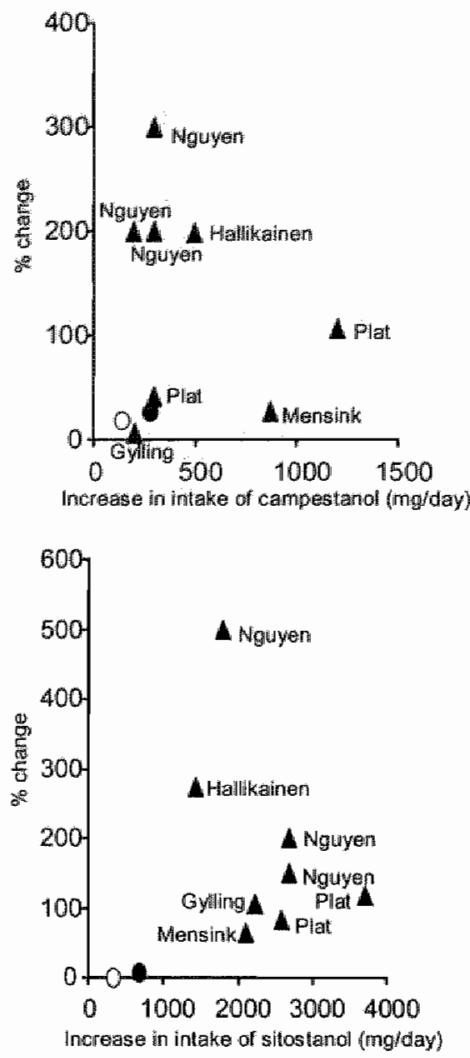

$\triangle$ Products enrikhed with plant stanols O High sterol margarine (present study)

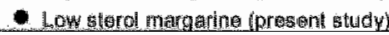

Figure 3.3 Increase in daily intake of plant stanols (mg) versus relative changes in serum cholesterolstandardized plant stanol concentrations (upper panel: campestanol, bottom panel: sitostanol) after consumption of products enriched with only plant stanols $[7,8,27-29]$ or with two mixtures of plant sterols plus plant stanols (present study). For further details: see Figure 3.2 legend.

Serum cholestlerol-standardized lathosterol concentrations increased by $11 \times 10^{2} \mu \mathrm{mol} / \mathrm{mmol}$ cholesterol $(14 \%)$ in the low sterol periad $(p=0.025)$ and by $18 \times 10^{2} \mu \mathrm{mol} / \mathrm{mmol}$ cholesterol $(15 \%)$ in the high sterol period $(p=0.010)$. The two mixtures did not differ. 


\section{Discussion}

The increase in serum cholesterol-standardized plant sterol levels after increasing plant sterol ester intake is well documented $[7,13-15,19-21]$. At the same time, many studies have shown reduced serum cholesterol-standardized plant sterol levels when products enriched with only plant stanol esters were consumed $[6,9-13,22]$. These findings suggest that plant stanols may lower the absorption of plant sterols. To examine this in more detail, we gave healthy subjects daily 2 gram of two mixtures with different ratios of plant sterol to stanol esters. Changes in cholesterol-standardized plant sterol concentrations were proportional to intakes and in line with those of studies using products enriched with only plant sterol esters (Figure 3.2). As expected [7, 14, 19, 21], serum cholesterol-standardized campesterol concentrations increased more than sitosterol concentrations. Our results therefore do not indicate that addition of dietary plant stanol esters to a plant sterol-enriched margarine significantly lowers the uptake of plant sterols. Taken together, plant stanol esters may only reduce serum plant sterol concentrations when no plant sterol-enriched products are consumed. When consumed simultaneously, serum cholesterol-standardized concentrattions of plant sterols are proportional to daily intakes and not greatly influenced by plant stanol ester intake.

Our results are supported by the findings of a recent study in 15 hypercholesterolemic subjects. In that study, a mixture that provided daily $0.9 \mathrm{~g}$ non-esterified plant sterols $10.4 \mathrm{~g}$ sitosterol, $0.3 \mathrm{~g}$ stigmasterol and $0.2 \mathrm{~g}$ campesterol) plus $0.9 \mathrm{~g}$ stanols $(0.6 \mathrm{~g}$ sitostanol and $0.3 \mathrm{~g}$ campestanol) increased serum cholesterol-standardized concentrations of campesterol by $55 \%$ and of sitosterol by $16 \%$. It should be noted, however, that these increases were not significant, which may be due to the relatively small number of subjects [23]. Three other studies also examined the effects on serum plant sterol concentrations of a mixture containing approximately $20 \%$ free sitostanol and $80 \%$ free plant sterols (circa $16 \%$ campesterol and $62 \%$ sitosterol). Results were not consistent. In hypercholesterolemic subjects, an intake of $1.6 \mathrm{~g}$ per day increased serum cholesterol-standardized campesterol concentrations by $47 \%$ (not significant) [24], whereas significant increases of $70 \%$ and $12 \%$ at intakes of 1.8 and $1.9 \mathrm{~g}$, respectively, were observed $[25,26]$. In normocholesterolemic subjects, serum cholesterol-standardized campesterol concentrations decreased nonsignificantly by $32 \%$ at a daily intake of $1.6 \mathrm{~g}$ [24]. Effects on cholesterol-standardized sitosterol levels were also variable. In hypercholesterolemic subjects, no changes were observed in two studies $[24,25]$, whereas a significant increase of $82 \%$ was seen in a third study [26]. In normocholesterolemic subjects, a nonsignificant increase of $31 \%$ in serum cholesterol-standardized sitosterol concentrations was observed [24]. For comparison, we found significant increases in serum cholesterol-standardized concentrations of campesterol $(20 \%)$ and sitosterol $(11 \%)$ during consumption of $2 \mathrm{~g}$ per day of a mixture containing equal amounts of plant sterols and stanols. The main difference between our study and the four studies mentioned above [23-26] is that we used mixtures of esterified pllant sterols and 
stanols instead of free plant sterols and stanols. However, because plant sterol and stanol esters are almost completely hydrolyzed in the intestinal lumen [4] and have a similar cholesterol-lowering effect, it is not likely that their effects an intestinal metabolism are very different.

Relative changes in serum cholesterol-standardized campestanol concentrations, although not significant, were comparable to those in other studies $[8,27,28]$ that used products enriched with only plant stanols (Figure 3.3). Serum cholesterol-standardized sitostanol concentrations did not change. This could be due to the relatively low daily intakes of sitostanol, which were 0.4 and $0.7 \mathrm{~g}$ for the high and low sterol margarine, respectively. Indeed, other studies have reported significant changes in cholesterol-standardized sitostanol concentrations when daily sitostanol intake exceeded $1 \mathrm{~g}$ (Figure 3.3) [7, 8, 27-29]. Taken together, these results do not suggest that the absorption of plant stanols was lowered due to the simultaneous consumption of plant sterol esters. It should be noted, however, that in one [15], but not all studies [7, 20], consumption of products enriched with only plant sterols lowered serum chalesterol-standardized plant stanol concentrations.

The mechanism underlying plant sterol absorption is still not completely understood, but studies in sitosterolemic patients have shown that ATP-binding cassette (ABC)G5 and $A B C G B$ are involved [30-32]. These intestinal sterol transporters pump plant sterols and stanols out of the enterocyte back into the intestinall lumen [30, 33-35]. We showed recently that sitostanol increases ABCA1 expression [36]. Because ABCA1, ABCG5 and ABCG8 are regulated by the same transcriptional pattwway $\left[34_{n} 37\right]$, it is expected that plant stanols also increase $\mathrm{ABCG} 5$ and $\mathrm{ABCG} 8$ expression. From the present study, we concluded that plant sterols do not affect serum plant stanol concentrations to any great extent and vice versa, suggesting that both plant sterols and plant stanols are equally potent ABCG5 and ABCGB activators; this must be confirmed in future studies.

Various studies demonstrated that plant stanol esters and sterol esters reduce cholesterol absorption and serum LDL cholesterol concentrations to the same extent $[6,7,13,14,38]$. This agrees with our finding that the plant sterol to stanol ratio does not change its $L D L$ cholesterol-lowering efficacy. However, in other studies using daily 2.0 to $2.2 \mathrm{~g}$ of either plant sterols or plant stanols $[7,9,21]$, reductions in serum LDL cholesterol of $8-16 \%$ were found, which are higher than the reductions of about $6.5 \%$ in the present study. One could speculate that this smaller reduction was caused by a decrease in the cholesterol-lowering effectiveness of mixtures of plant sterol and plant stanol esters. However, in other studies with mixtures of free plant sterols and stanols, even greater reductions in serum LDL cholesterol $(8.9-16 \%)$ were found at lower intakes (1.6-1.9 g per day) [23-26]. Compared with these latter studies, however, subjects in the present study had lower baseline LDL cholesterol concentrations. When we grouped our subjects into tertiles on the basis of serum $\mathrm{LDL}$ cholesterol concentrations during the control period, the first tertile (serum LDL cholesterol $\leq 2.26 \mathrm{mmol} / \mathrm{L}, 4$ men and 10 women) showed a decrease in serum $L D L$ cholesterol of $1.9 \%$ during the low and an increase of $1.8 \%$ during the high sterol period. For 
the second tertile (serum LDL cholesterol 2.27 to $3.36 \mathrm{mmol} / \mathrm{L}, 5$ men and 9 women), the decreases were $5.6 \%$ and $5.7 \%$ respectively "and for the third tertile (serum LDL cholesterol $\geq 3.36 \mathrm{mmol} / \mathrm{L}_{\mathrm{w}} 6 \mathrm{men}$ and 8 women) $6.8 \%$ and $8.7 \%$, respectively. These changes were different among the tertiles, possibly due to the fact that our study was not specifically designed to test this hypothesis. These findings do indicate, however, that contrary to previous observations $[6,21]$, relative changes in serum LDL cholesterol concentrations depend on initial serum LDL cholesterol concentrations.

In conclusion, our study suggests that changes in serum plant sterol and stanol concentrations are not greatly affected by the simultaneous consumption of plant sterols and plant stanols, but are proportional to intakes. Furthermore, both mixtures of plant sterol and stanol esters were equally effective in lowering serum LDL cholesterol concentrations.

\section{Acknowledgements}

We would like to thank all the volunteers for their co-operation and interest, and Mr. F.J.J. Cox for his assistance and analysis of serum plant sterol and stanol concentrations. This study was supported by RAISIO GROUP, Raisio, Finland. 


\section{References:}

1. Ostlund RE Ir. Phytosterols in human nutrition. Annu Rev Nutr 2002; 22:533-49.

2. Bosne MS, Lange LG, Stenson WF and Ostund RE Jr. Percent chollesterol absorption in nomal women and men quantified with dual stable isotopic tracers and negative ion mass spectrometry. ILipid Res 1999; 40:302-8.

3. Osttund RE Jir, McGill JB, Zeng CM, Covey DF, Steams J, Stenson WF and Spilburg CA. Gastrointestinal absorplion and plasma kinetics of soy Delta(5)-phytosterols and phytostanols in humans. Am I Physiol Endocrinol Metab 2002; 282:E911-E6.

4. Mettinen TA, Vuoristo $M$, Nissinen $M$, Jarvinen $H J$ and Gylling $H$. Serum, biliary, and fecal cholesterol and plant sterols in colectomized patients efore and during consumption of stanol ester margarine. Am J Clin Nutr 2000; 71:1095-1102.

5. Salen G, Ahrens EH and Grundy SM. Metabolism of beta-sitosterol in Man. J Clin Invest 1970; $49: 952-67$.

6. Weststrate JA and Meijer GW. Plant sterol-enriched margarines and reduction of plasma totaland LDL-cholesteral concentrations in normocholesterolaemic and mildy hypercholesterolaemic subjects. Eur $J$ Clin Nutr 1998; 52:334-43.

7. Hallkainen MA, Sarkkinen ES, Gylling $H$, Erkkila AT and Uusitupa MU. Comparison of the effects of plant sterol ester and plant stanol esters-enriched margarines in lowering serum cholesterol concentrations in hypercholesterolaemic subjects on a low-fat diet. Eur $\$$ Clin Nutr 2000; 54:715-25.

8. Plat $J$ and Mensink RP. Effects of diets enriched with two different plant stanol ester mixtures on plasma ubiquinot-10 and fat-soluble antioxidant concentrations. Metabolism 2001; 50:520-9.

9. Vanhanen HT, Kajander J, Lehtovirta $H$ and Miettinen TA. Serum levels, absorption efficiency, faecal elimination and synthesis of cholesterol during increasing doses of dietary sitostanol esters in hypercholesterolaemic subjects. Clin Sci Colch 1994; 87:61-7.

10. Gylling $H$, Radhakrishnan $R$ and Miettinen TA Reduction of serum cholesterol in postmenopausal women with previous myocardial infarction and cholesterol malabsorption induced by dietary sitostanol ester margarine: women and dietary sitostanol. Circulation 1997; 96:4226-31.

11. Mieftinen TA, Puska $P$, Gylling $H$, Vanhanen $H$ and Vartiainen $E$. Reduction of serum cholesterol with sitostanol-ester margarine in a mildiy hypercholesterolemic population. N Engl d Med 1995; 333."1308-12.

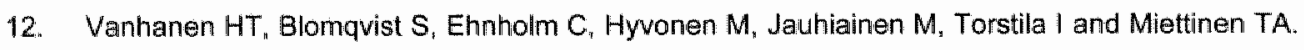
Serum cholesterol, cholesterol precursors, and plant sterols in hypercholesterolemic subjects with different apoE phenotypes during dietary sitostanol ester treatment. J Lipid Res 1993; 34:1535-44.

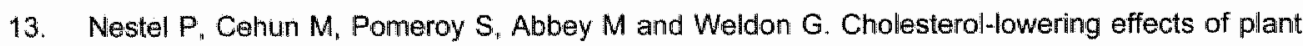
sterol esters and non-esterified stanols in margarine, butter and low-fat foods. Eur J Clin Nutr $2001 ; 55: 1084-90$. 
14. Normen L. Dutta P. Lia A and Andersson H. Soy sterol esters and beta-sitostanol ester as inhibitors of cholesterol absorption in human small bowel. Am J Clin Nutr 2000; 71:908-13.

15. Nell HA, Meijer GW and Roe LS. Randomised controlled trial of use by hypercholesterolaemic patients of a vegetable oil sterol-entiched fat spread. Atherosclerosis 2001; 156:329-37.

16. Centraal Begeleidingsorgaan voor de Intercollegiale Toetsing, in samenwerking met de Nederlandse Hartstichting et at. Behandeling en preventie van coronaire hartziekten door verlaging van de plasmacholesterolconcentratie. Utrecht: $\mathrm{CBO}$ " 1998.

17. Plat $J$ and Mensink RP. Vegetable oil based versus wood based stanol ester mixtures: effects on serum lipids and hemostatic factors in non-hypercholesterolemic subjects. Atherosclerosis 2000; 148:101-12.

18. Friedewald WT, Levy RI and Fredrickson DS. Estimation of the concentration of low-density lipoprotein cholesterol in plasma, without use of the preparative uitracentrifuge. Clin Chem 1972; 18:499-502.

19. Jones PJ, Raeini-Sarjaz M, Ntanios FY, Vanstone CA, Feng JY and Parsons WE. Modulation of plasma lipid levels and cholesterol kinetics by phytosterol versus phytostanol esters. J Lipid Res 2000; 41:697-705.

20. Mussner MJ. Parhofer KG, von Bergmann K, Schwandt $P$, Broedl $U$ and Otto $C$. Effects of phytosterol ester-enriched margarine on plasma lipoproteins in mild to moderate hypercholesterolemia are related to basal cholesterol and fat intake. Metabolism 2002; $51: 189$ 94.

21. Maki KC, Davidson $M H$, Umporowicz DM, Schaefer $E J$, et al. Lipid responses to plant-sterolenriched reduced-fat spreads incorporated into a National Cholesterol Education Program Step 1 diet. Am J Clin Nutr 2001; 74:33-43.

22. Vanhanen HT and Miettinen TA. Effects of unsaturated and saturated dietary plant sterols on their serum contents. Clin Chim Acta 1992; 205:97-107.

23. Vanstone $C$, Raeini-Sarjaz $M$, Parsons $W$ and Jones $P$. Unesterified plant sterols and stanols lower LDL-cholesterol concentrations equivalently in hypercholesterolemic persons. Am J Clin Nutr 2002; 76:1272-8.

24. Jones PJ, Ntanios FY, Raeini Sajaz M and Vanstone CA. Cholesterol-lowering efficacy of a sitostanol-containing phytosterol mixture with a prudent diet in hyperlipidemic men. Arru J Clin Nutr 1999; 69:1144-50.

25. De Graaf $\downarrow$, De Sauvage Nolting PR, van Dam M, Belsey EM, Kastelein JJP, Haydn Pritchard P and Stalenhoef AFH. Consumption of tall oil-derived phytosterols in a chocolate matrix significantly decreases plasma total and low-density lipoprotein-chollesterol levels. Br J Nutr 2002; 88:479-88.

26. Jones PJ, Howell T, MacDougall DE. Feng JY and Parsons W. Short-term administration of tall oill phytosterols improves plasma lipid profiles in subjects with different cholesterol levels. Metabolism 1998; 47:751-6. 
27. Mensink RP, Ebbing $\mathrm{S}$, Lindhout M, Plat $\mathbb{J}$ and van Heugten MM. Effects of plant stanol esters supplied in low-fat yoghurt on serum lipids and lipoproteins, non-cholesterol sterols and fat soluble antioxidant concentrations. Atherosclerosis 2002; 160: 205-213.

28. Gylling $H$ and Miettinen TA. Cholesterol reduction by different plant stanol mixtures and with variable fat intake. Metabolism 1999; 48:575-80.

29. Nguyen TT, Dale LC, von Bergmann $\mathrm{K}$ and Croghan IT. Cholesteral-lowering effect of stanol ester in a US population of mildly hypercholesterolemic men and women: a randomized controlled trial. Mayo Clin Proc 1999; 74:1198-1206.

30. Berge $K E$, Tian $H_{1}$ Graf $G A$, $Y u L_{\text {, }}$ et al. Accumulation of dietary cholesterol in sitosterolemia caused by mutations in adjacent $A B C$ transporters. Science 2000; 290:1771-5.

31. Lee $M H, L U K$, Hazard $S, Y u H$, et al. Identification of a gene, $A B C G 5$, important in the regulation of dietary cholesterol absorption. Nat Genet 2001:27:79-83.

32. Hubacek JA, Berge KE, Cohen $J \mathrm{C}$ and Hobbs HH. Mutations in ATP-cassette binding proteins G5 (ABCG5) and G8 (ABCG8) causing sitosterolemia. Hum Mutal 2001; 18: 359-60.

33. Berge KE, won Bergmann $K$, Lutjohann $D$, Guerra $R$, Grundy SM, Hobbs HH and Cohen JC. Heritability of plasma noncholesterol sterols and relationship to DNA sequence polymorphism in $A B C G 5$ and ABCGB. J Lipid Res 2002" 43:486-94.

34. Filtzgerald ML, Moore $\mathrm{KJ}$ and Freeman MW. Nuclear hormane receptors and cholesterol trafficking: the orphans find a new home. J Mol Med 2002; 80:271-81.

35. Chen HC. Molecular mechanisms of sterol absorption. J Nutr 2001; 131:2603-5.

36. Plat $\downarrow$ and Mensink RP. Increased intestinal ABCA1 expression contributes to the decrease in cholesterol absorption after plant stanol consumption. FASEB J 2002; 16:1248-53.

37. Schmitz $G$, Langmann $T$ and Heimerl S. Role of $A B C G 1$ and other $A B C G$ family members in lipid metabolism. J Lipid Res 2001; 42:1513-20.

38. Noakes M, Clifton P, Ntanios F, Shrapnel W, Record I and Mclnerney J. An increase in dietary carotenoids when consuming plant sterols or stanols is effective in maintaining plasma carotenoid concentrations. Am J Clin Nutr 2002; 75:79-86. 


\section{Chapter 4}

\section{The baseline serum lipoprotein profile is related to plant stanol induced changes in serum lipids and lipoproteins}

Elke Naumann ${ }^{1}$, Jogchum Plat ${ }^{1}$, Arnold D.M. Kester ${ }^{2}$, and Ronald P. Mensink"

'Maastricht University, Department of Human Biology, Maastricht, The Netherlands

${ }^{2}$ Maastricht University, Department of Methodology \& Statistics, Maastricht, The Netherlands

submitted 


\section{Abstract}

Background: Baseline characteristics of subjects might be related to the effect of plant stanols on the serum lipopratein profile.

Objective, The aim of the study was to examine effects of subjects' baseline characteristics (baseline serum concentrations of lipids and lipoproteins at the start of the study, lathosterol, campesterol and sitosterol; gender, age, BMI, smoking, use of oral contraceptives and menopause) on the effects of plant stanol esters on the serum lipoprotein profile.

Design: We used data of five studies performed at our Department. A random intercept mode was used for statistical analysis, using serum lipid and lipoprotein concentrations after plant stanol ester consumption, as dependent variables.

Results: After plant stanol ester consumption, higher baseline serum concentrations of total and LDL cholesteral resulted in larger absolute decreases in their respective serum concentrations. For the ratio of total to HDL cholesterol and for triacylglycerol, higher baseline serum concentrations resulted in larger absolute and relative decreases in their serum concentrations. HDL cholesterol concentrations increased in subjects with low baseline concentrations and decreased in those with high baseline concentrations. Effects however were small. No relationships were observed with baseline serum cholesterolstandardized lathosterol and campesterol concentrations ${ }_{\mathrm{y}}$ although LDL cholesterol concentrations tended to decrease more at higher baseline sitosterol concentrations. No effects of other baseline characteristics were found.

Conclusions: People with an unfavourable serum lipid and lipoprotein profile benefit even more of plant stanols than people with a more favourable profile. 


\section{Introduction}

A recent meta-analysis, based on mean reductions in serum $L D L$ levels obtained in selected clinical studies with plant sterols and stanols, showed that a_daily consumption of $2-2.59$ of plant sterols and stanols will lower serum concentrations of LDL cholesterol on average by $8.9 \%$ [1]. Between studies, however, reductions varied from $4 \%$ to $19 \%[2-14]$. These differences might - at least partly - be explained by differences in baseline characteristics of the subjects. Indleed, a positive relationship between baseline and decreases in serum LDL cholesterol concentrations has been reported in one study [15], but this could not be confirmed in other studies $[13,16,17]$. Recently, however, we also found that consumption of margarines enriched with a mixture of plant sterols and stanols hardly changed serum LDL cholesterol in subjects with baseline LDL cholesterol concentrations $\leq 2.26 \mathrm{mmol} / \mathrm{L}$, while it decreased serum concentrations of LDL cholesterol by approximately $0.35 \mathrm{mmol} / \mathrm{L}$ in subjects with baseline serum LDL cholesterol concentrations $\geq 3.36 \mathrm{mmol} / \mathrm{L}$ [18]. Although these differences in effects did not reach statistical significance, it provides evidence that the serum LDL cholesterol lowering effects of plant stanols may depend on baseline serum LDL cholesteral concentrations. Furthermore, it has been suggested that dietary plant stanols are especially of benefit for people with a high intestinal chollesterol absorption and a low endogenous cholesterol synthesis. Thuls, baseline serum concentrations of markers of cholesterol absorption (campesterol and sitosterol) and cholesterol synthesis (lathosterol) may also predict the LDL cholesterol-lowering effect of plant stanols [19]. Gender however may not be an important determinant to explain differences in response between studies. In most studies, effects on the serum lipoprotein profile were similar in men and women $[5,20$. 21], although Mussner et al. have suggested that plant sterol esters decreased LDL cholesterol slightly more in men than in women [22]. Finally, decreases in serum concentrations of LDL cholesteral were larger in elderly than those in younger people $[1,23]$. In general however, the statistical power of many of the individual studies was too low to examine the effects of these subjects" baseline characteristics on the effects of plant stanols on the serum lipid and lipoprotein profile. To address these possible relationships more systematically, we decided to carry out a meta-analysis using the individual data from five studies performed at our Department $[3,18,24-26]$. Furthermore, effects of BMI, smoking. use of oral contraceptives and menopause on plant stanol induced changes in serum lipids and lipoproteins were evaluated.

\section{Materials and methods}

\section{Characteristics of the studies}

Between 1997 and 2000 four randomized placebo-controlled trials on the effects of plant stanol esters on serum lipids and lipoproteins have been carried out at our Department $[3$, 
24-26]. In addition, one study was performed to examine the effects of two different mixtures of plant stanols and sterols on the serum concentrations of plant sterols. In that study, serum lipids were also measured [18]. For convenience however all diets are referred to as "enriched with plant stanols". In all studies plant stanols and sterols were esterified with rapeseed oil fatty acids. Characteristics of the studies are given in Table 4.1 and Table 4.2 . Three studies had a parallel design [24-26] and two studies had a cross-over design [3, 18]: Targeted daily intakes of plant stanols were 2 to 4 gram and duration of the treatments 3 to 8 weeks. In one study, plant stanols were incorporated into margarines and shortenings [3], in three studies into margarines $[18,24,26]$ and in one study into a low fat yogurt [25]. In total, 301 subjects participated in these five studies, 104 men and 197 women. Of these subjects 29 people participated in two, 2 in three and 4 in four of the studies. Subjects had no hypertension, no presence of glucosuria, no use of medication or a diet known to affect serum lipids and lipoproteins, no abuse of drugs or alcohol, and no history of coronary heart disease. Further, all subjects were weight stable, had not participated in another biochemical trial or donated blood within the previous 30 days, were not pregnant or breast-feeding and did not use food products enriched with plant sterols or stanols. Average BMI was 23 to 25 $\mathrm{kg} / \mathrm{m}^{2}$ in all studies, 26 women were post-menopausal and 97 women used oral contraceptives. Individual data of smoking habits were not available for one trial [3]. In the other trials, 44 subjects were smokers $[18,24-26]$. During the studies, subjects did not change their habitual diet, level of physical exercise, smoking habits or use of alcohol or oral contraceptives during the studies. The study protocols were approved by the medical ethical committee of Maastricht University. All subjects gave written informed consent before the start of the trials.

\section{Analysis of lipids, lipoproteins and non-cholesterol sterols}

All blood samples were taken after an overnight fast and after abstinence from drinking alcohol the previous day and smoking on the morning of blood sampling. In parallel trials, blood samples were taken twice at the end of the run-in periods and twice at the end of the intervention periods. In the cross-over trials, blood samples were taken twice at the end of each dietary period. The two blood samples were always taken with at least three days in between and results were averaged for statistical analyses. In addition, one blood sample was taken at the start of a study (baseline). 


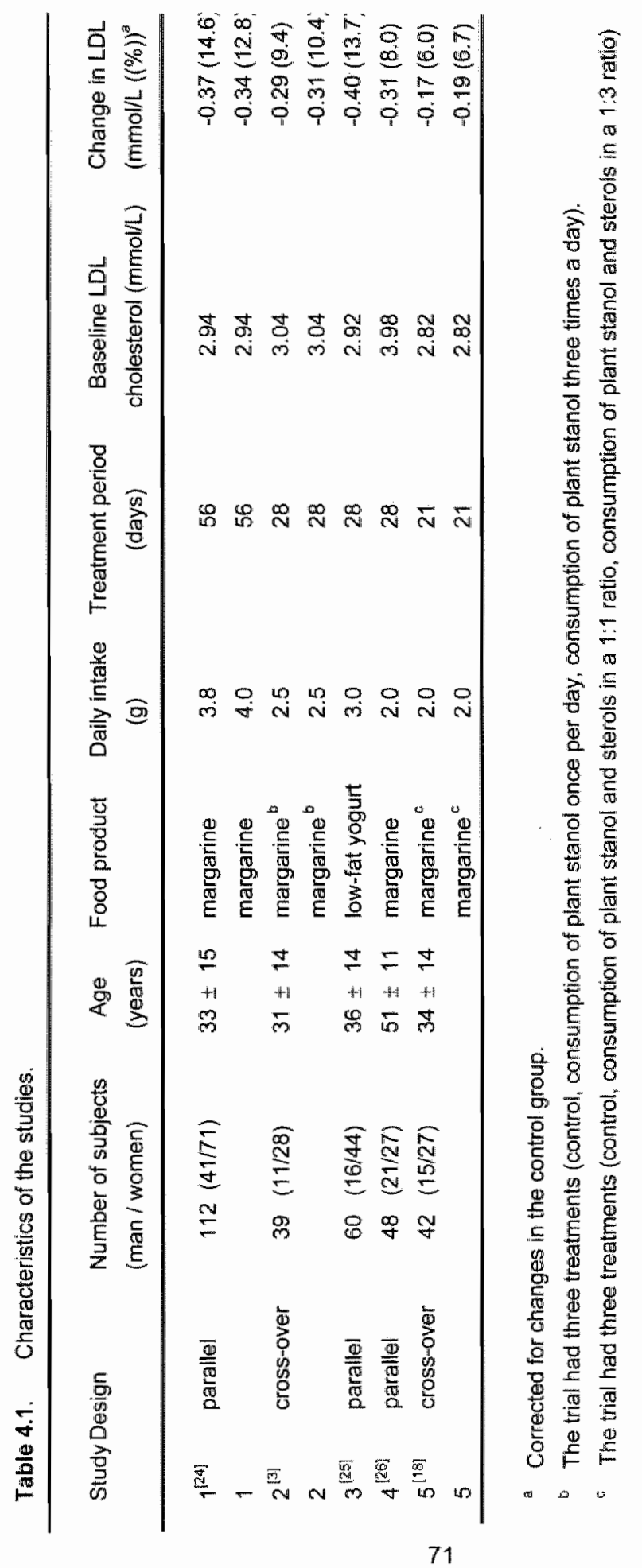




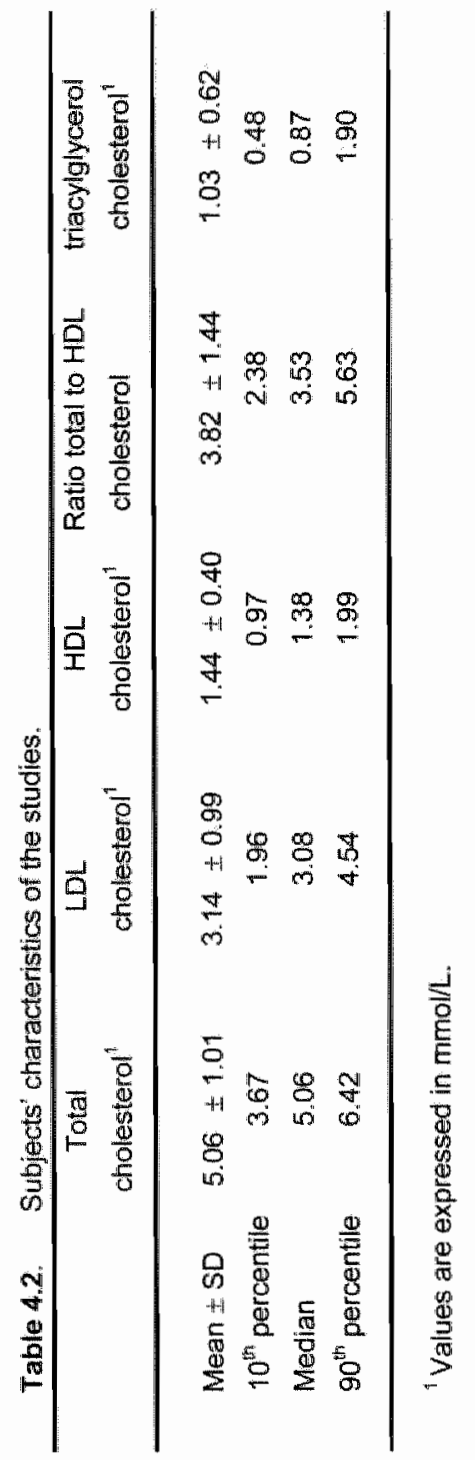


Analyses of lipids and lipoproteins were performed in all studies, analyses of lathosterol, campesterol and sitosterol in three of the five studies $[18,24,25,27]$. All analyses were done in serum obtained by centrifuging a serum tube for $15[3,25]$ or 30 minutes $[24,26,28]$ at $2000 \times \mathrm{g}$ at $4{ }^{\circ} \mathrm{C}$, at least 1 hour after venipuncture. All samples were stored at -80 " $\mathrm{C}$ until. analyses of lipids and lipoproteins and non-cholesterol sterols. Samples of one subject were always analyzed in one run. Serum concentrations of total cholesterol, HDL cholesterol and triacylglycerol were determined as described [24]. Serum concentrations of LDL cholesterol: were calculated using the Friedewald equation [29]. For analyses of non-cholesterol sterols; sera from two blood samples at the end of the run-in periods and at the end of the intervention periods for parallel trials and at the end of each dietary period for the cross-over trial were pooled. Analyses were performed as described elsewhere [27].

\section{Statistics}

A random intercept model was used for statistical analysis, using serum concentrations of total cholesterol, LDL cholesterol, HDL cholesterol, triacylglycerol and the ratio of total to HDL cholesterol as dependent variables. For this, the data were rearranged so that for crossover trials the end-of-period measurements and for parallel trials the end-of-run-in and endof-intervention values were on separate lines. Subject was included as random factor in order to obtain estimates of plant stanol effects based on within-subject differences. A fixed factor for measurement number was included to correct for possible time-trend effects. For parallel trials, this number was 1 or 2 , indicating respectively serum lipoprotein concentrations at the end of the run-in period and at the end of the intervention period. For cross-over trials, measurement numbers were 1,2 and 3 for serum lipoprotein concentrations at the end of the three dietary periods. In addition, a fixed factor for trial was included as well as the interaction between trial and measurement number to account for possible different period effects per trial. To answer the questions whether baseline subject characteristics are related to the cholesterol-lowering effects of plant stanols, the amount of daily plant stanol intake was included into the model as covariate, together with an interaction term for the variable of interest, for example the serum total cholesterol concentrations at baseline. A statistically significant interaction term indicates that effects of plant stanol intake are related to baseline concentrations of total cholesterol. In the same way, effects of other variables (baseline serum concentrations of LDL cholesterol, HDL cholesterol, triacylglycerol and the ratio of total to HDL cholesterol; cholesterol-standardized concentrations of lathosterol, campesterol, sitosterol and the ratios of lathosterol to campesterol and of lathosterol to sitosterol at the end of the run-in period for parallel trials and at the end of the control period for the cross-over trial (also referred to as baseline concentrations); gender, age, BMI "smoking, use of oral contraceptives and menopause) on the cholesterol lowering effects of plant stanols were tested. Unless otherwise indicated, all models included the interaction term between plant stanol intake and baseline serum concentration of the lipid variable of interest. A p-value of $<0.05$ was considered statistically 
significant: Analyses were performed using SPSS 11.5 (SPSS, Chicago, IL, USA) using the mixed model option within the General Linear Model procedure.

\section{Results}

\section{Effect of baseline serum lipids and lipoproteins}

The absolute decrease in serum total cholesterol concentrations after consumption of plant stanolls was related to baseline serum concentrations of total cholesterol $(p<0.002$ for the interaction term, Table 4.3).

Table 4.3. Estimated effects of baseline serum lipid and lipoprotein concentrations on changes in serum lipids and lipoproteins after consumption of plant stanol esters".

\begin{tabular}{lcc}
\hline Parameter & estimated effect & p-value \\
\hline $\begin{array}{l}\text { Totall cholesterol } \\
\quad \text { Plant stanol intake }\end{array}$ & & \\
$\quad$ Baseline total cholesterol x plant stanol intake & 0.017 & 0.669 \\
LDL cholesterol & -0.025 & 0.002 \\
$\quad$ Plant stanol intake & & \\
$\quad$ Baseline LDL cholesterol x plant stanol intake & -0.004 & $<0.001$ \\
HDL cholesterol & -0.033 & $<0.001$ \\
$\quad \begin{array}{l}\text { Plant stanol intake } \\
\text { Baseline HDL cholesterol x plant stanol intake }\end{array}$ & 0.023 & $<0.001$ \\
Ratio of total to HDL cholesterol & -0.016 & 0.031 \\
$\quad \begin{array}{l}\text { Plant stanol intake } \\
\text { Baseline total/HDL cholesterol x plant stanol intake }\end{array}$ & -0.036 & 0.061 \\
Triacylglycerol & & $<0.001$ \\
$\quad \begin{array}{l}\text { Plant stanol intake } \\
\text { Baseline triacylglycerol x plant stanol intake }\end{array}$ & -0.033 & $<0.001$ \\
\hline
\end{tabular}

1 Values for plant stanol intake are expressed per g of plant stanol intake per day: values for interactions of baseline lipids and lipoproteins $\mathrm{x}$ plant stanol intake are expressed in mmol/L. 
At a baseline serum total cholesterol concentration of $4.00 \mathrm{mmol} / \mathrm{L}$ and a daily plant stanol intake of $2 \mathrm{~g}$, the expected change in serum concentration of total cholesterol is calculated as: $(0.017 \times 2)-(0.025(4.0 \times 2))=-0.17$ moll $\mathrm{L}$ or $4.2 \%(95 \%$ confidence interval $(\mathrm{Cl}):-0.22$ to $-0.12 \mathrm{mmal} / \mathrm{L}$ or -5.5 to $-3.0 \%)$. At a similar intake, the expected decrease at a baseline serum concentration of $6.00 \mathrm{mmol} / \mathrm{L}$ is $0.27 \mathrm{mmol} / \mathrm{L}$ or $4.4 \%(95 \% \mathrm{Cl}:-0.32$ to $-0.22 \mathrm{mmol} / \mathrm{L}$ or -5.3 to $-3.7 \%$ ) and at a baseline serum concentration of 8.00 mmol/h the expected decrease is $0.37 \mathrm{mmol} / \mathrm{L}$ or $4.6 \%(95 \% \mathrm{Cl}$ : -0.47 to $-0.27 \mathrm{mmol} / \mathrm{L}$ or -5.9 to $-3.4 \%)$.

This indicates that baseline serum concentrations of total cholesterol are related to the absolute, but hardly to the rellative reductions in serum total cholesterol concentrations (Figure 4.1).

mmollL

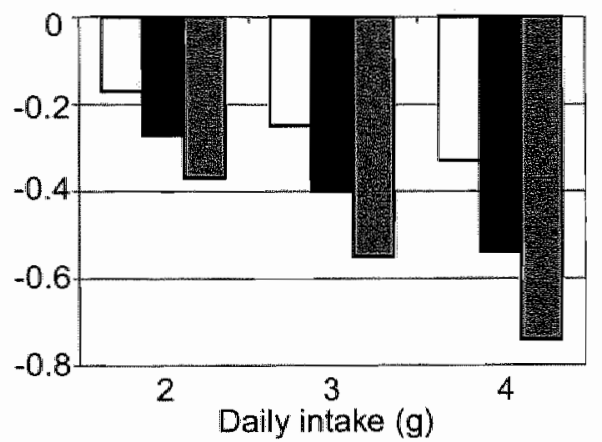

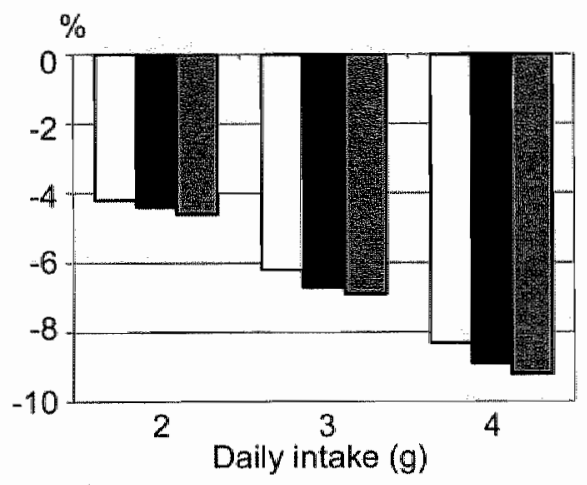

Baseline total cholesterol concentrations:

$\square 4.0 \mathrm{mmol} / \mathrm{L} \square 6.0 \mathrm{mmol} / \mathrm{L}$ 政 $8.0 \mathrm{mmol} / \mathrm{L}$

Figure 4.1. Predicted change in serum concentrations of total cholesterol at different baseline concentrations and at different amounts of daily plant stanol intake.

Baseline serum concentrations of LDL cholesterol were also only related to absolute decreases in serum LDL cholesterol $(p<0.001$ for the interaction term, Figure $4.2,95 \% \mathrm{Cl}$ for the changes at a baseline $L D L$ cholesterol concentration of $3.00 \mathrm{mmol} / \mathrm{L}:-0.24$ to -0.17 mmol/L or -8.0 to $-5.7 \%$ per $2 \mathrm{~g}$ of stanol intake; $95 \% \mathrm{Cl}$ at a baseline LDL cholesterol concentration of $4.00 \mathrm{mmol} / \mathrm{L}:-0.32$ to $-022 \mathrm{mmol} / \mathrm{L}$ or -8.0 to $-5.5 \%$ per $2 \mathrm{~g}$ of stanol intake; $95 \% \mathrm{Cl}$ at a baseline LDL cholesterol concentration of $5.00 \mathrm{mmol} / \mathrm{L}:-0.41$ to $-0.27 \mathrm{mmol} / \mathrm{L}$ or -8.2 to $-5.4 \%$ per $2 \mathrm{~g}$ of stanol intake). 
$\mathrm{mmol} / \mathrm{L}$

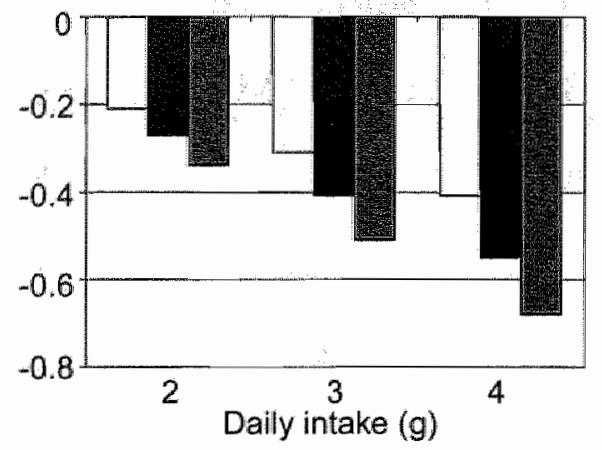

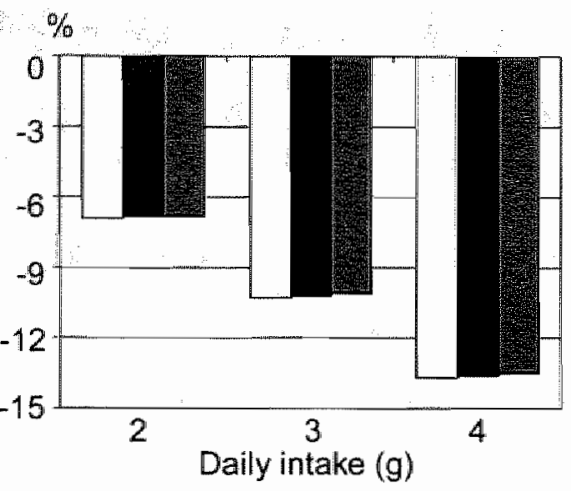

Baseline LDL cholesteral concentrations:

$\square 3.0 \mathrm{mmo} / \mathrm{L} \square 4.0 \mathrm{mmol} / \mathrm{L}$ 濇 $5.0 \mathrm{mmol} / \mathrm{L}$

Figure 4.2. Piredicted change in serum concentrations of LDL cholesterol at different baseline concentrations and at different amounts of dally plant stanol intake.

Effects on HDL. cholesteral did also depend on baseline concentrations ( $p<0.031$ for the interaction term, Filgure 4.3). Estimated changes were however small. At a baseline HDL cholesterol concentration of $1.00 \mathrm{mmol} / \mathrm{L}$, the estimated increase in $\mathrm{HDL}$ cholesterol was $0.01 \mathrm{mmol} / \mathrm{L}$ or $1.4 \%$. When the baseline concentration was $1.50 \mathrm{mmol} / \mathrm{L}$, the change was $0.00 \mathrm{mmol} / \mathrm{L}$ and at a baseline concentration of $2.00 \mathrm{mmol} / \mathrm{L}-0.02 \mathrm{mmol} / \mathrm{L}$ or $-0.9 \%$.

Absolute and relative decreases in the ratio of total to $\mathrm{HDL}$ cholesterol were more pronounced at higher baseline ratios $(p<0.001$ for the interaction term, Figure 4.4). At a baseline ratio of total to $\mathrm{HDL}$ cholesterol of 3.00 and a daily plant stanol intake of $2 \mathrm{~g}$, the expected decrease is 0.12 or $4.1 \%$ (95\% confidence interval (Ct): -0.17 to -0.07 or -5.7 to $2.3 \%$ ). At a similar intake, the expected decrease at a baseline ratio of total to HDL cholesterol of 4.00 is 0.19 or $4.9 \%(95 \% \mathrm{C}$ il: -0.24 to -0.15 or -6.0 to $-3.8 \%)$ and at a baseline ratio of total to HDL cholesterol of 5.00 the expected decrease is 0.27 or $5.3 \%(95 \% \mathrm{Cl}$ : 0.32 to -0.21 or -6.4 to $-4.2 \%$ ). 

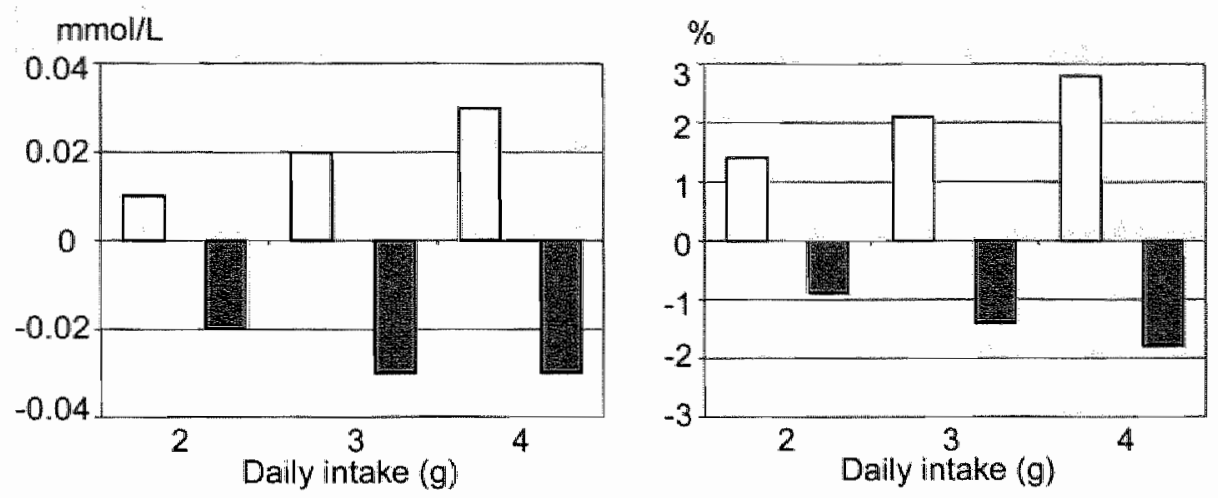

Baseline HDL cholesterol concentrations:

$\square 1.0 \mathrm{mmol} / \mathrm{L} \square 1.5 \mathrm{mmol} / \mathrm{L} \quad 2.0 \mathrm{mmol} / \mathrm{L}$

Figure 4.3. Predicted change in serum concentrations of HDL cholesterol at different baseline concentrations and at different amounts of daily plant stanol intake.
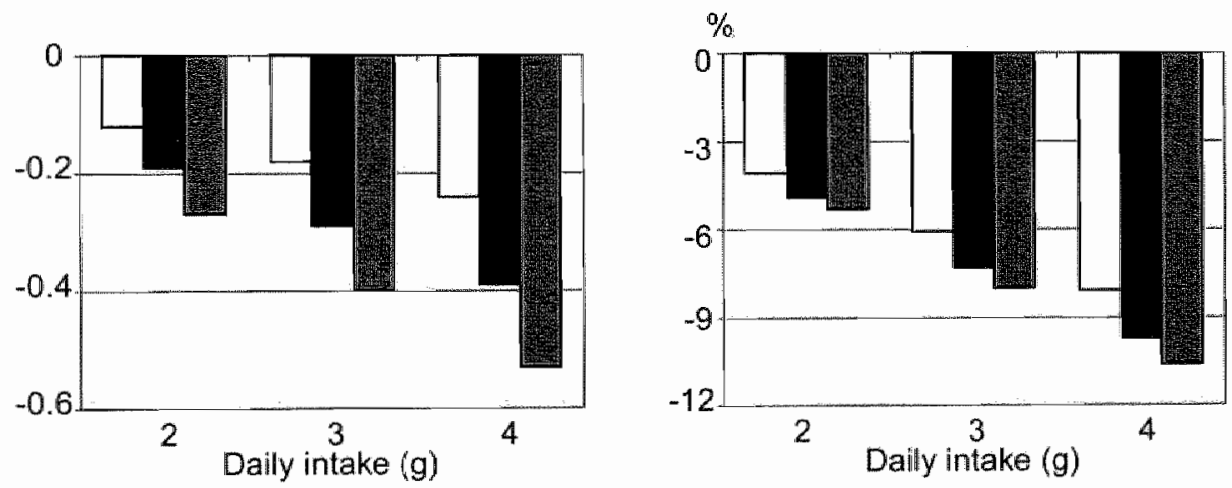

Baseline ratios of total to HDL cholesterol:

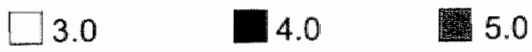

Fingure 4.4. Predicted change in the ratio of total cholesterol to HDL cholesterol at different baseline concentrations and at different amounts of daily plant stanall intake. 
For serum concentrations of triacylglycerol a similar pattern was found, indicating that both absolute and relative decreases in serum triacylglycerol concentrations were more pronounced at higher baseline concentrations $(p<0.001$ for the interaction term, Figure 4.5). At a baseline serum concentration of $1,00 \mathrm{mmol} / \mathrm{L}$ and a daily plant stanol intake of $2 \mathrm{~g}$, the expected decrease is $0.01 \mathrm{mmol} / \mathrm{L}$ or $1.0 \%$. At a similar intake, the expected decrease at a baseline serum concentration of triacylglycerol of $2.00 \mathrm{mmol} / \mathrm{L}$ is $0.08 \mathrm{mmol} / \mathrm{L}$ or $3.8 \%$ and at a baseline serum concentration of $3.00 \mathrm{mmol} / \mathrm{L}$ the expected decrease is $0.14 \mathrm{mmol} / \mathrm{L}$ or $4.7 \%$.
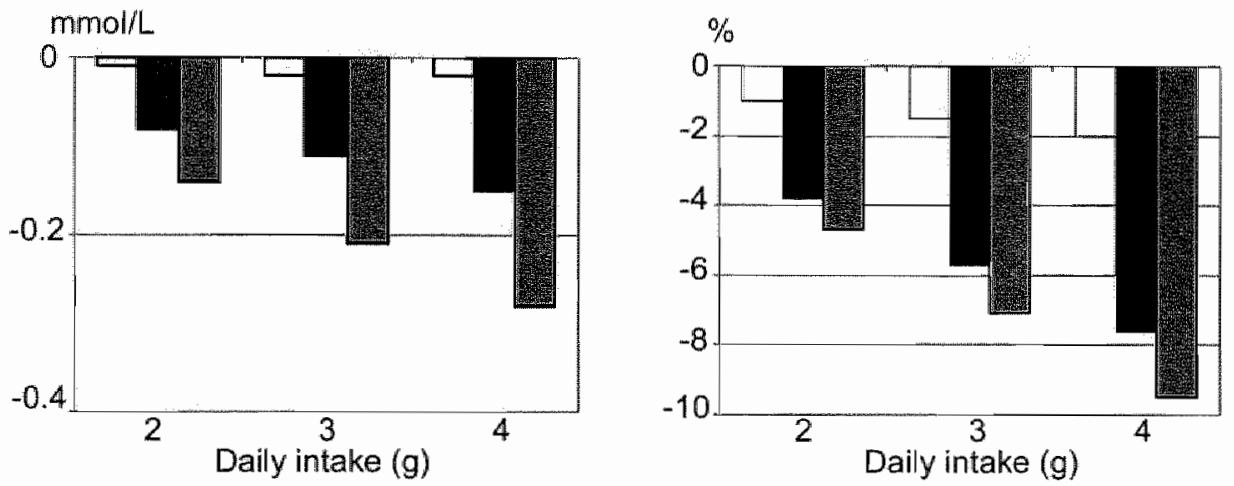

Baseline triacylglycerol concentrations:

$\square 1.0 \mathrm{mmol} / \mathrm{L} \square 2.0 \mathrm{mmol} / \mathrm{L}$ 䣱 $3.0 \mathrm{mmol} / \mathrm{L}$

Figure 4.5. Predicted change in serum concentrations of triacylglycerol at different baseline concentrations and at different amounts of daily plant stanol intake.

To examine the impact of each study on the results, analyses were repeated, each time excluding a different study. This however did hardly affect the estimated effects. In addition, the statistical model used, assumed a linear relationship between changes in serum lipids and plant stanol ester intake. To test the possibility that this relationship is non-linear and levels-off at higher intakes, we included the $2^{\text {nd }}$ order term for plant stanol intake into the model. This term however never reached statistical significance. 


\section{Effects of baseline serum lathosterol, campesterol and sitosterol}

Baseline serum concentrations of cholesterol-standardized lathosterol, campesterol and sitosterol of the three studies used in this meta-analysis are presented in Table 4.4 .

Tablle 4.4. Baseline serum cancentrations of lathosterol, campesterol and sitosterol in the three studies used in the metamanalysis ${ }^{\dagger}$

\begin{tabular}{|c|c|c|c|c|c|c|c|}
\hline \multicolumn{2}{|c|}{ Reference } & \multicolumn{3}{|c|}{ Lathosterol } & \multirow{2}{*}{$\begin{array}{l}\text { Campesterol } \\
398 \pm 141\end{array}$} & \multicolumn{2}{|c|}{ Sitosterol } \\
\hline \multirow[t]{2}{*}{26} & control group & 119 & \pm & 64 & & $173 \pm$ & 68 \\
\hline & experimental group & 106 & \pm & 59 & $368 \pm 143$ & $160 \pm$ & 61 \\
\hline \multirow[t]{3}{*}{25} & controll graup & 97 & \pm & 37 & $304 \pm 77$ & $114 \pm$ & 33 \\
\hline & vegetable oil-based group & 96 & \pm & 29 & $302 \pm 101$ & $114 \pm$ & 43 \\
\hline & wood-based group & 100 & \pm & 34 & $304 \pm 119$ & $118 \pm$ & 58 \\
\hline \multirow[t]{3}{*}{18} & control period & 133 & \pm & 60 & $354 \pm 140$ & $123 \pm$ & 49 \\
\hline & low steral period & 145 & \pm & 48 & $431 \pm 181$ & $133 \pm$ & 51 \\
\hline & high sterol period & 147 & \pm & 48 & $448 \pm 167$ & $139 \pm$ & 47 \\
\hline
\end{tabular}

1 Values are expressed as $10^{2} \times$ umol/mmol cholesterol.

Interaction terms for baseline serum concentrations of cholesterol-standardized lathosterol, campesterol, the ratio of lathosterol to campesterol ${ }_{i}$ the ratio of lathosterol to sitosterol and the ratio of lathosterol to plant sterols (campesterol plus sitosterol) $\times$ plant stanol intake were not significant, indicating that baseline non-cholesterol sterols were not related to decreases in serum concentrations of lipids and lipoproteins. The interaction term for baseline serum concentrations of sitosterol $x$ plant stanol intake nearly reached statistical significance for LDL cholesteral ( $p=0.062$, Table 4.5).

The results suggest that at higher baseline sitosterol concentrations, decreases in serum concentrations of LDL cholesterol were more pronounced (Figure 4.6). Baseline serum concentrations of sitosterol did not affect changes in total cholesterol, HDL cholesterol, triacylglycerol and the ratio of total to HDL cholesterol. Effects on serum lipids and lipoproteins of these three studies only were comparable to those of all five studies. 
Table 4.5. Estimated effects $(x 100)$ on serum LDL cholesterol of baseline LDL cholesterol, plant stanoll intake, baseline lathosterol, baseline campesterol, baseline sitosterol, and interactions."

\section{Lathosterol}

Plant stanol intake

Baseline LDL cholesterol $x$ plant stanol intake

Baseline lathosterol $x$ plant stanol intake

$\begin{array}{lr}-1.763 & 0.612 \\ -3.601 & <0.001 \\ 0.025 & 0.208\end{array}$

3.880

$-3.620$

$<0.001$

$-0.009$

0.228

Baseline campesterol $x$ plant stanol intake

4.606

0.204

$-3.562$

$<0.001$

$-0.030$

1 Values for diet are expressed per $\mathrm{g}$ of plant stanol intake per day; values for interactions of baseline lipids and lipoproteins $x$ plant stanol intake are expressed in mmol/L; values for interactions of baseline lathosterol, campesterol and sitosterol $x$ diet are expressed in $10^{2} \times \mu \mathrm{mol} / \mathrm{mmol}$ cholesteral.

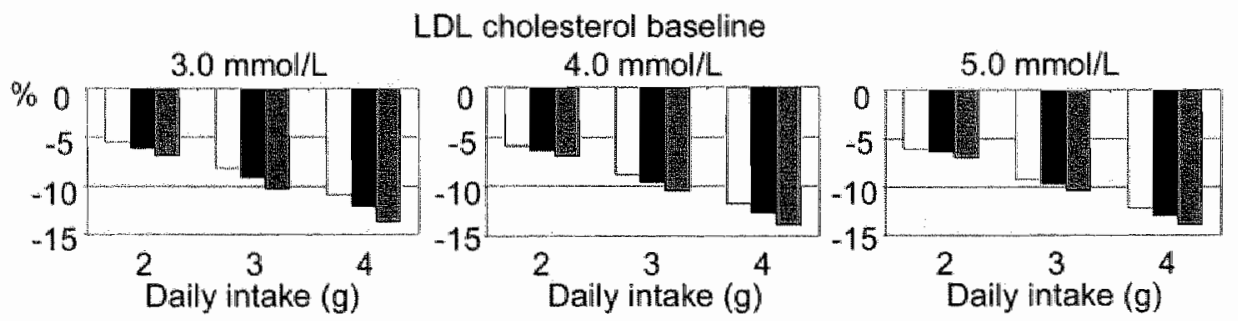

Figure 4.6. Predicted change in serum concentrations of LDL cholesterol at different baseline concentrations of sitosterol and of LDL cholesterol and at different amounts of daily plant stanol intake. 


\section{Effects of gender, age, BMII, smoking, use of orall contraceptives and menopause}

A trend was observed for effects of gender on the LDL cholesterol lowering effects of plant stanols, indicating that men were slightly more responsive $(p=0.083$ for the interaction of gender $x$ plant stanol intake). At the same baseline LDL cholesterol concentration and at daily plant stanol intakes of 2 and $4 \mathrm{~g}$, decreases were 0.05 and 0.10 mmol/L more in men than in women. Results did not change if the interaction of baseline LDL cholesterol $x$ plant stanol intake was included into the model suggesting that effects could not be explained by differences in $\mathrm{LDL}$ cholesterol concentrations between men and women. Baseline serum concentrations of LDL cholesterol were highly correlated with age $(r=0.549, p<0.001)$. To avoid collinearity, first a model was solved including the interaction age $x$ plant stanol intake, but not baseline LDL cholesterol $x$ plant stanol intake. The interaction term age $x$ plant stanol intake was significant $(p<0.05)$, but became non-significant when the baseline $L D L$ cholesterol $x$ plent stanol intake interaction term was included. This suggests that the effect of age on the LDL cholesterol lowering effect of plant stanols could be explained by the rise of about $0.30 \mathrm{mmol} / \mathrm{L}$ in serum $\mathrm{LDL}$ cholesterol concentrations every ten years of age. Age was also related to effects on HDL $(p<0.05$ when baseline HDL cholesterol $x$ plant stanol intake was not included) and the ratio of total to HDL cholesterol ( $p<0.002$ when baseline ratio of total to HDL cholesterol $x$ plant stanol intake was not included). Like for $L D L$ cholesterol, effects became non-significant when the baseline HDL cholesterol $x$ plant stanol intake and the baseline ratio of total to HDL cholesterol $x$ plant stanol intake interaction terms were included into the model. Therefore, effects of age on HDL cholesterol and the ratio of total to HDL cholesterol might be explained by decreased serum HDL cholesterol concentrations and increased ratios of total to HDL cholesterol at increasing age. No effects of BMI, smoking, use of oral contraceptives and menopause on the effects of plant stanols on the serum lipoprotein profile were found.

\section{Discussion}

Large variations thave been reported between studies and between subjects on the effects of consumption of free and esterified plant sterols and stanols on LDL cholesteroll concentrations [1]. These variations might not only be due to differences in experimental designs, but also to differences in baseline characteristics of the subjects. Single trials " however, normally lack the statistical power to identify subjects' characteristics related to changes in serum lipids and lipoproteins. We therefore decided to carry out a meta-analysis with individual data of five studies performed at our Department. In this way, variations in responses due to different study centers were excluded. We found that absolute but not relative decreases in serum $L D L$ cholesterol concentrations were related to their serum concentrations at the start of the study. Predicted reductions in serum LDL cholesterol at different doses of plant stanol intake were however slightly lower than those calculated from 
56 trial arms with plant sterols and stanols [1]. In our model, at a baseline LDL cholesterol concentration of $3.55 \mathrm{mmol} / \mathrm{L}$ (the rinean LDL cholesterol concentration in the placebo groups from the meta-analysis of Katan et al. [1]), the predicted decreases at daily doses of 1.7, 2.2 and $3 \mathrm{~g}$ of stanols were $5.8 \%, 7.5 \%$ and $10.2 \%$, while decreases were respectively $8.5 \%$, $8.9 \%$ and $11.3 \%$ in the meta-analysis [1].

In the present study we found that after plant stanol ester consumption HDL cholesterol increased slightly in people with low baseline concentrations, but decreased marginally in subjects with high baseline HDL cholesterol concentrations. This effect was not related to gender. These findings were unexpected, because most studies have reported no effects of plant stanols or sterols on serum concentrations of HDL cholesterol. However, in subjects with familial hypercholesterolemila plant sterols increased serum HDL cholesterol. This increase was larger the lower the baseline HDL cholesterol concentrations [30]. An increase in serum concentrations of HDL cholesterol has also been reported in subjects with type 2 diabetes mellitus using a cross-over design [31]. Although HDL cholesterol concentrations in that study were not extremely low during the control period $(1.13 \mathrm{mmol} / \mathrm{L})$, it is known that subjects with type 2 diabetes in general have lower HDL cholesterol levels than healthy controls [32]. In our study predicted changes were small. For example, at a baseline HDL cholesterol of $2.00 \mathrm{mmol} / \mathrm{L}$ and a daily plant stanol intake of $2 \mathrm{~g}$. HDL cholesterol concentrations are expected to decrease by only $0.02 \mathrm{mmol} / \mathrm{L}$. This will not increase cardiovascular risk, as at the same time LDL cholesterol will decrease substantially. Also, only a low proportion of the population will have baseline $\mathrm{HDL}$ cholesterol $>2.00 \mathrm{mmol} / \mathrm{L}$ and plant stanol enriched food products are not designed for this population. Both absolute and relative decreases in the ratio of total to HDL cholesterol, which is considered superior to total or lipoprotein cholesterol concentrations to estimate cardiovascular risk [33], were positively related to baseline concentrations. This suggests that especially people with an unfavourable ratio of total to HDL cholesterol benefit from plant stanol ester consumption.

Both absolute and relative decreases in serum triacylglycerol concentrations were positively related to those at baseline. As triacylglycerol, which is positively associated with the risk of coronary heart disease [34,35], is mainly transported by VLDL, it can be suggested that VLDL metabolism changes after plant stanol consumption. Gylling et al. indeed abserved decreased serum concentrations of VLDL cholesterol during sitostanol consumption, which might indicate that VLDL synthesis is reduced. However, serum concentrations of triacylglycerol remained unchanged [31]. On the other hand, in one study with 18 subjects, plant sterols lowered triacylglycerol concentrations [30]. The power of single studies is usually not sufficient to detect changes on serum triacylglycerol concentrations. Our model estimates a decrease of only $0.04 \mathrm{mmol} / \mathrm{L}$ at baseline concentrations of triacylg/ycerol of 1.5 $\mathrm{mmol} / \mathrm{L}$ and a daily plant stanol intake of $2 \mathrm{~g}$. To pick up this difference, about 450 subjects are needed in a crass-over trial and 1700 in a study with a parallel design with a statistical power of $80 \%$. 
In people with high cholesterol absorption and low cholesterol synthesis, indicated by high baseline plant sterol concentrations and low lathosterol concentrations, LDL cholesterol reduction is more pronounced than in people with low cholesterol absorption and high cholesterol synthesis $[15,19,36,37]$. To analyze if this was also present in our population, we included serum concentrations of lathosterol, campesterol and sitosterol and the ratio of serum concentrations of lathosterol to the plant sterols (campesterol plus sitosterol) in our model. However, we only observed a tendency for an increased reduction in serum concentrations of LDL cholesterol at increasing baseline sitosterol concentrations.

Effects of age were explained by baseline LDL cholesterol concentrations, which has been suggested previously [1]. We further observed that plant stanol esters may reduce LDL cholesterol slightly more in men than in women. This however does not mean that men will benefit more than women in terms of coronary heart disease risk. From our model and the data provided by Sacks and Katan [38], we can calculate the predicted reduction in coronary heart disease risk for men and women based on changes in serum lipids. For example, at a daily plant stanol intake of $2 \mathrm{~g}$ and baseline concentrations of LDL cholesterol of $4 \mathrm{mmol} / \mathrm{L}$, $\mathrm{HDL}$ cholesterol of $1 \mathrm{mmol} / \mathrm{L}$ and triacylglycerol of $2 \mathrm{mmol} / \mathrm{L}$, the expected decrease in coronary heart disease risk would be $10 \%$ for men and $12 \%$ for women. Another metaanalysis also reported differences between men and women in diet-induced LDL cholesterol responses [28]. In that study it was found that men would benefit more from decreasing saturated fatty acid intake than women for which there was no explanation.

To summarize, our meta-analysis showed that decreases in LDL cholesterol and the ratio of total to HDL cholesterol are most pronounced in subjects with the highest baseline levels of these cardiovascular risk markers. In addition, plant stanols may decrease serum concentrations of triacylglycerol especially in people with high serum concentrations of triacylglycerol. Other subjects' characteristics did not contribute substantially to the predicted changes, thereby underlining that functional foods enriched with plant stanol esters are of benefit for most people with an unfavourable lipoprotein profile. 


\section{References:}

1. Kattan MB, Grundy SM, Jones P. Law M, Miettinen T and Paoletti R. Efficacy and safety of plant stanols and sterols in the management of blood cholesterol levels: Mayo Clin Proc 2003; 78:965-78.

2. Vissers MN, Zock PL, Meijer GW and Katan MB. Effect of plant sterols from rice bran oil and triterpene alcohols from sheanut oil on sertum lipoprotein concentrations in humans. Am J Clin Nutr 2000; 72:1510-5.

3. Plat $J$, van Onselen ENM, van Heugten MMA and Mensink RP. Effects on serum lipids, lipoproteins and fat soluble antioxidant concentrations of consumption frequency of margarines and shortenings enriched with plant stanol esters. Eur J Clin Nutr 2000; 54:671-77.

4. Hallikainen MA and Uusitupa MI. Effects of 2 low-fat stanol ester-containing margarines on serum cholesterol concentrations as part of a low-fat diet in hypercholesterolemic subjects. Am J Clin Nutr 1999; 69:403-10.

5. Vanhanen HT, Kajander J, Lehtovirta $\mathrm{H}$ and Miettinen TA. Serum levels, absorption efficiency, faecal elimination and synthesis of cholesterol during increasing doses of dietary sitostanol esters in hypercholesterolaemic subjects. Clin Sci Colch 1994; 87:61-7.

6. Hallikainen MA, Sarkkinen ES, Gylling $H$, Erkkila AT and Uusitupa MIJ. Comparison of the effects of plant sterol ester and plant stanol esters-enriched margarines in lowering serum cholesteroll concentrations in hypercholesterolaemic subjects on a low-fat diet. Eur $\mathrm{J}$ Clin Nutr $2000 ; 54: 715-25$.

7. Hallikainen MA Sarkkinen ES and Uusitupa MI. Plant stanol esters affect serum cholesterol concentrations of hypercholesterolemic men and women in a dose-dependent manner. $J$ Nutr $2000 ; 130: 767-76$.

8. Neil HA, Meijer GW and Roe LS. Randomised controlled trial of use by hypercholesterolaemic patients of a vegetable oil sterol-enriched fat spread. Atherosclerosis 2001; 156:329-37.

9. Gylling $\mathrm{H}$ and Miettinen TA. Cholesterol reduction by different plant stanol mixtures and with variable fat intake. Metabolism 1999" 48:575-80.

10. Nguyen TT, Dale $L C$, won Bergmann $K$ and Croghan IT. Cholesterol-lowering effect of stanol ester in a US population of mildly hypercholesterolemic men and women: a randomized controlled trial. Mayo Clin Proc 1999; 74:1198-206.

11. Andersson A, Karlstrom B, Mohsen R and Vessby B. Cholesterol-lowering effects of a stanol ester-containing low-fat margarine used in conjunction with a strict lipid-lowering diet. Eur Heart $\checkmark$ Supplements 1999; 1:S80-S90.

12. Noakes $M$, Clifton $P, N$ tanios $F$, Shrapnel $W$, Record II and Mclnemey J. An increase in dietary carotenoids when consuming plant sterols or stanols is effective in maintaining plasma carotenoid concentrations. Am J Clin Nutr 2002; 75:79-86.

13. Maki KC, Davidson MH, Umporowicz DM, et al. Lipid responses to plant-sterol-enriched reduced-fat spreads incorporated into a National Cholesterol Education Program Step I diet. Am $J$ Clin Nutr 2001: 74:33-43. 
14. Nestel $P$, Cehun $M$. Pomeroy $S$, Abbey $M$ and Weldion $G$. Cholesterol-lowering effects of plant sterol esters and non-esterified stanols in margarine, butter and low-fat foods. Eur J Clin Nutr 2001; 55:1084-90.

15. Miettinen TA, Vuoristo M, Nissinen $M$, Jarvinen $H J$ and Gylling $H$. Serum, billary, and fecal cholesterol and plant sterols in colectomized patients before and during consumption of stanol ester margarine. Am J Clin Nutr 2000; 71:1095-102.

16. Weststrate JA and Meijer GW. Plant sterol-enriched margarines and reduction of plasma totaland LDL-cholesterol concentrations in normocholesterolaemic and mildly hypercholesterolaemic subjects. Eur J Clin Nutr 1998; 52:334-43.

17. Judd JT, Baer DJ, Chen SC, et al. Plant sterol esters lower plasma lipids and most carotenoids in mildly hypercholesterolemic adults. Lipids 2002; 37:33-42.

18. Naumann E, Plat $\mathrm{J}$ and Mensink RP. Changes in serum concentrations of noncholesterol sterols and lipoproteins in healthy subjects do not depend on the ratio of plant sterols to stanols in the diet. INutr 2003; 133:2741-7.

19. Gylling $H_{s}$ Puska $P$, Vartiainen $E$ and Miettinen TA. Serum sterols during stanol ester feeding in a mildly hypercholesterolemic population. I Lipid Res 1999; 40:593-600.

20. Vanhanen HT, Blomqvist S, Ehnholm C, et al. Serum cholesterol, cholesterol precursors, and plant sterals in hypercholesterolemic subjects with different apoE phenotypes during dietary sitostanol ester treatment. I Lipid Res 1993; 34:1535-44.

21. Miettinen TA and Vanhanen H. Dietary sitostanol related to absorption, synthesis and serum level of cholesterol in different apolipoprotein $E$ phenotypes. Atherosclerosis 1994; 105:217-26.

22. Mussner MJ, Parhofer $K G$, Von Bergmann $K$, Schwandt $P$, Broedl $U$ and Otto $C$. Effects of phytosterol ester-enriched margarine on plasma lipoproteins in mild to moderate hypercholesterolemia are related to basal cholesterol and fat intake. Metabolism 2002; $51: 189$ 94.

23. Law MR. Plant sterol and stanol margarines and health. West $\mathrm{J}$ Med 2000; 173:43-7.

24. Plat $J$ and Mensink RP. Vegetable oil based versus wood based stanol ester mixtures: effects on serum lipids and hemostatic factors in non-hypercholesterolemic subjects. Atherosclerosis 2000; 148:101-12.

25. Mensink RP, Ebbing $S$, Lindhout $M$, Plat $J$ and wan Heugten MM. Effects of plant stanol esters supplied in low-fat yoghurt on serum lipids and lipoproteins, non-cholesterol sterols and fat soluble antioxidant concentrations. Atherosclerosis 2002; 160:205-13.

26. Kerckhoffs DA. Dietary components and cardiovascular risk markers: effects of tocotrienols " beta-glucan and plant stanol esters. Thesis. Faculty of Health Sciences, Department of Human Biology. 2003, Maastricht University: Maastricht.

27. Plat $J$ and Mensink RP. Effects of diets enriched with two different plant stanol ester mixtures on plasma ubiquinol-10 and fat-soluble antioxidant concentrations. Matabolism 2001.

28. Weggemans $R M$, Zock PL, Urgert $R$ and Katan MB. Differences between meri and women in the response of serum cholesterol to dietary changes. Eur J Clin Invest 1999; 29:827-34. 
29. Friedewald WT, Levy RI and Fredrickson DS. Estimation of the concentration of low-density lipoprotein cholesterol in plasma, without use of the preparative ultracentrifuge. Clin Chem $1972 ; 18: 499-502$

30. Ketomakl A, Gylling H and Miettinen TA. Non-cholesterol sterols in serum, lipoproteins, and red cells in statin-treated FH subjects off and on plant stanol and sterol ester spread. Clin Chim Acta 2005; 353:75-86.

31. Gylling $H$ and Miettinen TA. Serum cholesteral and cholesterol and lipoprotein metabolism in hypercholesterolaemic NIDDM patients before and during sitostanol ester-margarine treatment. Diabetologia 1994: 37:773-80.

32. Rohrer $\mathbb{L}$. Hersberger $M$ and von Eckardstein $A$. High density lipoproteins in the intersection of diabetes mellitus, inflammation and cardiovascular disease. Curr Opin Lipidoll 2004; 15:269-78.

33. Despres J-P. Lemieux I, Dagenais G-R, Cantin B and Lamarche B. HDL-cholesterol as a marker of coronary heart disease risk: the Quebec cardiovascular study. Atherosclerosis 2000; 153:263-72.

34. Austin MA, Hokanson JE and Edwards KL. Hypertriglyceridemia as a cardiovascular risk factor. Am J Cardiol 1998; 81:7B-12B.

35. NIH Consensus Development Panel on triglyceride, high-density lipoprotein, and coronary heart disease. Triglyceride, high-density lipoprotein "and coronary heart disease. JAMA 1993; 269:505-10.

36. Miettinen TA, Puska $P$, Gylling $H$, Vanhanen $H$ and Vartiainen $E$. Reduction of serum cholesterol with sitostanol-ester margarine in a mildly hypercholesterolemic population. $\mathrm{N}$ Engl J Med 1995; 333:1308-12.

37. Thuluva SC, Igel $M$, Lutjohann $D$, Sudhop $T$ and Von Bergmann $K$. Ratio of lathosterol to campesterol in serum predicts the cholesterol-lowering effect of sitostanol-supplemented margarine. Int J Clin Pharmacol Ther. 2005; 43:305-10.

38. Sacks FM and Katan MB. Randomized clinical trials on the effects of dietary fat and carbohydrates on plasma lipoproteins and cardiowascular disease. Am J Med 2002; $113(9 B): 13 S-24 S$. 


\section{Chapter 5}

\section{$\beta$-Glucan incorporated into a fruit drink effectively lowers serum LDL cholesterol concentrations}

Elke Naumann ${ }^{1}$,Angelina B. van Rees ${ }^{1}$, Gunilla Önning ${ }^{2}$, Rickard Öste ${ }^{3}$, Markus Wydra and Ronald P. Mensink ${ }^{1}$

'Department of Human Biology "Maastricht University, Maastricht, The Netherlands

${ }^{2}$ Division of Biomedical Nutrition, Centre for Chemistry and Chemical Engineering, University of Lund, Lund, Sweden

${ }^{3}$ CEBA AB, Lund, Sweden

${ }^{4}$ Döhler GmbH, Darmstadt, Germany

Based on: American Journal of Clinilical Nutrition, in press

Support: This study was funded by the European Commission (QLK1-CT-2000-00535) 


\section{Abstract}

Background: $\beta$-Glucan can reduce serum concentrations of total and LDL cholesterol. The mechanism of action however is not clear and it is difficult to predict the cholesterol-lowering effect of a food product enriched with $\beta$-glucan.

Objective: We examined the effects of a $\beta$-glucan enriched fruit juice on the serum lipids and lipoproteins and on markers of chollesterol absorption (serum concentrations of plant sterols) and of cholesterol synthesis (serum concentrations of lathosterol). In adidition, we measured effects on lipid-soluble anti-oxidants.

Design: After a three-week run-in period, healthy subjects consumed daily a fruit drink providing $5 \mathrm{~g}$ of rice starch (placebo, $\mathrm{N}=22$ ) or $\beta$-glucan from oat $(\mathrm{N}=25)$ for five weeks (parallel design). At the end of the run-in period and at the end of the intervention blood samples were taken for analysis of lipids and lipoproteins, non-cholesterol sterols and fatsoluble anti-oxidants. Changes between end of run-in and end of intervention were calculated for each subject. Differences in changes between the groups were statistically analyzed.

Results: Compared with the control group, the change in serum concentrations of total and LDL cholesterol in the $\beta$-glucan group were $-4.8 \%(p=0.012)-7.7 \%(p=0.005)$, respectively. In the $\beta$-glucan group the change in serum concentrations of lathosteral was $13 \%(p=0.023)$ and of sitosterol $-11 \%(p=0.030)$. No effects were found on fat-soluble anti-oxidants.

Conclusions: $\beta$-Glucan lowers serum concentrations of total and LDL cholesterol when incorporated into a fruit drink. A reduced cholesterol absorption contributes to the cholesterol-lowering effect of $\beta$-glucan without affecting plasma concentrations of lipid soluble anti-oxidants. 


\section{Introduction}

$\beta$-Glucan is a non-starch polysaccharide composed of $\beta-(1 \rightarrow 4)$-linked glucose units separated every two to three units by $\beta-(1 \rightarrow 3)$-linked glucose. This soluble fiber, which is present in oats has received much attention, because of its potential to lower LDL. cholesterol. In 1997, the Food and Drug Administration (FDA) therefore allowed the health claim that a diet high in soluble fiber from whole oats (oat bran. oatmeal and oat flour) and low in saturated fat and cholesterol may reduce the risk of cardiovascular disease [1]. Indeed "many studies have demonstrated LDL cholesterol lowering effects of products enriched with B-glucan [2], although some recent studies did not [3, 4]. Differences in solubility and molecular weights of the $\beta$-glucans used might explain these contrasting findings, since these characteristics affect intestinal viscosity [5-7]. An increased intestinal viscosity, and a subsequent reduced bile acid absorption, is one of the proposed mechanisms by which $\beta-$ glucan reduces serum cholesterol concentrations [8-10]. In addition, the increased intestinal viscosity may also lower cholesterol absorption [9, 10], although a reduced cholesterol absorption was not found in other studies [8, 11]. It has further been suggested that the intestinal viscosity depends on food processing or on the food matrix of the $\beta$-glucan rich product [12]. If this is true, then it is difficult to predict the cholesterollowering effect of a food product enriched with $\beta$-glucan. In the present study, we therefore examined the effects of a fruit drink enriched with $\beta$-glucan on the serum lipoprotein profile. To further elucidate the mechanism of action, we examined effects of the fruit drink on markers of cholesterol absorption (serum concentrations of plant sterols) and cholesterol synthesis (serum concentrations of lathosterol). Moreover, a greater intestinal viscosity might enlarge the intestinall unstirred water layer [13], which suggests that $\beta$-glucan may affect absorption of other fat-soluble components as well. Therefore, plasma concentrations of lipid soluble anti-oxidants were also analyzed.

\section{Subjects and methods}

\section{Subjects}

Volunteers were recruited through announcements in local newspapers or among subjects that had participated in earlier studies at our Department. Ninety six subjects were invited for two screening visits if they met our first inclusion criteria. These criteria were: age between 18 and 70 years, BMI between 20 and $32 \mathrm{~kg} / \mathrm{m}^{2}$, stable body weight (weight gain or loss $\mathrm{s}$ $5 \%$ in the past three months), no intention to change the physical activity pattern during the study, no use of medication or a prescribed diet known to affect lipid metabolism, not pregnant or breast feeding, no participation in another biochemical trial at the same time, willing to stop the consumption of vitamin supplements, or products enriched with plant stanol or sterol esters three weeks before the start of the study, and no planned holiday in 
weeks of blood sampling. During the screening visits, blood pressure, body weight and height were measured and a urine sample was analyzed for the presence of glucose. Blood samples were taken from fasting subjects for lipid and lipoprotein analysis with at least three days in between. All subjects filled in a medical questionnaire. Forty eight subjects were included in the study. They had mean serum concentrations of total cholesterol $\leq 8.0 \mathrm{mmol} / \mathrm{L}$ and of triacylglycerol $\leq 4.0 \mathrm{mmol} / \mathrm{L}$, no indication for treatment for hyperlipidemia according to the Dutch Cholesteral Consensus [14], diastolic blood pressure $\leq 95 \mathrm{mmHg}$ and systolic blood pressure $\leq 160 \mathrm{mmHg}$, no presence of glucosuria, no clinical condition known to affect lipid metabolism, no drug or alcohol abuse, no history of coronary heart disease, decompensatio cordis (Class III or IV), cardiomyopathy, kidney-, liver- and pancreatic disease or malignancy $<5$ years ago. At the start of the trial, one man decided not to participate, because of personal reasons. Therefore, forty-seven subjects (18 men and 29 womeri) started the study.

The women were $49 \pm 16$ years of age (mean \pm SD) and had a BMl of $23 \pm 3 \mathrm{~kg} / \mathrm{m}^{2}$. Their mean serum concentrations of total cholesterol were $6.71 \pm 0.77 \mathrm{mmol} / \mathrm{L}$, of LDL cholesterol $4.33 \pm 0.68 \mathrm{mmol} / \mathrm{L}$, of $\mathrm{HDL} 1.63 \pm 0.40 \mathrm{mmol} / \mathrm{L}$, and of triacylglycerol $1.66 \pm 0.64 \mathrm{mmol} / \mathrm{L}$. Eight women smoked, 9 used oral contraceptives and 12 were menopausal. The men were $56 \pm 9$ years of age and had a BMI of $26 \pm 2 \mathrm{~kg} / \mathrm{m}^{2}$ "Their mean serum concentrations of total cholesterol was $7.25 \pm 0.61 \mathrm{mmol} / \mathrm{L}$, of LDL cholesteral $4.97 \pm 0.53 \mathrm{mmol} / \mathrm{L}$, of $\mathrm{HDL}$ cholesterol $1.53 \pm 0.23 \mathrm{mmol} / \mathrm{L}$, and of triacylglcyerol $1.62 \pm 0.49 \mathrm{mmol} / \mathrm{L}$. Two men were smokers.

\section{Study design}

The study was designed as a placebo-controlled, double blind parallel design. During the first three weeks of the study (run-in period) subjects consumed two packages ( $250 \mathrm{~mL}$ each) of a fruit drink, providing $5 \mathrm{~g}$ of rice starch (placebo) per day. Then, the volunteers were randomly allocated to one of two treatment groups. For the next 5 weeks of the study, one group continued to consume $500 \mathrm{~mL}$ of the placebo fruit drink $(\mathrm{N}=22$ ), while the other group received daily the fruit drink enriched with $5 \mathrm{~g}$ of $\beta$-glucan from oat $(N=25)$. Subjects were required to consume the beverages during two of the three main meals (breakfast, lunch and dinner) and to record the daily time of consumption, any sigins of illness or physical discomfort in the diary.

B-Glucan preparations were manufactured by CEBA AB (Lund, Sweden). The fruit drinks, with an apple/pear taste, were produced by Döhler GmbH (Darmstadt, Germany: Table 5.1). The beverages were sent to Maastricht at regular intervals during the study. Subjects visited the Department at least every second week to receive a supply of experimental beverages or for blood sampling. Subjects received exactly the amount of fruit drinks that they had to consume between two visits at the Department. 
Table 5.1. Composition of placebo and $\beta$-glucan beverage.

Placebo beverage $\quad \beta$-glucan beverage

\begin{tabular}{lrr}
\hline & \multicolumn{2}{c}{$g / 100 \mathrm{~g}$ of beverage } \\
Ash & 0.1 & 0.1 \\
Lipids & 0.7 & 0.7 \\
Protein & 0.5 & 1.4 \\
Moisture & 88.2 & 86.9 \\
Totall dietary fiber & 0.0 & 1.3 \\
Carbohydrate & 10.6 & 10.0 \\
Rice starch & 1.0 & 0.0 \\
B-glucan & 0.0 & 1.0 \\
\hline
\end{tabular}

"Mean molecular weight $80 \mathrm{kDa}$.

Food intake was measured at the end of the run-in and the intervention period, using a food frequency list. Energy and nutrient intakes were calculated using the Dutch Food Composition Table (NEVO-tabel) [15].

The subjects were requested not to change their usual diets, level of physical exercise, smoking habits, or use of alcohol during the study. The study protocol was approved by the Ethical Committee of Maastricht University. All subjects signed informed consent before entering the study.

\section{Methods}

At weeks $0,2,3,7$ and 8 subjects were weighed after an overnight fast, wearing light indoor clothing and no shoes, and fasting blood samples were taken. At each occasion a $10 \mathrm{~mL}$ serum tube (Becton Dickinson Vacutainer Systems, Franklin Lakes, USA) was used. To obtain serum, the tube was left for at least one hour after venipuncture at room temperature. Then, serum was prepared by centrifuging the tube at $2000 \times 9$ for 30 minutes at $4{ }^{\circ} \mathrm{C}$. Serum samples were stored at $-20^{\circ} \mathrm{C}$ until the end of the study. In all serum samples totall cholesterol (ABX Diagnostics, Montpellier, France), HDL-cholesterol (precipitation method: Roche Diagnostics Corporation, Indianapolis, USA), and triacylglycerol with correction for free glycerol (Sigma Aldrich Chemie, Steinheim, Germany) were analyzed enzymatically. Serum LDL cholesterol concentrations were calculated using the Friedewald formula [16]. Serum concentrations of plant sterols were analyzed as described elsewhere [17]. At weeks $2,3,7$ and 8 blood was aiso sampledi in a $10 \mathrm{~mL}$ EDTA tube (Becton Dickinsion Vacutainer Systems, Franklin Lakes, USA). To obtain plasma for measurements of concentrations of lipid soluble anti-oxidants ( $\alpha$-carotene, $\beta$-carotene, lycopene, lutein canthaxanthin, $\beta$ - 
cryptoxanthin, $\alpha$-tocopherol, $\beta+\gamma-$ tocopherol 8 -tocopherol, and phytofluene) and retinol, the EDTA tube was centrifuged at $2000 \times \mathrm{g}$ for 30 minutes at $4{ }^{\circ} \mathrm{C}$. Plasma concentrations of retinol and these lipid soluble anti-oxidants were analyzed as described [17]. Before analyses, plasma samples of weeks 2 and 3 and of weeks 7 and 8 were pooled. At weeks 0 . 3 and 8 hematological parameters (number of white blood cells of red blood cells and of platelets) were analyzed in EDTA blood on a Coulter Ac.T (Beckman Coulter, Inc, Miami, USA) and parameters of liver function (ALAT, ASAT, bilirubin, $\gamma-G T$, alkaline phosphatase), kidney function (creatinin) and inflammation (CRP) using a Beckman Synchron CX7 System (Beckman instruments, Inc, Palo Alto, CA, U.S.A.).

\section{Statistics}

Before the start of the study it was calculated that the power to detect a difference of 0.30 mmol/L between the treatment groups was $80 \%$. For lipids and lipoproteins results of the serum samples taken at the end of the run-in period (weeks 2 and 3 ) and at the end of the intervention period (weeks 7 and 8) were averaged before statistical analyses. For each subject, responses to the fruit dirinks were calculated as the changes between walues at the end of the run-in period and the end of the intervention period. Differences between groups in serum concentrations of lipids and lipoproteins, plant sterols and stanols, body weight and nutrient intake were evaluated by analysis of variance (ANOVA). Differences between groups in variables that were not normally distributed (lipid soluble anti-oxidant concentrations, hematological parameters and parameters of liver function, kidney function and inflammation) were analyzed using the Mann Whitney Test. Statistical analyses were performed using SPSS for Macintosh 11.0 (SPSS, Chicago, IL, USA). Values are presented as means $\pm S D$, non-normally distributted values as medians (ranges). A P-value $<0.05$ was considered statistically significant.

\section{Results}

\section{Dietary intakes, fruit drink consumption, body weight, and safety parameters}

During the run-in period, mean daily intake of energy was $9.3 \pm 2.4 \mathrm{MJ}$, of total fat $35 \pm 5 \%$ of energy intake, of saturated fatty acids $12 \pm 2 \%$ of energy intake, of protein $16 \pm 2 \%$ of energy intake, of carbohydrates $46 \pm 6 \%$ of energy intake, of cholesterol $192 \pm 71 \mathrm{mg}$ and of dietary fiber $25 \pm 8 \mathrm{~g}$ for all subjects. There were no differences between the groups during the run-in period and the intervention period, except for $\beta$-glucan intake (dlata not shown).

Inspection of the diaries showed no serious deviations from the protocol, except for one subject of the $\beta$-glucan group, who did not consume 4 drinks during the run-in period (week 3 ) and 8 drinks during the intervention period (weeks 4 and 5). Exclusion of this subject did not change the outcomes of the study. 
Changes in body weight were $0.2 \pm 1.1 \mathrm{~kg}$ for the control group and $0.5 \pm 1.0 \mathrm{~kg}$ for the $\beta$ glucan group $(\rho=0.363)$. There were no significant differences between the groups in the number of white blood cells, of red blood cells and of platelets and in serum concentrations of ALAT, ASAT, bilirubin, y-GT, alkaline phosphatase, creatinin, and CRP (data not shown).

\section{Serum lipids and lipoproteins}

Mean changes in serum concentrations of lipids and lipoproteins are given in Table $\mathbf{5 . 2}$. Compared with the control group, the change in serum concentrations of total and LDL cholesterol in the $\beta$-glucan group were $-0.30 \mathrm{mmol} / \mathrm{L}$ or $-4.8 \%(95 \% \mathrm{Cl}$ for the difference in changes: -0.07 to $-0.52 \mathrm{mmol} / \mathrm{L}$ ) for total cholesterol and $-0.34 \mathrm{mmo} / \mathrm{L}$ or $-7.7 \%$ for $\mathrm{LDL}$ cholesterol $(95 \% \mathrm{Cl}$ for the difference in changes: -0.10 to $-0.52 \mathrm{mmol} / \mathrm{L})$. No differences between the groups were obserwed in changes in serum concentrations of HDL cholesterol ( $95 \% \mathrm{Cl}$ for the difference in changes: 0.02 to $-0.08 \mathrm{mmol} / \mathrm{L}$ ), triacylglycerol ( $95 \% \mathrm{Cl}$ for the difference in changes: 0.32 to $-0.24 \mathrm{mmol} / \mathrm{L}$ ) and the ratio of total to $\mathrm{HDL}$ cholesterol $(95 \%$ Cll for the difference in changes: 0.03 to $-0.41 \mathrm{mmol} / \mathrm{L}$ ). Except for the ratio of total to HDL cholesterol $(p=0.033)$, variables at the end of the run-in period did not differ significantly between the groups.

\section{Serum lathosterol and plant sterols}

Table 5.3 shows that the change in serum concentrations of lathosterol was $2010^{2} \times$ umol/mmol cholesterol in the $\beta$-glucan group when compared with the control group. The difference between the groups in changes in serum campesterol concentrations was not statistically significant $(p=0.099)$. Compared with the control group, the change in serum concentrations of sitosteral in the $\beta$-glucian group was $-1110^{2} \times \mu \mathrm{mol} / \mathrm{mmol}$ cholesterol.

Variables at the end of the run-in period did not differ significantly between the groups. 
Table 5.2. Mean serum concentrations of total cholesterol, LDL cholesterol, HDL cholestenol and triacylglycerol".

\begin{tabular}{|c|c|c|c|}
\hline & Control group & Beglucan group & $p$-value ${ }^{2}$ \\
\hline \multicolumn{4}{|l|}{ Total cholesterol } \\
\hline Run-in & $5.57 \pm 0.66$ & $5.94 \pm 0.76$ & \\
\hline Test period & $5.67 \pm 0.66$ & $5.75 \pm 0.58$ & \\
\hline Change & $0.11 \pm 0.37$ & $-0.19 \pm 0.39$ & 0.012 \\
\hline Change (\%) & $2.14 \pm 6.81$ & $-2.70 \pm 6.06$ & \\
\hline \multicolumn{4}{|l|}{ LDL cholesterol } \\
\hline Run-in & $3.45 \pm 0.68$ & $3.87 \pm 0.80$ & \\
\hline Test period & $3.54 \pm 0.71$ & $3.67 \pm 0.61$ & \\
\hline Change & $0.10 \pm 0.34$ & $-0.21 \pm 0.37$ & 0.005 \\
\hline Change $(\%)$ & $3.23 \pm 9.99$ & $-4.51 \pm 8.50$ & \\
\hline \multicolumn{4}{|l|}{ HDL cholesterol } \\
\hline Run-in & $1.34 \pm 0.28$ & $1.25 \pm 0.33$ & \\
\hline Test period & $1.40 \pm 0.31$ & $1.27 \pm 0.32$ & \\
\hline Change & $0.06 \pm 0.10$ & $0.03 \pm 0.08$ & 0.256 \\
\hline Change $(\%)$ & $4.49 \pm 7.50$ & $2.74 \pm 6.97$ & \\
\hline \multicolumn{4}{|l|}{ Triacylglycerol } \\
\hline Run-in & $1.70 \pm 0.76$ & $1.96 \pm 1.00$ & \\
\hline Test period & $1.58 \pm 0.57$ & $1.88 \pm 0.95$ & \\
\hline Change & $-0.11 \pm 0.47$ & $-0.07 \pm 0.48$ & 0.761 \\
\hline Change (\%) & $0.44 \# 28.38$ & $-1.26 \pm 23.45$ & \\
\hline \multicolumn{4}{|c|}{$\begin{array}{l}\text { Total to HDL cholesterol } \\
\text { ratio }\end{array}$} \\
\hline Run-in & $4.32 \pm 1.00$ & $5.05 \pm 1.26$ & \\
\hline Test pertod & $4.22 \pm 0.96$ & $4.77 \pm 1.14$ & \\
\hline Change & $-0.09 \pm 0.36$ & $-0.28 \pm 0.40$ & 0.093 \\
\hline Change $(\%)$ & $-1.88 \pm 8.07$ & $-4.90 \pm 6.88$ & \\
\hline
\end{tabular}

Values are means $\pm S D$ and expressed in mmol/L; $n=22$ in the control group, $n=25$ in the $\beta$-glucan group.

${ }^{2}$ P-values for dliet effects were calculated by ANONA with group as fixed factor. 
Table 5.3. Mean serum concentrations of lathosterol, campesterol and sitostercl.

\begin{tabular}{|c|c|c|c|c|c|c|c|}
\hline Lathosterol & \multicolumn{3}{|c|}{ Control group } & \multicolumn{3}{|c|}{$\beta$-glucan group } & prvalue ${ }^{2}$ \\
\hline Run-in & 184 & \pm & 53 & 195 & \pm & 69 & \\
\hline Test period & 175 & \pm & 60 & 205 & \pm & 65 & \\
\hline Change & -9 & \pm & 29 & 41 & \pm & 29 & 0.023 \\
\hline Change $(\%)$ & -5 & \pm & 7 & 8 & \pm & 19 & \\
\hline \multicolumn{8}{|l|}{ Campesterol } \\
\hline Run-in & 352 & \pm & 135 & 325 & \pm & 124 & \\
\hline Test period & 345 & \pm & 118 & 300 & \pm & 133 & \\
\hline Change & -7 & \pm & 36 & -25 & $\sharp$ & 40 & 0.099 \\
\hline Change $(\%)$ & 1 & \pm & 16 & -8 & \pm & 11 & \\
\hline \multicolumn{8}{|l|}{ Sitosteral } \\
\hline Run-in & 129 & \pm & 57 & 121 & \pm & 43 & \\
\hline Test period & 136 & \pm & 51 & 116 & \pm & 45 & \\
\hline Change & 7 & \pm & 17 & -4 & \pm & 18 & 0.030 \\
\hline Change $(\%)$ & 9 & \pm & 16 & -2 & \pm & 22 & \\
\hline
\end{tabular}

\footnotetext{
${ }^{1}$ Values are means $\pm S D$ and expressed in $10^{2} \times \mu$ mol/mmol cholesterol; $n=22$ in the control group. $\mathrm{n}=25$ in the $\beta$-glucan group.

${ }^{2}$ P-values for diet effects were calculated by ANOVA with group as fixed factor.
}

\section{Lipid soluble anti-oxidants}

No significant differences between the groups were observed in absolute changes in lipid soluble anti-oxidants, although reductions in the plasma concentrations of lycopene and total hydrocarbon carotenoids (the sum of $\alpha$-carotene, $\beta$-carotene and lycopene) tended be more pronounced in the $\beta$-glucan group as compared with the contral group (Table 5.4). No differences in LDL cholesterol standardized plasma concentrations of anti-oxidants were observed between the groups. 
Tablle 5.4. Plasma concentrations of lipiid soluble anti-oxidants.

\begin{tabular}{|c|c|c|c|}
\hline & $\begin{array}{l}\text { Control } \\
\text { group }\end{array}$ & $\begin{array}{l}\text { Beta-glucan } \\
\text { group }\end{array}$ & $p$-value \\
\hline \multicolumn{4}{|l|}{ Retinal } \\
\hline Runitin & $3.21(1.85-4.46)$ & $3.09(1.86-4.51)$ & \\
\hline Test period & $3.28(1.86-4.97)$ & $3.12(2.18-4.35)$ & \\
\hline Change & $0.15(-2.11-11.79)$ & $0.07(-1.01-0.67)$ & 0.337 \\
\hline \multicolumn{4}{|l|}{ Totall carotenoids } \\
\hline Run-in & $0.93(0.53-2.73)$ & $1.04(0.69-1.72)$ & \\
\hline Test period & $0.91(0.60-1.66)$ & $0.98(0.76-1.61)$ & \\
\hline Change & $-0.03(-1.07-0.24)$ & $-0.04(-0.32-0.19)$ & 0.456 \\
\hline \multicolumn{4}{|c|}{ Total hydrocarbon carotenoids } \\
\hline Run-in & $1.62(1.00-3.86)$ & $1.93(1.30-2.93)$ & \\
\hline Test period & $1.52(1.31-2.65)$ & $1.73(1.29-2.55)$ & \\
\hline Change & $-0.01(-1.21-0.36)$ & $-0.11(-0.58-0.71)$ & 0.061 \\
\hline \multicolumn{4}{|l|}{ Q-Carotene } \\
\hline Run-in & $0.33(0.25-0.58)$ & $0.41(0.25-0.59)$ & \\
\hline Test period & $0.33(0.25-0.49)$ & $0.39(0.25-0.53)$ & \\
\hline Change & $0.00(-0.17-0.12)$ & $0.00(-0.18-0.10)$ & 0.509 \\
\hline \multicolumn{4}{|l|}{ p-Carotene } \\
\hline Run-in & $0.61(0.28-2.15)$ & $0.71(0.33-1.15)$ & \\
\hline Test period & $0.58(0.31-1.25)$ & $0.64(0.41-1.13)$ & \\
\hline Change & $-0.03(-0.90-0.18)$ & $-0.01(-0.21-0.13)$ & 0.717 \\
\hline \multicolumn{4}{|l|}{ Lycopene } \\
\hline Run-in & $0.69(0.32-1.12)$ & $0.78(0.58-1.22)$ & \\
\hline Test period & $0.64(0.47-1.04)$ & $0.72(0.50-1.31)$ & \\
\hline Change & $0.04(-0.43-0.44)$ & $-0.11(-0.36-0.53)$ & 0.064 \\
\hline \multicolumn{4}{|l|}{ Lutein } \\
\hline Run-in & $0.14(0.02-0.29)$ & $0.15(0.05-0.33)$ & \\
\hline Test period & $0.12(0.05-0.25)$ & $0.14(0.06-0.35)$ & \\
\hline Change & $0.00(-0.21-0.10)$ & $-0.01(-0.13-0.19)$ & 0.348 \\
\hline \multicolumn{4}{|l|}{ Canthaxanthin } \\
\hline Run-in & $0.14(0.08-0.28)$ & $0.16(0.11-0.26)$ & \\
\hline Test period & $0.14(0.08-0.34)$ & $0.15(0.09-0.24)$ & \\
\hline Change & $0.00(-0.06-0.08)$ & $-0.01(-0.05-0.05)$ & 0.296 \\
\hline
\end{tabular}


Table 5.4. Continued.

$\begin{array}{lc}\text { Control } & \text { Beta-glucan } \\ \text { group } & \text { group }\end{array}$

B-Cryptoxanthin

$\begin{array}{llll}\text { Run-in } & 0.34(0.16-1.77) & 0.45(0.24-1.03) & \\ \text { Test period } & 0.32(0.20-0.23) & 0.41(0.17-1.49) & \\ \text { Change } & 0.03(-0.94-0.46) & 0.00(-0.26-0.45) & 0.701\end{array}$

Total tocopherols

Run-in

Test period

$29.73(13.61-50.21) \quad 31.31(20.49-45.19)$

Change

$29.19(20.12-48.41) \quad 31.26(21.33-43.40)$

$0.44(-20.56-11.80) \quad-1.14(-7.22-11.80) \quad 0.296$

ck-Tocopherol

Run-in

Test period

$27.84(12.52-46.75) \quad 29.27(19.36-42.56)$

Change

$27.46(19.00-45.35)$

$28.26(19.62-40.10)$

$0.36(-19.51-11.36) \quad-1.01(-6.33-11.63) \quad 0.277$

$\beta+\gamma$-Tocopherol

Run-in

$1.43(0.89-3.27)$

$1.74(0.83-3.58)$

Test period

$1.61(0.92-2.82)$

$1.67(1.00-4.35)$

Change

$0.03(-0.98-0.74)$

$0.00(-0.75-1.23)$

0.765

8-Tocopherol

Run-in

$0.18(0.09-0.27)$

$0.20(0.08-0.39)$

Test period

$0.17(0.11-0.36)$

$0.19(0.11-0.34)$

Change

$0.03(-0.13-0.13)$

$0.01(-0.18-0.16)$

0.536

Phytofiuene

Run-in

Test period

$10.96(3.65-22.35) \quad 13.32(5.59-35.58)$

Change

$12.25(4.82-22.43)$

$13.18(4.86-23.60)$

$-1.04(-6.43-15.84)$

$-1.24(-11.98-4.40) \quad 0.348$

Values are medians (ranges) and are expressed in $\mu \mathrm{mal} / \mathrm{L}$, except for phytofluerve ( $\mu \mathrm{V} / \mathrm{min}$ ute) .

\section{Discussion}

In the present study serum concentrations of total cholesterol decreased significantly by $0.060 \mathrm{mmol} / \mathrm{L}$ and of $\mathrm{LDL}$ cholesterol by $0.062 \mathrm{mmol} / \mathrm{L}$, when expressed per gram of $\beta-$ glucan intake. This is approximately twice as high as the reductions in total cholesterol of $0.037 \mathrm{mmol} / \mathrm{L}$ and in LDL cholesterol of $0.032 \mathrm{mmol} / \mathrm{L}$ for each gram of solubie fiber intake from oats, as calculated by Brown et al. in their meta-analysis [2]. It has however been 
suggested that the cholesterol-lowering effect of $\beta$-glucan depends on the food matrix or food processing of the oal products. Indeed, Kerckhoffs et al. have reported that $\beta$-glucan incorporated into bread and cookies lowered serum LDL cholesterol non-significantly by $0.020 \mathrm{mmol} / \mathrm{L}$ for each gram of $\beta$-glucan. When the same source of $\beta$-glucan was incorporated into a fruit juice, this decrease was $0.052 \mathrm{mmol} / \mathrm{L}$ [12]. In addition, incorporation of p-glucan into oat milk lowered serum concentrations of LDL cholesterol by $0.063 \mathrm{mmol} / \mathrm{L}$. for each gram of $\beta$-glucan [18]. These results are in good agreement with the results of the present study and they do suggest that the efficacy of $\beta$-glucan preparations increases when incorporated into liquid products. Beer et al. did not find a cholesteral-lowering effect of a $\beta-$ glucan enriched instant whip. This lack of effect was explained by the low solubility and moderate molecular weight $(1000 \mathrm{kDa})$ of the $\beta$-glucan used [5]. A high molecular weight might be associated with an increased intestinal viscosity, which might decrease the absorption of bile acids and cholesterol [19]. Recently, however, it was shown that in healthy volunteers both high and low molecular weight $\beta$-glucan (217 or $797 \mathrm{kDa}$ ) reduced serum concentrations of total and LDL cholesterol equally compared to baseline [20]. Similar findings were observed in hamsters consuming $\beta$-glucan with molecular weights of either 175 $\mathrm{kDa}$ or $1000 \mathrm{kDa}$ [21]. In the present study we used B-glucian with a mean molecular weight of only $80 \mathrm{kDa}$ and still found a reduction in serum cholesterol concentrations. These results suggest that the molecular weight alone cannot predict the cholesterol-lowering effects of $\beta$ glucan. Another reason why Beer et al. did not find cholesterol-lowering effects of $\beta$-gllucan might be the low baseline concentrations of cholesterol of their participants [5]. In fact, Ripsin et all. reported a more pronounced decrease in serum concentrations of total cholesterol when baseline concentrations were increased [22]. On the other hand, Brown et al. found no evidence that initial serum concentrations of total cholesterol were related to changes in total cholesterol. However, LDL cholesterol concentrations decreased more at higher baseline concentrations of LDL cholesterol [2].

Why B-glucan can lower serum LDL cholesterol concentrations is not clear. One of the proposed mechanisms is that $\beta$-glucan binds bile acids or increases intestinal viscosity, which results in a decreased re-absorption of bile acids and increased bile acid excretion [810]. As a consequence, bille acid excretion and synthesis is raised [23]. At the same time, hepatic cholesterol synthesis will increase as well [8], because of a higher need for cholesterol in the liver for bile acid production [8]. Indeed, in a study with ileostomy subjects [8], a strong positive correlation was found between changes in lathosterol concentrations and bile acid excretion. Thus, the increased cholesterol synthesis after $\beta$-glucan consumption in our study may be due to an increased bile acid excretion. However, an increased cholesterol synthesis can also be due to a decreased cholesterol absorption. As markers of cholesterol absorption, we measured cholesterol-standardized campesterol and sitosterol concentrations. Concentrations of both markers decreased, suggesting a decreased cholesterol absorption, although only the effect on sitosterol was statistically significant. Our findings agree with the increased excretion of plant sterols and the reduced cholesterol 
absorption found in ileostomy subjects after consumption of $\beta$-glucan [9]. On the other hand. Lia et all. did not find changes in cholesterol absorption in lleostomy subjects after consumption of $\beta$-glucan [8], but the authors mentioned that this finding should be interpreted with caution, because of a low statistical power. Also Uusitupa et al. did nol find any change in serum concentrations of campesterol or sitosterol during dally consumption of $10 \mathrm{~g} \mathrm{B-}$ glucan for eight weeks. However, serum concentrations of total cholesterol also did nol change [11]. Based on these findings, we conclude that not only an increased bile acid synthesis, but also a decreased cholesterol absorption contributes to the cholesterol lowering effect of $\beta$-glucan.

As $\beta$-glucam may enlarge the intestinal unstirred water layer [13], absorption of lipid soluble anti-oxidants may also be affected. However, we did not observe any change in absolute or LDL cholesterol-standardized concentrations of lipid soluble anti-oxidants, although absolute plasma concentrations of lycopene and total hydrocarbon carotenoids ( $\alpha$-carotene, $\beta$ carotene and lycopene) tended to decrease in the B-glucan group. Information from other studies on effects of $\beta$-glucan on lipid soluble antioxidants is limited. Kerckhoffs et al. reported decreases in absolute plasma concentrations of tocopherols and hydrocarbon carotenoids [24]. However, $\angle D L$ cholesterol-standardized plasma concentrations were not affected by $\beta$-glucan, which is agreement with the findings of the present study.

To summarize, results of the present study indicate that our $\beta$-glucan preparation lowers serum concentrations of total and LDL cholesterol when incorporated into a fruit drink. Not only an increase in bile acid synthesis $[8,10,23]$, but also a reduced cholesterol absorption contributes to the cholesterol-lowering effect of $\beta$-glucan without affecting plasma concentrations of lipid soluble anti-oxidants.

\section{Acknowledgements}

We would like to thank all the volunteers for their co-operation and interest, and Mr. F.J.J. Cox and Ms. H. Aydeniz for their analytical assistance. RPM and GO were responsible for the study design. EN and ABR were responsible for the daily management of the study. RO was responsible for the $\beta$-glucan preparation and MW for the production of the fruit drinks. All authors were responsible for writing the manuscript. No author had any financial oi personal interest in the organization supporting the research. This study is part of a European Union project (QLK1-CT-2000-00535) entitled "Design of foods with improved functionality and superior health effects using cereal $\beta$-glucans". It does not necessarily reflect its views and in no way anticipates the Commission's future policy in this area. 


\section{References}

1. FDA Talk Paper. FDA allows whole oat foods to make health claim on reducing the risk of heart disease. 1997: Available at http/www cfisan fda.gov/-1rd/tpoats html. Accessed April 27, 200月.

2. Brown L, Rosner B, Willett WW and Sacks FM. Cholesterol-lowering effects of dietary fiber: a meta-analysis: Am $₫$ Clin Nutr 1999; 69:30-42.

3. Leadbetter J, Ball $\mathrm{MJ}$ and Mann $\mathrm{Jl}$. Effects of increasing quantities of oat bran in hypercholesterolemic people. Am J Clin Nutr 1991; 54:841-5.

4. Lovegrove JA, Clohessy $A$, Milon $H$ and Wiltiams CM. Modest doses of beta-glucan do not reduce concentrations of potentially atherogenic lipoproteins. Am J Clin Nutr 2000; 72;49-55.

5. Beer MU, Arrigoni $E$ and Amado R. Effects of oat gum on blood cholesterol levels in healthy young men. Eur J Clin Nutr 1995; 49:517-22

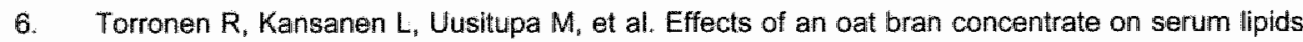
in free-living men with mild to moderate hypercholesterolaemia. Eur J Clin Nutr 1992; 46:621-7.

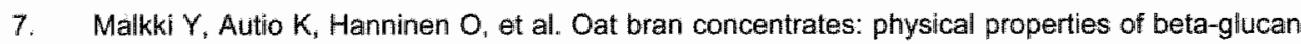
and hypocholesterolemic effects in rats. Cereal Chem 1992; 69:647-53.

8. Lla $A_{i}$ Andersson $H_{1}$ Mekki $N$, Juhel $C$, Senft M and Lairon D. Postprandial lipemia in relation to sterol and fat excretion in lleastomy subjects given oat-bran and wheat test meals. Am J Clin Nutr 1997;66:357-65

9. Lia $A$, Hallmans $G$, Sandberg $A S_{s}$ Sundberg $B$. Aman $P$ and Andersson $H$. Oat beta-glucan increases bile acid excretion and a fiber-rich barley fraction increases cholesterol excretion in ileostomy subjects. Am J Clin Nutr 1995; 62"'1245-51.

10. Marlett JA, Hosig KB, Vollendorf NW, Shinnick FL, Haack VS and Story JA. Mechanism of serum cholesterol reduction by oat bran. Hepatology $1994 ; 20: 1450-7$.

11. Uusitupa MI, Miettinen TA, Sarkkinen ES, Ruuskanen E, Kervinen $K$ and Kesaniemi YA. Lathosterol and other non-cholesterol sterols during treatment of hypercholesterolaemia with beta-glucan-rich oat bran. Eur J Clin Nutr 1997; 51:607-11.

12. Kerckhoffs DA, Hornstra $G$ and Mensink RP. Cholesterollowering effect of beta-glucam from oat bran in milldly hypercholesteralemic subjects may decrease when beta-glucan is incorporated into bread and cookies. Am J Clin Nutr 2003; 78:221-7.

13. Johnson IT and Gee JM. Effect of gel-forming gums on the intestinal unstirred layer and sugar transport in vitro. Gut $1981 ; 22: 398-403$.

14. Centraal begeleidingsorgaan voor de intercollegiale toetsing. Behandeling en preventie van coronaire hartziekten door verlaging van de plasma cholesterolconcentratie. Utrecht, The Netherlands: Centraal begeleidingsorgaan voor de intercollegiale toetsing, 1998.

15. Stichting NEVO. Dutch Food Composition Table 2001. Den Haag "The Netherlands: Stichting NEVO, 2001

16. Friedewald WT, Levy RI and Fredrickson DS. Estimation of the concentration of low-density lipoprotein cholesterol in plasma, without use of the preparative ultracentrifuge. Clin Chem $1972 ; 18: 499-502$. 
17. Plat $J$ and Mensink RP. Effects of diets ennched with two different plant stenol ester mixtures on plasma ubiquinol-10 and fat-soluble antioxidant concentrations. Metabolism 2001; 50:520-9.

18. Öning $G$, Wallmark $A$, Persson M, Akesson B, Elmstahl $S$ and Oste R. Consumption of oat milk for 5 weeks lowers serum cholesterol and LDL cholesterol in free-living men with moderate hypercholesterolemia. Ann Nutr Metab 1999; 43:301-9.

19. Sundberg $B$, Wood P. Lia $A_{s}$ et al. Mixed-linked beta-glucan from breads of different cereals is partly degraded in the human ileostomy model. Am J Clin Nutr 1996; 64:878-85.

20. Frank J, Sundberg B, Kamal-Eldin A, Vessby B and Aman P. Yeast-Leawened Oat Breads with High or Low Molecular Weight beta-Glucan Do Not Differ in Their Effects on Blood Concentrations of Lipids, Insulin, or Glucose in Humans. J Nutr 2004; 134:1384-8.

21. Wilson $T$, Nicolosi $R$, Delaney $B$, et al. Reduced and high molecular weight barley beta-glucans decrease plasma total and non-HDL-cholesterol in hypercholesterolemic syrian golden hamsters. JNutr 2004; 134:2617-22.

22. Ripsin $\mathrm{CM}$, Keenan $\mathrm{JM}$, Jacobs $\mathrm{DR}, \mathrm{J}$., et al. Oat products and lipid lowering: A meta-analysis. Jama 1992; 267:3317-25.

23. Andersson $M$, Ellegard $L$ and Andersson $H$. Oat bran stimulates bile acid synthesis within $8 \mathrm{~h}$ as measured by Talpha-hydiroxy-4-cholesten-3-one. Am J Clin Nutr 2002; 76:1111-6.

24. Kerckhoffs DAJM. Dietary components and cardiovascular risk markers; effects of tocotrienols, beta-glucan and plant stanol esters. Thesis. Maastricht, Department of Human Biology. Maastricht University, 2003. 


\section{Chapter 6}

Cis-9, trans- 11 and trans-10, cis-12 conjugated linoleic acid (CLA) do not affect the plasma lipoprotein profile in moderately overweight subjects with LDL phenotype $B$

Elke Naumann1, Yvon A. Carpentier ${ }^{2}$, Asgeir Saebo ${ }^{3}$, Taous S. Lassel ${ }^{4}$, Jean-Michel Chardigny ${ }^{5}$, Jeari-Louis Sébédio ${ }^{5}$ and Ronald P. Mensink ${ }^{1}$ for the FunCLA study group.

${ }^{1}$ Department of Human Biology, Maastricht University, Maastricht, The Netherlands; ${ }^{2} \mathrm{~L}$. Deloyers Laboratory for Experimental Surgery, Universitë Libre de Bruxelles, Brussels, Belgium; ${ }^{3}$ Natural ASA, Industriveien, Hovdebygda, Norway; ${ }^{4}$ Danone-Vitapole Palaiseau, France; ${ }^{5}$ INRA, Unité de Nutrition Lipidique, Dijon, France.

Based on: Atherosclerosis, in press 


\section{Abstract}

Background: Results of a pilot study suggested that cis-9, trans-11 conjugated linoleic acid (CLA) improved LDL phenotype in moderately overweight subjects with LDL phenotype B.

objective: Initiated by the results of this pilot study, we have specifically designed a study to test the hypothesis that cis-9, trans-11 conjugated linoleic acid (CLA) improves LDL phenotype in moderately overweight subjects with LDL phenotype B. Effects on the serum lipid profile, on plasma glucose and insulin concentrations, and on clinical parameters were also examined.

Design: Volunteers with LDL phenotype B were divided into three groups consuming daily a drinkablle dairy product not enriched with CLA (placebo, $n=34$ ), the same dairy product enriched with $3 \mathrm{~g} \mathrm{c9,} \mathrm{t11} \mathrm{CLA}(n=34)$, or the dairy product enriched with $3 \mathrm{gt} t 0, \mathrm{c} 12 \mathrm{CLA}$ $(n=19)$ for 13 weeks.

Results: Median changes in the proportions of plasma small dense LDL were $-2.0 \%$ in the control group and $-0.1 \%$ in the $c 9, t 11$ CLA and $t 10, c 12$ CLA groups ( $p=0.981$ for the differences between the groups). $c 9, \$ 11$ CLA or $110, c 12$ CLA did also not affect serum concentrations of LDL and $\mathrm{HDL}$ cholesterol, and of triacylglcyerol, and plasma concentrations of glucose and insulin.

Conclusions: In humans with LDL phenotype $B_{1}, c 9, t 11$ CLA and $t 10, c \| 2$ CLA do not beneficially change risk factors for cardiovasicular disease or diabetes. 


\section{Introduction}

Conjugated linoleic acid (CLA), a mixture of positional and geometric conjugated isomers of linoleic acid, may have positive effects on a wide variety of health parameters. This can be concluded from many, mostly animal and in vitro, studies suggesting that CLA has anticarcinogenic effects, decreases adiposity, and improves immune function [1]. In addition, it has been proposed that CLA has anti-atherogenic properties, although results are controversial. In one study, for example, feeding rabbits with an atherogenic diet rich in CLA reduced atherosclerotic lesion sizes [2]. These findings however could not be confirmed in a mouse model [3]. Results from human studies are also conflicting. Although CLA decreased plasma triacylglycerol and VLDL cholesterol in one study [4], other human trials did not confirm effects of CLA on serum lipids and lipoproteins [5-9]. These contrasting results may be due to differences in the composition of the CLA mixture used, because the two most common isomers in intervention studies (cis-9, trans-11 (c9, t11) and trans10, cis-12 (t10, c12)) CLA have distinct physiological effects [10]. This was also suggested by findings of our previous study [11]. In that study, moderately overweight subjects received for 18 weeks daily 1.5 or $3.0 \mathrm{~g}$ of either $\mathrm{c} 9, \mathrm{t} 11$ or $\$ 10, \mathrm{c} 12 \mathrm{CLA}$. No effects on body composition were observed, but results from a small number of subjects suggested that $c 9,111$ CLA in particular could decrease concentrations of small dense $L D L$. Effects were most pronounced in subjects having phenotype $B$. This is of interest as a high proportion of small dense $L D L$ (phenotype $B: \geq 35 \% \mathrm{LDL}$ cholesterol in $\mathrm{LDL} \geq 1.040 \mathrm{~g} / \mathrm{mL}$ ) is related with an approximate threefold increase in risk for coronary artery disease [12]. This phenotype, which is especially evident in overweight subjects, is also associated with increases in plasma triacylglycerol and intermediate density lipoproteins (IDL), and reductions in plasma HDL cholesterol and insulin sensitivity [12]. Thus, if c9, 111 CLA truly changes LDL phenotype, this could be of great benefit for a large segment of the population. We therefore decided to specifically design a study to test the hypothesis that c9, 111 CLA improves LDL phenotype in moderately overweight subject with phenotype B. Effects on the serum lipid profile, on plasma glucose and insulin concentrations, and on clinical parameters were also examined.

\section{Subjects and Methods}

\section{Subjects}

Ninety-two middle aged ( $35-65$ years) heaithy men ( $N=51$ ) and women $(N=41)$ classified as having the LDL-phenotype $\mathrm{B}$ were included in the study, which was performed simultaneously at two centers (Brussels, Belgium and Maastricht, The Netherlands). Volunteers were recruited through announcements in local newspapers (Maastricht) or among subjects that had participated in earlier studies (Brussels). Since LDL phenotype B is more likely to occur in overweight subjects, this was a criterium for inviting subjects for a 
screening visit. Eligible subjects completed a standard blood test and filled in a medical questionnaire. All subjects were moderately overweight (BMl $25-32.5 \mathrm{~kg} / \mathrm{m}^{2}$ ) and had normal or slightly elevated lipid concentrations (mean serum total cholesterol $<7.0 \mathrm{mmol} / \mathrm{L}$ and mean serum triacylglycerol $<3.0 \mathrm{mmol} / \mathrm{L}$ as measured on two separate occasions after an overnight fast). Exclusion criteria were diastolic blood pressure $>85 \mathrm{mmHg}$ or systolic blood pressure $>150 \mathrm{mmHg}$, unstable body weight or attempts to lose weight during the past 3 months; presence of proteinuria or glucosuria; use of medication, a diet or a clinical condition known to affect lipid or glucose metabolism; drug or alcohol abuse; history of coronary heart disease, decompensatio cordis (Class III or IV), cardiomyopathy, kidney-, liver- and pancreatic disease or malignancies < 5 years ago; pregnant or breast-feeding; participation in another trial < 30 days ago. The subjects were requested not to change their usual diets, level of physical exercise, smoking habits, or use of alcohol during the study. The Ethical Committees from both centers had approved the study protocol. All subjects signed informed. consent before entering the study.

\section{Study design}

The study was designed as a placebo-controlled, double blind parallel design. During the first week of the study (run-in period) subjects consumed dally a drinkable dairy product providing $3 \mathrm{~g}$ of a high oleic acid sunflower oil (placebo). Thereafter, the volunteers were randomly allocated to one of three treatment groups. For the next 13 weeks of the study, the first group continued to consume the drinkable dairy product with $3 \mathrm{~g}$ of high oleic acid sunflower oil. The second group received daily the dairy product with $3 \mathrm{~g}$ of $c 9,411 \mathrm{CLA}$; the third group received daily the dairy product with $3 \mathrm{~g}$ of $t 10, c 12 \mathrm{CLA}$. As the $\mathrm{cg}, \mathrm{t11} \mathrm{CLA}$ isomer was suggested to reduce the proportion of small dense LDL in our previous study, power calculations were based on the expected difference in the amount of small dense LDL between the $\mathrm{c} 9, \mathrm{t} 11 \mathrm{CLA}$ group and the control group. Therefore, 68 subjects were equally divided over these two groups and 19 subjects were allocated to the 110, c12 CLA group. During the study, subjects recorded in diaries any signs of illness, or any experienced side effects.

The two isomers were given as a triacylglycerol and were produced by Natural ASA (Hovdebygda, Norway). Briefly "ethyl-linoleate ( $94 \%$ purity) from safflower oil was treated with a solution of $\mathrm{KOH}$ in ethanol. This resulted in the formation of CLA, almost exclusively c9, 111 CLA and $t 10,012$ CLA in almost equal amounts. The mixture of isomers was dissolved in acetone and cooled to $-60^{\circ} \mathrm{C}$. At this temperature, most of the $110, \mathrm{c} 12$ ethyl osters precipitated, and were collected by filtration. By repeated crystallizations, two concentrates of CLA were obtained. The $\mathrm{c} 9, \mathrm{t} 11 \mathrm{CLA}$ concentrate contained $>80 \% \mathrm{c9}, \mathrm{t} 11$ CLA, $<5 \%+10, c 12 C L A$, and other isomers in minor amounts. The $110, c 12$ CLA concentrate contained $>80 \% t 10, \mathrm{c} 12 \mathrm{CLA},<5 \% \mathrm{c} 9, \mathrm{t} 11 \mathrm{CLA}$, and other isomers in minor amounts. After removal of acetone, the concentrates were saponified and converted into triacylglycerols by addition of glycerol and Novozyme 435 (Candida antartica lipase, Novo Nordisk AS, 
Bagsvaerd. Denmark): Finally, the oil was redistilled to remove free fatty acids and all traces of solvents. This resulted in a mixture of $>80 \%$ pure CLA-triacylglycerol: The triacylglycerol of each CLA isomer was stored under nitrogen atmosphere in airtight steel containers.

The CLA was incorporated into a drinkable yogurt-like deiry product manufactured by Danone (Palaiseau, France), which contained (w/w) 67.0\% water, $20 \%$ milk (3.2\% proteins, $5 \%$ lactose, $0.7 \%$ minerals (1250 ppm Ca) and $0.05 \%$ fat), $4.1 \%$ oils, $8 \%$ saccharose, $0.4 \%$ pectin, $0.35 \%$ citric acid, and $0.12 \%$ aromas. The product was stored in bottles of $100 \mathrm{~mL}$, sealed and coded for each group. Bottles were delivered to the investigators in boxes with shelf life date. Subjects received a box containing 7 bottles of dairy product during the run-in period and boxes containing 14 bottles every second week during the remainder of the study period. Subjects had to consume one bottle per day during the evening meal.

\section{Methods}

Subjects attended the study center at least every second week to collect experimental products and / or for measurements. At weeks 1, 8, and 14, subjects were weighed after an overnight fast, wearing light indoor clothing and no shoes. Fasting bload samples were taken at the end of the run-in period and at the end of the intervention period. At each occasion a $10 \mathrm{~mL}$ serum tube and a $10 \mathrm{~mL}$ EDTA tube (Becton Dickinson Vacutainer Systems, Franklin Lakes, USA) were used. To obtain serum, the tube was left for at least one hour after venipuncture at room temperature. Then, serum was prepared by centrifuging the tube at $2000 \times \mathrm{g}$ for 30 minutes at $4{ }^{\circ} \mathrm{C}$. Serum samples were stored at $-40^{\circ} \mathrm{C}$ untill the end of the study. In all samples, cholesterol was measured in total serum (CHOD-PAP method, Roche Diagnostic Systems, Hoffmann-La Roche Ltd., Basel, Switzerland), and in HDL after precipitation of apoB-containing lipoproteins by adding phosphotungstic acid and magnesium ions (precipitation method: $A B X$ Diagnostics, Montpellier, France); triacylglycerols were analyzed enzymatically with correction for free glycerol (GPO Trinder: Sigma Diagnostics, St Louis, USA). Serum LDL cholesterol concentrations were calculated using the Friedewald formula [13]. To obtain plasma concentrations of small dense LDL. plasma was first separated by low speed centrifugation $(1000 \times \mathrm{g})$ at $4{ }^{\circ} \mathrm{C}$ for 10 minutes. Plasma lipoproteins were then isolated by sequential ultracentrifugation at $4{ }^{\circ} \mathrm{C}$. The $\mathrm{LDL}$ fraction was separated at density ranges between 1.019 and $1.063 \mathrm{~g} / \mathrm{mL}$. LDL profiles were then determined by isopycnic ultracentrifugation. The LDL fraction was adjusted to $d=1.040 \mathrm{~g} / \mathrm{mL}$ and layered between potassium bromide solutions (containing EDTA and sodium azide 0.01\%) of different densities $(d=1.019,1.025,1.040,1.054$ and $1.085 \mathrm{~g} / \mathrm{mL})$ and centrifuged for 40 hours in a L8-55 ultracentrifuge (Beckman Coulter Inc) using a swinging bucket rotor (SW41Ti), Beckman Coulter Inc). A high density potassium bromide solution $(1.29 \mathrm{~g} / \mathrm{mL}$ ) was then injected through the bottom of the tube (2232 Microperpex S Peristaltic Pump. LKB, Bromma, Sweden) and 25 subfractions of increasing density were recovered from the top of the tube. Density and cholesterol content were measured in each subfraction as described above. The proportion of cholesterol carried by the small dense subfraction was obtained by 
dividing the LDL cholesterol above density $1.040 \mathrm{~g} / \mathrm{ml}$. by total LDL cholesterol. Fatty acid composition of plasma phospholipids were analyzed as described [14]. Plasma concentrations of glucose were analyzed enzymatically (Roche Diagnostic Systems, Hoffmann-La Roche Ltd., Basel, Switzerland) and of insulin using an ELISA method (Mercodia Insulin ELISA, Mercodia AB, Uppsala, Sweden). The HOMA index, a measure of insulin sensitivity, was calculated as described by Matthews ef al. [15]. Hematological parameters (number of white blood cells, of red blood cells, and of platelets) were analyzed in EDTA blood on a Coulter Microdiff 18 (Coulter Corporation, Miami, USA). Parameters of liver function (ALAT, ASAT, bilirubin, $\gamma$-GT, alkaline phosphatase), kidney function (creatinin) and acute phase response (CRP) were analyzed using a Beckman Synchiron $C X 7$ System (Beckman Instruments, Palo Alto, CA, U.S.A.).

\section{Statistics}

In our previous study [11], we detected a decrease of $6 \%$ in the proportion of small dense LDL during daily consumption of $3 \mathrm{~g} \mathrm{c9}, 111 \mathrm{CLA}$. Before the start of the study, it was calculated that 28 subjects in the placebo and in the $c 9,11$ group were needed to reach a power of $80 \%$ to detect a difference of $3.75 \%$ in the proportion of small dense LDL with an alpha of $5 \%$. For each subject, responses to the dietary dairy products were calculated as the change between values at the end of the run-in period and the end of the intervention period. For parameters that were nomally distributed, differences between groups were evaluated by analysis of variance (ANOVA). For ANOVA a model was used including interaction terms between diet $x$ gender and diet $x$ center, which were excluded from the model if they were not significant $(P>0.05)$. If significant effects were found, the Tukey method was used to compare the three groups pairwise. For parameters that were not normally distributed, differences between the dietary dairy products were analyzed using the Kruskal- Wallis test, followed by the Mann-Whitney test if a significant diet effect was found. Statistical analyses were performed using SPSS for Macintosh 10.0 (SPSS, Chicago, $\mathrm{IL}_{\text {, }}$ USA). Normally distributed values are presented as means $\pm S D$, non normally distributed values as medians (ranges). A P-value for the diet effect of $<0.05$ was considered as statistically significant. If a Tukey or Mann-Whitney test was performed, a P-value $<0.017$ was considered as statistically significant.

\section{Results}

In Maastricht, one man from the control group dropped out during the situdy at week 3 , because of appearance of rash, one woman from the $c 9,111$ CLA group at week 10 , because of high serum concentrations of $\gamma$-glutamyl transpeptidase, one man from the 110 , C12 CLA group at week 3 , because of participation in a pharmaceutical trial, and one woman from the 110, c12 CLA group at week 8 , because of lung infection. At the end of the study: 
Table 6.2. Proportions of $C 9,411$ CLA and $t 10,012$ CLA in phospholipids:

\begin{tabular}{|c|c|c|c|}
\hline & Contral & $\mathrm{C} 9, \mathrm{t} 11 \mathrm{CLA}$ & $110, \mathrm{C} 12 \mathrm{CLA}$ \\
\hline 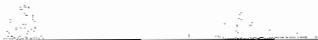 & & & \\
\hline & \multicolumn{3}{|c|}{$\%$ of total fatty acids (w/w) } \\
\hline \multicolumn{4}{|l|}{ CLA CQ } \\
\hline \multirow[t]{2}{*}{ Rum-in period } & 0.09 & 0.14 & 0.12 \\
\hline & $(0.00-0.82)$ & $(0.05-0.73)$ & $(0.07-0.24)$ \\
\hline \multirow[t]{2}{*}{ Experimental period } & 0.12 & 0.77 & 0.18 \\
\hline & $(0.00-0.34)$ & $(0.08-1.37)$ & $(0.10-0.65)$ \\
\hline \multirow[t]{2}{*}{ Change } & 0.01 & $0.62^{\mathrm{a}}$ & $0.08^{b, c}$ \\
\hline & $(-0.72-0.23)$ & $(-0.18-1.32)$ & $(-0.10-0.46)$ \\
\hline \multicolumn{4}{|l|}{ C A t10,c12 } \\
\hline \multirow[t]{2}{*}{ Run-in period } & 0.00 & 0.00 & 0.00 \\
\hline & $(0.00-0.00)$ & $(0.00-0.10)$ & $(0.00-0.56)$ \\
\hline \multirow[t]{2}{*}{ Experimental period } & 0.00 & 0,06 & 0.43 \\
\hline & $(0.00-0.89)$ & $(0.00-0.93)$ & $(0.00-0.76)$ \\
\hline \multirow[t]{2}{*}{ Change } & 0.00 & $0.06^{\circ}$ & $0.42^{d, e}$ \\
\hline & $(0.00-0.89)$ & $(-0.05-0.93)$ & $(0.00-0.76)$ \\
\hline
\end{tabular}

Values are medians (ranges)

a control versus $c 9$, $\$ 1$ CLA: $p<0.001$

- control versus t10, c12 CLA: $p<0.05$

c c9, 111 CLA versus $\$ 10$, c 12 CLA: $p<0.001$

d) control versus 110,012 CLA: $p<0.001$

- c9, 111 CLA versus c10, t12 CLA: $p<0.01$

For the 09,111 CLA group, the change in the proportion of $c 9,111$ CLA was significantly greater as compared with the changes in the control $(p<0.001)$ and 110, c12 CLA groups ( $p$ $<0,001$ ). The 110,012 CLA group had significantly greater increases in the proportions of $110, c 12$ CLA than the control $(p<0.001)$ and $c 9$, t11 CLA groups $(p<0.01)$. Changes in body weight during the intervention period were not statistically different between the groups (data not shown).

We did not observe significant differences between the groups for changes in the proportions of plasma small dense LDL (Table 6.3). Median changes were $-2.0 \%$ in the control group and $-0.1 \%$ in the $c 9, t 11$ CLA and $t 10, c 12$ CLA groups ( $p=0.981$ for the differences between the groups). 
Table 6.3. Proportion of LDL cholesterol in LDL particles with a density $\geq 1.040 \mathrm{~g} / \mathrm{mL}$.

Control $\quad c 9, t 11 \mathrm{CLA} \quad 110, \mathrm{c12} \mathrm{CLA}$

LDL-phenotype

Run-in period

Experimental period

Change
41.2

$(30.2-64.5)$

39.4

$(27.9-632)$

$-2.0$
44.6

$(28.8-65.1)$

41.4

$(27.2-57.2)$

$-0.1$

$(-17.9-9.3)$
43.0

$(34.0-62.0)$

43.4

$(28.9-53.3)$

$-0.1$

$(-15.8-11.0) \quad(-17.9-9.3) \quad(-24.0-11.5)$

Values are medians (ranges).

* LDL phenotype B; $\geq 35 \% \mathrm{LDL}$ cholesterol in LDL $\geq 1.040 \mathrm{~g} / \mathrm{mL}$.

Changes in serum total cholesterol concentrations were significantly different between the three groups ( $p=0.046$ for diet effect), which appeared to be due to an effect of $t 10$, c12 CLA. After correction for multiple comparisons, however, the change in serum total cholesterol concentrations in the $t 10,012$ CLA group was not significantly different from the change in the control group $(p=0.214)$ or the $c 9,111$ group $(p=0.174)$. However, total cholesterol was the only parameter for which a center effect was observed (diet $x$ center: $p=0.048$ ). When only data of Brussels were analyzed, total cholesterol concentrations tended to be higher in the $110, c 12$ CLA group compared with the control group $(p=0.054)$ and the $c 9, t 11$ CLA group $(p=0.021)$. For Maastricht, no differences between the groups were observed. No differences between the groups were found for changes in LDL cholesterol concentrations $(p=0.120)$, $H D L$ cholesteral $(p=0.410)$, triacylglycerol $(p=0.455)$, the ratio of total to $H D L$ cholesteral $(p=0.655)$, and the ratio of $L D L$ to HDL cholesterol $(p=0.745$, Tabie 6.4 ). The standard deviation for the change in triacylglycerol during the control diet was relatively large, which was caused by two extreme responses. When these two values were excluded, differences between groups remained non significant for serum concentrations of triacylglycerol $(\rho=0.267)$, LDL cholesterol $(p=0.269)$ and the ratio of LDL to HDL cholesterol $(p=0.971)$. 
Table 6.4. Mean serum concentrations of total cholesterol, LDL cholesterol, HDL cholesterol, triacylglycerol, the ratio of lotal to HDL cholesterol and of $L D L$ to $H D L$ cholesterol.

Contral $\quad$ C9, t11 CLA $\quad$ t10, C12 CLA

\begin{tabular}{|c|c|c|c|c|c|c|}
\hline \multicolumn{7}{|l|}{ Total cholesterol (romol/L) } \\
\hline Ruin-in period & $5.65 \pm$ & 1.21 & $5.81 \pm$ & 0.85 & $5.73 \pm$ & \pm 1.10 \\
\hline Experimental period & $5.58 \pm$ & 1.19 & $5.74 \pm$ & 0.85 & $6.02 \pm$ & $\pm \quad 1.11$ \\
\hline Change & $-0.03 \pm$ & 0.75 & $-0.06 \pm$ & 0.61 & $0.29 \pm$ & \pm 0.75 \\
\hline \multicolumn{7}{|l|}{ LDL cholesterol (mmol/L) } \\
\hline Run-in period & $3.69 \pm$ & 1.06 & $3.66 \pm$ & 0.91 & $3.80 \pm$ & \pm 1.03 \\
\hline Experimental period & $3.64 \pm$ & 1.02 & $3.63 \pm$ & 0.81 & $3.97 \pm$ & \pm 0.99 \\
\hline Change & $-0.02 \pm$ & 0.70 & $-0.02 \pm$ & 0.52 & $0.17 \pm$ & \pm 0.62 \\
\hline \multicolumn{7}{|l|}{ HDL cholesteral (mmal/L) } \\
\hline Run-in period & $1.42 \pm$ & 0.53 & $1.47 \pm$ & 0.56 & $1.32 \pm$ & \pm 0.34 \\
\hline Experimental period & $1.41 \pm$ & 0.49 & $1.38 \pm$ & 0.49 & $1.28 \pm$ & \pm 0.28 \\
\hline Change & $-0.01 \pm$ & 0.26 & $-0.09 \pm$ & 0.23 & $-0.04 \pm$ & $\pm \quad 0.22$ \\
\hline \multicolumn{7}{|l|}{ Triacylglycerol (mmol/L) } \\
\hline Run-in period & $1.36 \pm$ & 0.70 & $1.50 \pm$ & 0.70 & $1.35 \pm$ & \pm 0.55 \\
\hline Experimental period & $1.45 \pm$ & 0.82 & $1.61 \pm$ & 0.76 & $1.70 \pm$ & $\pm \quad 0.78$ \\
\hline Change & $0.08 \pm$ & 1.03 & $0.12 \pm$ & 0.70 & $0.35 \pm$ & 0.52 \\
\hline \multicolumn{7}{|l|}{ Ratio total to } \\
\hline \multicolumn{7}{|l|}{ HDL cholesteral } \\
\hline Run-in period & $4.32 \pm$ & 1.47 & $4.38=$ & 1.54 & $4.68 \pm$ & $\pm \quad 1.74$ \\
\hline Experimental period & $4.28 \pm$ & 1.45 & $4.53 \pm$ & 1.33 & $4.93 \pm$ & \pm 1.47 \\
\hline Changa & $-0.02 \pm$ & 1.31 & $0.15 \pm$ & 0.94 & $0.25 \pm$ & $\pm \quad 0.89$ \\
\hline \multicolumn{7}{|l|}{ Ratio LLL to } \\
\hline \multicolumn{7}{|l|}{ HDL cholesterol } \\
\hline Rukn-in period & $2.87 \pm$ & 1.21 & $2.84 \pm$ & 130 & $3.17 \pm$ & \pm 1.48 \\
\hline Experimental period & $2.85 \pm$ & 1.23 & $2.94 \pm$ & 1.16 & $3.27 \pm$ & \pm 1.23 \\
\hline Change & $-0.01 \pm$ & 1.02 & $0.10 \pm$ & 0.75 & $0.11 \pm$ & \pm 0.74 \\
\hline
\end{tabular}

Values are means \pm SD.

Plasma concentrations of glucose and insulin and the HOMA-index did not change differently between the groups (Table 6.5). 
Table 6.5. Mean plasma concentrations of glucose and insulin, and the glucose:insulin ratio.

\begin{tabular}{|c|c|c|c|}
\hline & Control & $\mathrm{C9}, 111 \mathrm{CLA}$ & $\$ 10,012$ CLA \\
\hline \multicolumn{4}{|l|}{ Glucose $(\mathrm{mm} n \mathrm{l} / \mathrm{L})^{*}$} \\
\hline Run-in period & $5.58 \pm 0.62$ & $5.74 \pm 0.58$ & $5.43 \pm 0.41$ \\
\hline Experimental period & $5.51 \pm 0.61$ & $5.82 \pm 0.66$ & $5.70 \pm 0.54$ \\
\hline Change & $-0.06 \pm 0.62$ & $0.09 \pm 0.53$ & $0.27 \pm 0.46$ \\
\hline \multicolumn{4}{|l|}{ Insulin (mL/A) } \\
\hline Run-in period & $\begin{array}{c}6.4 \\
(1.7-36.0)\end{array}$ & $\begin{array}{c}8.8 \\
(3.2-822)\end{array}$ & $\begin{array}{c}6.7 \\
(3.2-14.4)\end{array}$ \\
\hline Experimental period & $\begin{array}{c}6.7 \\
(0.8-97.6)\end{array}$ & $\begin{array}{c}9.8 \\
(1.7-19.7)\end{array}$ & $\begin{array}{c}6.5 \\
(2.7-36.0)\end{array}$ \\
\hline Change & $\begin{array}{c}0.5 \\
(-2.9-81.0)\end{array}$ & $\begin{array}{c}1.0 \\
(-6.0-51.2)\end{array}$ & $\begin{array}{c}-0.5 \\
(-2.7-10.4)\end{array}$ \\
\hline \multicolumn{4}{|l|}{ HOMA** } \\
\hline Run-in period & $\begin{array}{c}1.5 \\
(0.4-8.5)\end{array}$ & $\begin{array}{c}2.3 \\
(0.7-18.5)\end{array}$ & $\begin{array}{c}1.6 \\
(0.8-3.9)\end{array}$ \\
\hline Experimental period & $\begin{array}{c}1.7 \\
(0.2-7.3)\end{array}$ & $\begin{array}{c}2.3 \\
(0.8-21.3)\end{array}$ & $\begin{array}{c}1.6 \\
(0.5-6.7)\end{array}$ \\
\hline Change & $\begin{array}{c}0.2 \\
(-1.1-1.2)\end{array}$ & $\begin{array}{c}0.2 \\
(-1.8-17.4)\end{array}$ & $\begin{array}{c}0.1 \\
(-0.8-2.6)\end{array}$ \\
\hline
\end{tabular}

* Vaiues are means \pm SD.

* Values are medians (ranges)

No differences between the groups were found in changes in hematological parameters (data not shown), but an increase in concentrations of ASAT and creatinine was seen in the $t 10$, $c 12$ CLA group as compared with the control and $c 9,111$ CLA groups, as well as a trend for an increased ALAT concentration in the t10, c12 CLA group as compared with the control and $c 9,111$ CLA groups (Table 6.6). 
Table 6.6. Liver, kidney and an acute phase response parameter.

\begin{tabular}{|c|c|c|c|}
\hline & Control & $\mathrm{Cg}_{\mathrm{g}}, 11 \mathrm{CLA}$ & 110,012 CLA \\
\hline \multicolumn{4}{|l|}{ ALAT (UUNL) } \\
\hline Run-in period & $\begin{array}{c}25.0 \\
(11.0-57.0)\end{array}$ & $\begin{array}{c}22.0 \\
(7.0-99.0)\end{array}$ & $\begin{array}{c}24.0 \\
(9.0-47.0)\end{array}$ \\
\hline Experimental period & $\begin{array}{c}22.5 \\
(8.0-66.0)\end{array}$ & $\begin{array}{c}21.0 \\
(10.0-129.0)\end{array}$ & $\begin{array}{c}29.0 \\
(3.0-75.0)\end{array}$ \\
\hline Change & $\begin{array}{c}-1.5 \\
(-27.0-33.0)\end{array}$ & $\begin{array}{c}-2.0 \\
(-85.0-37.0)\end{array}$ & $\begin{array}{c}4.0^{*} \\
(-12.0-28.0)\end{array}$ \\
\hline \multicolumn{4}{|l|}{ ASAT (IU/L) } \\
\hline Run-in period & $\begin{array}{c}19.0 \\
(10.0-37.0)\end{array}$ & $\begin{array}{c}20.0 \\
(5.0-119.0)\end{array}$ & $\begin{array}{c}17.0 \\
(7.0-28.0)\end{array}$ \\
\hline Experimental period & $\begin{array}{c}18.0 \\
(10.0-37.0)\end{array}$ & $\begin{array}{c}17.0 \\
(7.0-52.0)\end{array}$ & $\begin{array}{c}21.0 \\
(9.0-32.0)\end{array}$ \\
\hline Change & $\begin{array}{c}-2.0 \\
(-15.0-11.0)\end{array}$ & $\begin{array}{c}-2.0 \\
(-101.0-9.0)\end{array}$ & $\begin{array}{c}3.0^{0.0} \\
(-6.0-10.0)\end{array}$ \\
\hline \multicolumn{4}{|l|}{ ALP $(I \cup / L)$} \\
\hline Run-in period & $\begin{array}{c}85.0 \\
(42.0-229.0)\end{array}$ & $\begin{array}{c}83.0 \\
(46.0-263.0)\end{array}$ & $\begin{array}{c}95.0 \\
(32.0-229.0)\end{array}$ \\
\hline Experimental period & $\begin{array}{c}75.0 \\
(40.0-114.0)\end{array}$ & $\begin{array}{c}67.0 \\
(38.0-113.0)\end{array}$ & $\begin{array}{c}71.0 \\
(29.0-148.0)\end{array}$ \\
\hline Change & $\begin{array}{c}-5.5 \\
(-143.0-31.0)\end{array}$ & $\begin{array}{l}-10.0 \\
(-192.0-8.0)\end{array}$ & $\begin{array}{c}-2.0 \\
(-134.0-33.0)\end{array}$ \\
\hline \multicolumn{4}{|l|}{ Total bilirubin (fmol/L) } \\
\hline Run-in period & $\begin{array}{c}9.6 \\
(0.3-35.3)\end{array}$ & $\begin{array}{c}9.5 \\
(0.3-20.8)\end{array}$ & $\begin{array}{c}7.7 \\
(0.5-19.4)\end{array}$ \\
\hline Experimentall period & $\begin{array}{c}11.6 \\
(0.3-35.6)\end{array}$ & $\begin{array}{c}10.2 \\
(0.3-24.8)\end{array}$ & $\begin{array}{c}10.1 \\
(0.4-19.0)\end{array}$ \\
\hline Change & $\begin{array}{c}0.3 \\
(-3.6-7.5)\end{array}$ & $\begin{array}{c}0.1 \\
(-5.6-4.7)\end{array}$ & $\begin{array}{c}0.9 \\
(-4.8-5.2)\end{array}$ \\
\hline \multicolumn{4}{|c|}{$\gamma$-glutamyltranspeptidase (IU/L) } \\
\hline Run-in period & $\begin{array}{c}26.0 \\
(10.0-85.0)\end{array}$ & $\begin{array}{c}24.0 \\
(12.0-71.0)\end{array}$ & $\begin{array}{c}25.0 \\
(8.0-63.0)\end{array}$ \\
\hline Experimental period & $\begin{array}{c}23.5 \\
(7.0-99.0)\end{array}$ & $\begin{array}{c}21.0 \\
(9.0-67.0)\end{array}$ & $\begin{array}{c}24.0 \\
(10.0-60.0)\end{array}$ \\
\hline Change & $\begin{array}{c}0.0 \\
(-33.0-41.0)\end{array}$ & $\begin{array}{c}-2.0 \\
(-18.0-8.0)\end{array}$ & $\begin{array}{c}1.0 \\
(-21.0-18.0)\end{array}$ \\
\hline
\end{tabular}


Table 6.6. Continued.

Control $\quad 9,111$ CLA $\quad 110,612 \mathrm{CLA}$

$\begin{array}{lccc}\text { Creatinine (fmoll/L) } & & \\ \text { Run-in period } & 72.5 & 73.5 & 67.0 \\ \text { Experimental period } & (0.6-1.25 .0) & (0.6-125.0) & (0.7-108.0) \\ \text { Change } & 76.0 & 74.0 & 73.0 \\ & (0.6-117.0) & (0.6-101.0) & (0.7-107.0) \\ \text { C-reactive protein }(\mathrm{mg} / \mathrm{L}) & 0.1 & -0.1 & 2.5^{6.8} \\ \text { Run-in period } & (-25.0-27.0) & (-24.0-9.0) & (-8.0-12.0) \\ & & & 5.0 \\ \text { Experimentall period } & 5.0 & 5.0 & (0.1-7.6) \\ & (0.1-31.7) & (0.1-12.3) & 5.0 \\ \text { Change } & 5.0 & 5.0 & (0.2-14.4) \\ & (0.1-13.8) & (0.1-10.2) & 0.0 \\ & (-26.7-8.8) & (-7.3-1.9) & (-2.4-7.2)\end{array}$

\footnotetext{
Values are medians (ranges)

a control versus 110, c12 CLA: $p<0.05$

- c9, t11 CLA versus t10, c12 CLA: $p<0.05$

c control versus t10, c 12 CLA: $P<0.017$

a $c 9, t 11$ CLA versus $t 10$, c12 CLA: $p<0.017$
}

\section{Discussion}

In the present study, specifically designed to test the effects of c9, t11 CLA on LDL phenotype, we could not confirm our hypothesis that this CLA isomer affects serum small dense LDL cholesterol concentrations in moderately overweight subjects with LDL phenotype B. This hypothesis had emerged from a previous study [11]. Small dense LDL is derived from VLDL1 particles, which are larger and contain more triacylglycerol than VLDL2 particles [16]. A decrease in small dense LDL therefore usually goes together with a decrease in VLDL triacylglycerol. In support of our hypothesis was therefore the finding of Noone et al. [4] that CLA decreased VLDL-triacylglycerol concentrations. This effect might in particular be due to c9, $t 11$ CLA, as this isomer decreased VLDL-cholesterol concentrations significantly. Further, a mixture of $c 9, \mathrm{t} 11 \mathrm{CLA}$ and 110,012 CLA reduced apalipoprotein $B$ secretion in human 
Hep 62 cells [17], which lends further support for a reduction in VLLL production. Contrary to these findings, mixtures containing equal amounts of $c 9,111 \mathrm{CLA}$ and $110, \mathrm{c} 12 \mathrm{CLA}$ did not affect VLDL-triacylglycerol in obese men with the metabolic syndrome [18] and in healthy men and women [5]. In this latter study however, serum concentrations of apo B were increased [5]. As we also did not observe any effect on LDL phenotype, there is only equivocal evidence that any of the CLA isomers changes VLDL metabolism in humans. We also did not observe any effects of $\mathrm{c9}, \mathrm{t} 11 \mathrm{CLA}$ and of $\mathrm{t10}, \mathrm{c} 12 \mathrm{CLA}$ on serum lipoprotein cholesterol or triacylglycerol concentrations. This agrees well with studies in healthy subjects [5-7] and in obese middle-aged men with the metabolic syndrome [8]. Recently, however, Tricon et al, showed in healthy subjects that serum concentrations of total cholesterol $L D L$ cholesterol, triacylglycerol, and the ratio of total to $\mathrm{HDL}$ cholesterol were higher during consumption of $t 10,012$ CLA than of $c 9, t 11$ CLA [19]. Since no control group was used it is not clear whether $c 9,111$ CLA decreased these parameters or whether 110, c12 CLA increased them. In another study with obese middle-aged subjects a decrease in serum concentrations of HDL cholesterol was found after consumption of $110, \mathrm{C12} C L A$ [17]. Dailly CLA intake in these studies ranged between 0.7 and $4.2 \mathrm{~g}$. In our study, $3 \mathrm{~g}$ of $\mathrm{C9}, \mathrm{t11}$ CLA and of t10, c12 CLA did not affect the serum lipoprotein profile. Taken together, however, these studies carried out in various population groups do not suggest that a mixture of CLA or any of its isomers favourably changes the serum lipid and lipoprotein profile. If anything, results suggest that the $110,012 \mathrm{CLA}$ isomer negatively affects the serum lipoprotein profile [18]. Possible differential effects of the two CLA isomers are difficult to explain. Trans monounsaturated fatty acids increase serum total cholesterol concentrations and lower those of HDL [20]. c9, t11 CLA also contains a trans double bond, but does not change serum LDL or HDL cholesterol concentrations. In contrast, 110,012 CLA may have comparable effects as trans monounsaturated fatty acids. It can then be speculated that configuration or the position of the double bond near the carboxyl or methyl end is important. This suggestion, as well as the differential effect of CLA isomers on cholesterol metabolism, warrants further investigation.

Both CLA isomers, 09, 111 CLA and 110,012 CLA, decreased insulin sensitivity in obese men $[18,21]$. In patients with type 2 diabetes mellitus, a mixture of these isomers also decreased insulin sensitivity [22]. Contrary to these findings, we did not observe any effects of CLA on plasma glucose and insulin concentrations, or the HOMA-index. Subjects in the present study had lower baseline plasma insulin concentrations than subjects in the other studies $[18,21]$, It is therefore possible that CLA has only diabetogenic effects when insulin sensitivity is already impaired. This would agree with the lack of effect on fasting glucose and insulin concentrations in other human studies $[4,5,8,23]$ carried out with mixtures composed of various amounts of $c 9, t 11$ CLA and $t 10, C 12$ CLA.

Although values remained within the normal range increases in ALAT and ASAT as an index of liver function and in creatinin as a measure of kidney function in the 110, c12 CLA group 
suggests that supplementation with this isomer may have unwanted side effects. It remains to be determined however whether or not these changes are transient.

Many animal studies have observed favourable effects of CLA. Anti-atherogenic effects have been found in rabbits [2] and hamsters [24], although not in mice [3]. CLA also decreased serum total cholesterol concentrations in most [24-26], but not all [27] hamster studies. In other animal species, like rats, chicks, pigs and mice, CLA feeding had no favourable effects on total cholesterol $[3,28-30]$. Anti-diabetic effects of CLA, especially of the 110, C12 CLA isomer, have been demonstrated in obese Zucker rats $[31,32]$, while no benefits or even adverse effects were found in mice [33-36]. Thus, it is clear that the anti-atherogenic and anti-diabetic effects of CLA are species dependent. From the present study we conclude that moderately overweight humans do not benefit of C9, 111 CLA or 110,012 CLA supplementation to lower risk factors for cardiovascular disease or diabetes.

\section{Acknowledgements}

This study was financially supported by a grant from the European Commission "CLA in functional food: A potential benefit for overweight middle-aged Europeans". Fifth (EC) framework program grant number QLK1-1999-00076. 


\section{References}

1. Belury MA. Dietary conjugated linoleic acid in health: physiological effects and mechanisms of action. Annu Rev Nutr 2002,22:505-31.

2. Lee $K N$, Kritchevsky D, Pariza MW. Conjugated linoleic acid and atherosclerosis in rabbits. Atherosclerosis 1994,$108 ; 19-25$.

3. Munday JS, Thompson KG, James KA. Dietary conjuglated linoleic acids promote fatty streak formation in the C57BL/6 mouse atherosclerosis model. Br J Nutr 1999;81:251-5.

4. Noone EJ, Roche HM, Nugent AP, Gibmey MJ. The effect of dietary supplementation using isomeric blends of conjugated linoleic acid on lipid metabolism in healthy human subjects. $\mathrm{Br} J$ Nutr 2002;88:243-51.

5. Smedman $A$, Vessby $B$. Conjugated linoleic acid supplementation in humans - metabolic effects. Lipids 2001;36:773-81.

6. Benito P. Nelson G., Kelley DS, Bartolini G, Schmidt PC, Simon V. The effect of conjugated linoleic acid on plasma lipoproteins and tissue fatty acid composition in humans. Lipids 2001;36:229-36.

7. Mougios $V_{0}$ Matsakas $A_{1}$ Petridou $A_{\text {, }}$ et al. Effect of supplementation with conjugated linoleic acid on human serum lipids and body fat. J Nutr Biochem 2001;12:585-594.

8. Riserus $U$, Berglund $L$, Vessby $B$. Conjugated linoleic acid (CLA) reduced abdominall adipose tissue in obese middle-aged men with signs of the metabolic syndrome: a randomised controlled trial. Int J Obes Rellat Metab Disord 2001;25:1129-35.

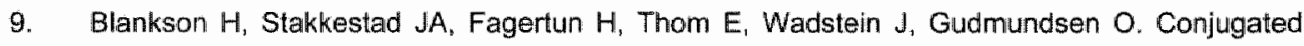
linoleic acid reduces body fat mass in overweight and obese humans. J Nutr 2000;130;2943-8

10. Pariza MW, Park $Y$, Cook ME. Mechanisms of action of conjugated linoleic acid: evidence and speculation. Proc Soc Exp Biol Med 2000;223:8-13.

11. Malpuech-Brugère $C$, Verboeket-van de Venne WPHG Mensink RP, et al. Effects of two conjugated linoleic acid isomers on body fat mass in overweight humans. Obes Res $2004 ; 12$ $591-9$.

12. Krauss RM. Atherogenic lipoprotein phenotype and diet-gene interactions. $J$ Nutr 2001;131:3405-3S.

13. Friedewald WT, Levy RI, Fredrickson DS. Estimation of the concentration of low-density lipoprotein cholesterol in plasma, without use of the preparative ultracentrifuge. Clin Chem $1972 ; 18: 499-502$.

14. Sebedio $\mathrm{JL}$, Vermunt $\mathrm{SH}, \mathrm{Chardigny} J \mathrm{M}$, et al. The effect of dietary trans alphamlinolenic acid on plasma lipids and platelel fatty acid composition: the TransLinE study. Eur J Clin Nutr 2000;54:104-13.

15. Matthews DR, Hosker JP, Rudenski AS, Naylor BA, Treacher DF, Turner RC. Homeostasis model assessment: insulin resistance and $b$-cell function from fasting plasma glucose and insulin concentrations in man. Diabetologia 1985;28:412-9. 
16. Berneis KK, Krauss RM. Metabolic origins and clinical significance of LDL heterogeneity. $J$ Lipid Res 2002;43:1363-79.

17. Pariza MW, Park $Y$, Cook ME. The biologically active isomers of conjugated linoleic acid. Prog Lipid Res 2001;40:283-98.

18. Riserus U, Arner P, Brismar $K$, Vessby $B$. Treatment with dietary trans10cis 12 conjugated linoleic acid causes isomer-specific insulin resistance in obese men with the metabolic syndrome. Diabetes Care 2002;25:1516-21.

19. Tricon $S$, Burdge $G C_{1}$, Kew $S$, el al. Opposing effects if cis-9, trans-11 and trans-10, cis 12 conjugated linoleic acid on blood lipids in healthy humans. Am J Clin Nutr 2004:80:614-20

20. Mensink RP, Zock PL, Kester ADM, Katan MB. Effects of dietary fatty acids and carboliydrates on the ratio of serum total to HDL cholesterol and on serum lipids and apolipoproteins: a metaanalysis of 60 controlled trials. Am $\mathrm{A}$ Clin Nutr 2003;77:1146-55

21. Risérus U, Vessby $B_{n}$ Ärnlöv J, Basu S. Effects of cis-9, trans-11 conjugated linoleic acid supplementation on insulin sensitivity, lipid peroxidation, and inflammatory markers in obese men. Am J Clin Nutr 2004;80:279-83.

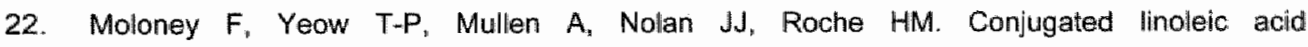
supplementation, insulin sensitivity, and lipoprotein metabolism in patients with type 2 diabetes mellitus. Am J Clin Nutr 2004;80:887-95.

23. Medina $\mathrm{EA}$ Horn WF, Keim NL, et al. Conjugated linoleic acid supplementation in humans: effects on circulating leptin concentrations and appetite. Lipids $2000 ; 35: 783-8$.

24. Wilson T, Nicolosi Ru, Chrysam M, Kritchevsky D. Conjugated linoleic acid reduces early aortic atherosclerosis greater than linoleic acid in hypercholesterolemic hamsters. Nutr Res 2000;20:1795-1805.

25. Nicolosi RJ, Rogers EJ, Kritchevsky D, Scimeca JA, Huth PJ. Dietary conjugated linoleic acid reduces plasma lipoproteins and early aortic atherosclerosis in hypercholesterolemic hamsters. Artery 1997;22:266-77.

26. Thomas Yeung $\mathrm{CH}$, Yang $L$, Huang $Y$, Wang $J$, Chen $Z Y$. Dietary conjugated linoleic acid mixture affects the activity of intestinal acyl coenzyme A: cholesterol acyltransferase in hamsters. Br J Nutr 2000;84:935-41.

27. Sher J, Pronczuk A, Hajri T, Hayes KC. Dietary conjugated linoleic acid lowers plasma cholesterol during cholesterol supplementation, but accentuates the atherogenic lipid profile during the acute phase response in hamsters. J Nutr 2003;133:456-60.

28. Stangi Gl "Muller $\mathrm{H}$. Kirchgessner $\mathrm{M}$. Conjugated linoleic acid effects on circulating hormones, metabolites and lipoproteins, and its proportion in fasting serum and erythrocyte membranes of swine. Eur J Nutr 1999;38:271-7.

29. Du M, Ahn DU. Dietary CLA affects lipid metabolism in broiler chicks. Lipids 2003;38:505-11.

30. Stangl GI. Conjugated linoteic acids exhibit a strong fat-to-lean partitioning effect, reduce serum VLDL lipids and redistribute tissue lipids in food-restricted rats. J Nutr 2000:130:1140-6. 
31. Herriksen EJ, Teachey MKK, Taylor ZC, et al. Isomer-specific actions of conjugated linoleic acid on muscle glucose transport in the obese Zucker rat. Am I Physiol Endocrinol Metab 2003:285:E98-E105.

32. Ryder JW, Portocarrero CP, Song $X M$, al. Isomer-specific antidiabetic properties of conjugated :inoleic acid. Improved glucose tolerance, skeletal muscle insulin action, and UCP-2 gene expression. Diabeles 2001:50:1149-57.

33. Tsuboyama-Kasaoka $N$, Takahashi $M$, Tanemura $K$, et al. Conjugated linoleic acid supplementation reduces adipose tissue by apoptosis and develops lipodystrophy in mice. Diabetes 2000;49:1534-42.

34. DeLany JP, Blohm F, Truett AA, Scimeca JA, West DB. Conjugated linoleic acild rapidly reduces body fat content in mice without affecting energy intake. Am J Physiol 1999;276:R1172-9.

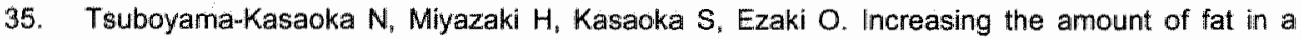
conjugated linoleic acid-supplemented diet reduces lipodystrophy in mice. I Nutr 2003;133:1793-9.

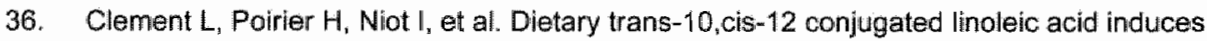
hyperinsulinemia and fatty liver in the mouse. J Lipid Res 2002;43:1400-9. 
Chapter 7

General discussion 


\section{Generall discussion}

Functional foods that tavourably affect cardiovascular risk markers are useful for people who are at increased risk for coronary heart disease. In this thesis; we focused on plant sterols and stanols, p-glucan and CLA as possible ingredients for functional foods.

During the past years many studies have demonstrated the cholesterol-lowering effects of plant sterols and stanols. In addition, it has been shown that serum plant sterol concentrationsi increase during plant sterol consumption. Although the same is true for plant stanols, only for plant sterols there are indications that their serum concentrations are positively associated with cardiovascular risk [1]. As consumption of plant stanol enriched food products reduces serum concentrations of plant sterols, we hypothesized that a mixture of plant sterols and stanols prevents the increase in serum concentrations of plant sterols, but still lowers serum LDL cholesterol (Chapter 3). Howewer, results of this study indicated that the increase in serum concentrations of plant sterols was not affected by the simultaneous consumption of plant stanols, but was proportional to intake of plant sterols. Serum concentrations of LDL cholesterol were reduced, but to a lesser extent than was expected from previous studies. We speculated that this smaller decrease was due to the low mean baseline serum LDL cholesterol concentrations of the subjects and decided to carry out a meta-analysis to study effects of subjects' baseline characteristics that may be related with the cholesterol-lowering effects of plant stanols (Chapter 4).

Another food component with possible cholesterol-lowering properties is $\beta$-glucan, but results of studies are less consistent than those of plant sterols and stanols. For the moment, it is hard to predict the cholesterol-lowering effect of a food product enriched with $\beta$-glucan, which makes it necessary to test nearly every new food product to substantiate a claim. We therefore studied the effects of a fruit drink enriched with $\beta$-glucian on serum lipids and lipoproteins (Chapter 5). We also studied effects of $\beta$-glucan on cholesterol absorption and synthesis to gain more insight into possible mechanisms of action.

Animal studies have suggested anti-atherogenic properties of CLA. Although results in several human studies are less convincing, a pilot study at our Department suggested an effect of CLA on small dense LDL cholesterol concentrations. We therefore decided to examine effects of CLA in the serum lipoprotein profile in a larger number of subjects (Chapter 6).

In this chapter the main outcomes of the studies will be discussed first. Next, the discussion will focus on the position of functional foods in a regular diet. 


\section{Effects of plant sterols and stanols, $\beta$-glucan and CLA on risk factors for cardiovascular disease}

\section{Plant sterols and stanols}

It has been estimated that plant sterols and stanols reduce serum concentrations of $\mathrm{LDL}$ cholesterol by about $9 \%$ at a daily intake of $2-2.5 \mathrm{~g}$ [2]. In our study using mixtures of plant sterols and stanols a reduction of $6-7 \%$ was found (Chapter 3 ). In that study two different mixtures of plant sterois and stanols were used, containing both plant sterols and stanols in equal amounts or $1.5 \mathrm{~g}$ of plant sterols plus $0.5 \mathrm{~g}$ of plant stanols. Both mixtures reduced serum concentrations of LDL cholesterol to the same extent. This shows that the LDL cholesterol-lowering effect of plant sterois and stanols is comparable, which agrees with earlier studies [3-5]. However, other studies using comparable mixtures of plant sterols and stanols found larger decreases in serum concentrations of LDL cholesterol [5-7]. Since baseline serum concentrations in our study were low, we wondered if this could have affected the LDL chollesterol response. Data of five studies carried out at our Department were therefore used to analyze subject characteristics that may be related to changes in the serum lipoprotein profile. It was found that baseline serum concentrations of LDL cholesterol were strongly related to absolute, but not to relative decreases in LDL cholesterol. Therefore, the reduction of $6-7 \%$ in LDL cholesterol during consumption of mixtures of plant sterols and stanols could not be explained by the low baseline serum LDL cholesteral concentrations of our subjects (Chapter 4). It has also been suggested that the response to plant stanols is affected by baseline cholesterol absorption and synthesis. People with a high cholesterol absorption might respond better to plant stanols than people with a low absorption [8]. For endogenous cholesterol synthesis, the opposite relation has been suggested. In our metaanalysis (Chapter 4) high baseline serum concentrations of sitosterol, indicating a high intestinal cholesterol absorption, tended to be associated $(p=0.062)$ with lower serum concentrations of LDL cholesterol after consumption of plant stanols. Comparing baseline serum concentrations of sitosterol of subjects participating in our study using mixtures of plant sterols and stanols. (Chapter 3) with those of other studies using about $2 \mathrm{~g}$ of plant sterols or stanols per day, the relationship between serum concentrations of sitosterol at baseline $[7,9,10]$ or during placebo treatment $[5,11,12]$ and the decrease in LDL cholesterol is also evident (Figure 7.1). From this figure, it can be suggested that the smaller decrease in LDL cholesterol in our study (Chapter 3) can be explained by low baseline serum sitosterol concentrations of the subjects. 


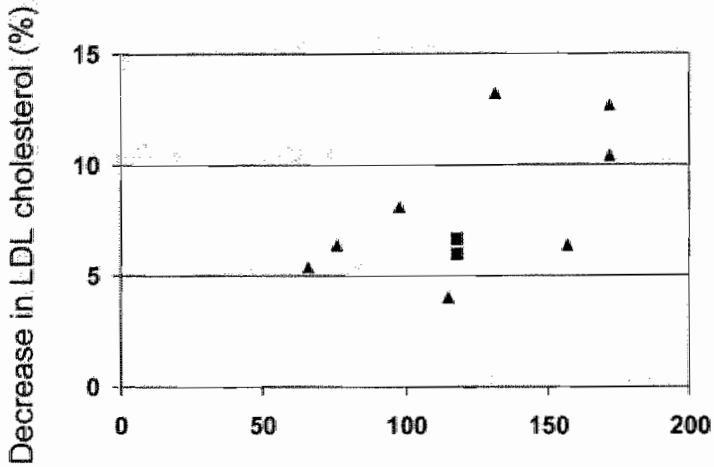

Baseline serum concentration of sitosterol $\left(10^{2} \times \mu \mathrm{mol} / \mathrm{mmol}\right.$ cholesterol)

Figure 7.1: Relative decrease in serum LDL cholesterol at a daily plant stanol intake of $2 \mathrm{~g}$ of plant sterols or stanols at different serum sitosterol concentrations at baseline $[7,9,10]$ or during placebo treatment $[5,11,12]$. Decreases in LDL cholesterol in our study (Chapter 3 ) are indicated by squares.

Further, both absolute and relative decreases in serum concentrations of triacylglycerol and the ratio of total to HDL cholesterol were most pronounced in subjects with the highest baseline concentrations of these cardiovascular risk markers. The decrease in serum concentrations of triacylglycerol has only been found in a study with subjects with familial hypercholesterolemia during consumption of a plant sterol enriched spread [13]. The underlying mechanism is unclear. Changes might be related to effects of plant sterols and stanols on VLDL-metabolism. Thus, although plant stanol enriched foods are recommended only for people who have high serum LDL cholesterol concentrations, results of metaanalysis (Chapter 4) suggest that also people with high serum triacylglycerol concentrations might benefit from the use of these products. In addition, serum concentrations of HDL cholesterol increased slightly at low baseline concentrations and decreased marginally at high baseline concentrations. The expected decrease in coronary heart disease risk is about $10 \%$ for men and $12 \%$ for women at a daily plant stanol intake of $2 \mathrm{~g}$ and baseline concentrations of $\mathrm{LDL}$ cholesterol of $4 \mathrm{mmol} / \mathrm{L}$, $\mathrm{HDL}$ cholesterol of $1 \mathrm{mmo} / \mathrm{L}$ and triacylglycerol of $2 \mathrm{mmol} / \mathrm{L}$ (Chapter 4). Since other subjects' characteristics did not contribute substantially to the predicted changes, functional foods enriched with plant stanol esters are therefore of benefit for people with an unfavourable lipoprotein profile. 
Serum concentrations of plant sterols and stanols increase during consumption of these compounds. Although it has been suggested that they may influence each others' serum concentrations, we could not demonstrate this in a study using mixtures of plant sterols and stanols. Rather, the increase in serum plant sterol concentrations was proportional to intake, since the increase was similar for both mixtures when expressed per $\mathrm{g}$ of intake. Serum concentrations of plant stanols also increased, but this increase was lower than for plant sterols, because absorption of plant stanols is much lower than of plant sterols [14]. Extremely high serum plant sterol concentrations may induce atherosclerosis and death of coronary heart disease at a very young age in patients with the inherited disease sitosterolemia [15]. Without this disease, consumption of functional foods enriched with plant sterols will not result in such high serum concentrations of plant sterols. A recent casecontrol analysis showed that non-sitosterolemic, high risk (ten-year risk of a coronary event $>20 \%$ ) subjects in the highest quartile of serum sitosterol concentrations had an 3-fold further increase in the risk of a coronary event, compared with subjects in the lower quartiles of serum sitosterol concentrations [1]. Although serum cholesterol-standardized campesteral and sitosterol concentrations have been related to coronary heart disease in other studies as well $[16,17]$, Wilund et al. did not find an association between ellevated plasma plant sterol concentrations and atherosclerosis [18]. Thus, there is no strong evidence that plant sterols are atherogenic. In fact, animal studies have provided evidence that plant sterols and stanols lower the risk of atherosclenosis [19-22]. Food products enriched with plant sterols and stanols are on the market for several years now. Finland was the first country to introduce plant stanol enriched food products in 1995 and so far no adverse effects have been reported $[2,23,24]$. In addition, studies in animals showed no signs of toxicity during plant sterol or stanol consumption of more than 150 times the recommended dose for humans [2, 25,26 ]. In humans, a daily plant sterol intake of up to $9 \mathrm{~g}$ did not cause any side effects [27]. However, if the number of functional foods enriched with plant sterols and stanols increases, it is possible that people consume more than $9 \mathrm{~g}$ per day [28]. Decreases in plasma concentrations of $\alpha$-carotene, $\beta$-carotene and lycopene during consumption of plant sterols or stanols have been reported frequently [29]. In a meta-analysis, a significant reduction of $12 \%$, adjusted for changes in serum total cholesterol, was only found for beta-carotene. Although it has not been properly tested, this decrease probably does not have serious adverse health effects [2]. Overall, it can be concluded that daily intake of $2-3 \mathrm{~g}$ of plant sterols and stanols seems safe for most people, although attention for long-term consumption is warranted. Plant sterol and stanol enriched food products are useful for people with increased risk for coronary heart disease, characterized by increased LDL cholesterol concentrations and total to HDL cholesterol ratios. In addition, our meta-analysis (Chapter 3) suggests that also people with high triacylglyceroll concentrations benefit from plant stanols. This latter observation, however, needs to be confirmed in randomized controlled trials in people with elevated triacylglycerol concentrations. 


\section{p-glucan}

Studies on the cholesterol-lowering capacities of $\beta$-glucan are not consistent. In our study, $\beta$ glucan incorporated into a fruit juice reduced serum concentrations of LDL cholesterol by $0.062 \mathrm{mmol} / \mathrm{L}$ per gram of $\beta$-glucan (Chapter 5 ). A reduction in $L D L$ cholesterol of 0.05 mmol/L per gram of $\beta$-glucan was found by Kerckhoffs et al. [30], when $\beta$-glucan was incorporated into an orange juice. In this latter study however, oat $\beta$-glucan reduced serum concentrations of LDL non-significantly by $0.12 \mathrm{mmol} / \mathrm{L}(0.02 \mathrm{mmol} / \mathrm{L}$ per gram of $\beta$-glucan or $3 \%$ ) when incorporated into bread and cookies. suggesting that the food matrix affects the cholesterol-lowering properties of $\beta$-glucan. However, recently Pró-FIT bread containing $\beta$ glucan was introduced in the Netherlands. Health benefits of this bread have been assessed in accordance with the Code of Practice for assessing the scientific evidence for health benefits stated in health claims on food and drink products 1998 [31]. It was concluded that daily consumption of 4 slices of bread ( $140 \mathrm{~g}$ ), providing $3 \mathrm{~g}$ of $\beta$-glucan from oat bran, reduced serum concentrations of $L D L$ cholesterol significantly by $0.14 \mathrm{mmol} / \mathrm{L}(0.05 \mathrm{mmol} / \mathrm{L}$ per gram of $\beta$-glucan) or $3 \%$ within three weeks in persons with elevated serum cholesterol levels [32]. The reason for these inconsistent results is not clear, but may be related to different preparations of the breads or differences in baseline cholesterol concentrations (hypercholesterolemic in the Pró-FIT bread study and mildly hypercholesterolemic in the study by Kerckhoffs et al.). Although Pró-FIT ${ }^{\odot}$ bread reduces serum LDL cholesterol, no effects on serum concentrations of total cholesterol and the ratio of total to HDL cholesterol were found. Nevertheless, in the assessment report it was concluded that there was sufficient evidence to allow a health claim for this new bread [32]. It was also concluded that positive effects of this bread on serum lipids and lipoproteins are small. According to this report a $1 \%$ reduction of LDL cholesterol would imply a reduction of $2-3 \%$ in coronary heart disease risk. Theoretically, a reduction in LDL cholesterol of $3 \%$ by the use of this bread will decrease the risk of coronary heart disease by $6-9 \%$ [32]. Since there was sufficient scientific evidence for a health claim on the LDL cholesterol-lowering effect of this bread, it can be reasoned that there is also strong evidence for a health claim for the fruit drink we have used in our study. Health claims for cholesterollowering effects of $\beta$-glucan are allowed already in the US, UK and Sweden.

A suggested mechanism of action of $\beta$-glucan is a reduced absorption of bile acids, resulting in an increased bille acid synthesis. This will result in an increased use of cholesterol for bile acid synthesis, which reduces serum cholesterol concentrations. Our study indicates an increased cholesterol synthesis during $\beta$-glucan consumption, which may be the consequence of the increase in bile acid synthesis. In addition, an increase in cholesterol synthesis is also related to a reduced cholesterol absorption. Indeed, we observed a decrease in serum plant sterol concentrations, a biomarker for cholesterol absorption. Therefore, we suggest that not only an increase in bile acid synthesis, but also a reduced cholesterol absorption contributes to the chclesterol-lowering effects of $\beta$-glucan. 
Compared with plant sterols and stanols, less is known about possible adverse health eftects of $\beta$-glucan. Results of our study (Chapter 5) showed no effect of $\beta$-glucan consumption on parameters of liver and kidney function, inflammation and hematological parameters. In adidition, toxicity studies concluded that it is not likely that 3 -glucan causes adverse immunological or inflammatory effects $[33,34]$. Contrary to effects of plant sterols and stanols, no effects of $\beta$-glucan on anti-oxidant concentrations were found. Together these results suggest that consumption of $\beta$-glucan is safe. An additional argument to advocate an increased intake of $\beta$-glucan is that it also favourably reduces postprandial glucose and insulin leveis in subjects with and without type 2 diabetes mellitus due to delayed absorption of glucose from the gut [35-37].

\section{CLA}

CLA has received a lot of attention during the past years, especially as it effectively reduced body fat mass in various animal models [38]. However, CLA also reduced atherosclerosis in rabbits [39] and lowered serum total cholesterol in hamsters [40-42]. Although indications for effects of CLA on serum lipoprotein concentrations were weak, a rather unexpected finding of our previous study on CLA was a reduction in the proportion of small dense LDL particles by the $c 9, t 11$ CLA isomer in particular. Therefore, a larger study was designed to examine if CLA indeed decreased small dense LDL cholesterol concentrations (Chapter 6). For this, we studied two different isomers $(c 9,+11$ CLA and $t 10, c 12$ CLA) separately. This contrasted most other studies that used mixtures of CLA isomers, often containing comparable amounts of $c 9, t 11$ CLA and $t 10, c 12$ CLA, making it impossible to attribute effects to either of two isomers. Unfortunately, no effect of $c 9, \$ 1$ CLA or $t 10, c 12$ CLA on small dense LDL cholesterol was observed. In addition, serum concentitations of lipoprotein cholesterol and triacylglycerol did not change.

It has been suggested that CLA has several positive health effects, including effects on carcinogenesis, immune function, inflammation, atherosclerosis, diabetes mellitus, body weight and body fat content [43]. Unfortunately, a lot of these positive effects have only been demonstrated in vitro and animal studies. In humans, no consistent effects of CLA were found on body weight and body composition and on risk factors for development of atherosclerosis and diabetes mellitus. Taken together, there is no evidence to support a health claim for CLA on the serum lipoprotein profile. In addition, it is even disputable that a health claim for CLA to reduce body fat mass or to control body weight is supported by scientific evidence, despite the large amount of advertisements in weekly journals in The Netherlands. Effects of CLA on body composition are still controversial [44], although in a placebo-controlled parallel study with 157 subjects, body fat mass was reduced, but only by about $2 \mathrm{~kg}$, after one year of CLA consumption of about $3.5 \mathrm{gl}$ per day [45]. In addition, it is not known if long-term intake of CLA capsules is safe in humans. In some animal studies CLA induced insulin resistance and increased liver and spleen sizes [46]. Results off the few studies on safety of CLA in humans are conflicting. Berven et al. found no effect on 
hematological parameters (hemoglobin concentration and the number of erythrocytes, white blood cells and platelets), on liver function (concentrations of ALAT, ASAT, bilirubin and $\gamma=$ GT) and on kidney function (creatinin) during dally consumption of $3.4 \mathrm{~g}$ of CLA (mixture of c9, 111 CLA and $110, c 12$ CLA) for 12 weeks [47]. The same amount of CLA (mixture of $c 9$, 111 CLA and 110, c12 CLA) increased serum concentrations of ASAT after 12 and 24 months in other studies $[45,48]$. lin addition, $t 10, c 12$ CLA increased CRP concentrations in men with the metabolic syndrome and was suggested to be pro-inflammatory [49]. In our study (Chapter 6), serum concentrations of ALAT, ASAT and creatinin were increased in the $110, c 12$ CLA group, but not in the $c 9_{1} t 11$ CLA group. Although serum concentrations in the 110,012 CLA group remained within normal ranges, these results do suggest that $t 10, c 12$ CLA might have adverse effects on liver and kidney function. Several animal studies indeed showed that the 110,012 CLA isomer induced fatty liver disease [50-52]. In humans, nonalcoholic fatty liver disease is associated with increased concentrations of ALAT [53-56] and ASAT $[55,56]$. In addition to increased insulin resistance in men with the metabolic syndrome during consumption of $t 10, c 12$ CLA $[49,57]$, our results indicate that $t 10_{n} C 12$ CLA may have unwanted health effects in humans.

Overall, CLA supplementation has no strong pasitive effects on risk factors of atherosclerosis in heallthy humans. In addition, results on body composition are not consistent [44]. Therefore, consumption of these supplements should not be encouraged for body weight control. On the other hand, contrary to $110,012 \mathrm{CLA}_{1}$ the $c 9, t 11 \mathrm{CLA}$ isomer might not have adverse health effects. Although c9, 11 CLA does not favourably affect cardiovascular risk factors, this isomer might have favourable effects on other parameters, like cancer [38].

Taken together, plant stanols are useful for lowering serum concentrations of LDL cholesterol and the ratio of total to HDL. cholesterol. Effects on serum triacylglycerol concentrations need to be examined in future trials in subjects with elevated serum concentrations of triacylglycerol. For $\beta$-glucan, cholesterol-lowering effects seem to depend on the food to which the fiber is added. However, if the cholesterol-lowering effect of a functional food enriched with $\beta$-glucan is proven, it is suitable for use. Finally, $c 9,111 \mathrm{CLA}$ and $t 10, c 12 \mathrm{CLA}$ isomers do not favourably affect risk markers for cardiovascular disease and should not be recommended for this purpose. In addition, the $110, \mathrm{c} 12$ CLA isomer might have adverse health effects.

\section{Combining functional foods ingredients}

Since plant stanols and $\beta$-glucan both reduce serum concentrations of total and LDL cholesterol, it is interesting to study the effects of functional foods enriched with both compounds. Especially since in the Netherlands both bread enriched with $\beta$-glucan and plant sterol enriched margarines are on the market. Using both functional foods simultaneously might have an additional cholesterol-lowering effect. However, this has not been directly investigated. Although the mechanism of action of $\beta$-glucan has not been elucidated, the most likely mechanism is an increased bile acid excretion and reduced absorption of bile 
acids and cholesterol due to an increased intestinal viscosity (Chapter 5). If this is true, than it can be speculated that $\beta$-glucan not only decreases absorption of bile acids, but also of plant sterols. Plant sterols affect cholesterol absorption due to effects within the intestinal lumen and within the intestinal cells. This may suggest that if $\beta$-glucan reduces absorption of plant sterols into enteracytes, the cholesterol-lowering properties of plant sterols will be smaller. If this is true, a combination of $\beta$-glucan with plant sterols will result in a smalleir cholesterol-lowering effect than each compound separately. Therefore, the cholesterollowering effect of combinations of plant sterols with $\beta$-glucan needs further investigation. Dietary portfolios combining plant sterols, viscous fiber, soy protein and almonds reduced serum concentration of LDL cholesterol by $21-23 \%$ and the ratio of total to HDL cholesterol by $15-18 \%[58,59]$. This indicated that different cholesterol-lowering ingredients could be used simultaneously to increase the cholesterol-lowering effect. In fact, reductions in LDL cholesterol were comparablle to those achieved by the statin lovastatin [58]. However, such a diet is very different from a typical western diet. It is therefore not likely that many people will consume such diets. A reduction in LDL cholesterol as observed during consumption of functionall foods with plant stanols or B-glucan will lower the need for cholesterol-lowering medication. This will reduce the costs of prescription of statins, the most commonly used cholesterol-lowering drugs. Recently however, the patent for production of some statins has expired, which might lead to the introduction of cheaper statins on the Dutch market. In the UK, low dose over-the-counter statins are soid already. If this will also be true in future in the Netherlands, the use of functional foods might reduce. On the other hand, effects of plant sterols and stanols are additive to the effect of statins $[11,60-62]$, suggesting that a combination of plant sterols or stanols with statins may reduce the dose of statins.

\section{A recommended diet comes in first place}

\section{Recommended changes in the Dutch diet}

A recommended diet is needed to stay healthy. Functional foods should be part of a healthy diet but can never counterbalance the effects of an unhealthy diet. Addition of a single component, like plant stanols, does not make an unhealthy diet healthy. Currently, the diet for many people in the Netherlands does not meet recommended intakes. It has been estimated that unfavourable diet compositions reduce life expectancy by 1.2 years in people over 40 years of age. In overweight people, this reduction is 0.8 years [63]. In the coming years special attention should be paid on intakes of energy, saturated fatty acids "trans fatty acids, fruit and vegetables and fish.

In the past 25 years the number of people with obesity has increased by approximately $50 \%$. In $200310 \%$ of men and $12 \%$ of women in the Netherlands were obese. Increases in obesity in adults are expected to increase by $50 \%$ in the coming 20 years. In addition, the number of overweight children increased by $50 \%$ between 1980 and 1997 . In 1997 about $7-16 \%$ of 
boys and 8-16\% of girls between 6 and 18 years of age were overweight. Obese people have a 5-12 times higher risk for diabetes mellitus type 2 and a 2-3 times higher risk for atherosclerosis and some types of cancer, making prevention of obesity an important issue [63]. Since obesity is the result of an imbalance between energy intake and energy expenditure, prevention of obesity therefore requires changes in dietary intakes and energy expenditure.

Saturated fatty acids and trans fatty acids have unfavourable effects on serum lipids and lipoproteins. The intake of saturated fatty acids is still higher then the recommended tolerable upper intake level of $10 \%$ of energy. In 1998 intake of saturated fatty acids was about $14 \%$ of energy in the Netherlands in 1998, and 13\% of energy in 2003 in men and women between 19 and 30 years of age $[64,65]$. Trans fatty acid intake was reduced during the past years, due to changes in food processing and approaches the tolerable upper intake level of $\leq 1 \%$ of energy in people between 19 and 30 years of age in 2003. Fish consumption provides unsaturated fatty acids that affect serum lipids and lipoproteins in a favourable way. However, fish consumption in the Netherlands is about $8 \mathrm{~g} / \mathrm{day}$, which is less then the recommended $70-280 \mathrm{~g}$ per week and will not provide the recommended $0.2 \mathrm{~g}$ of $\mathrm{n}-3$ fatty acids from fish per day $[65,66]$. Fruit and vegetable consumption is about half the recommended intakes $[64,65]$. Consumption of fruit and vegetables might reduce the risk of coronary heart disease and some types of cancer. In addition, fruit and vegetables provide dietary fibre. Increasing intakes of dietary fibres are associated with decreased risks of obesity, coronary heart disease and diabetes mellitus type 2. In addition, a diet with high amounts of vegetables and fruit might positively affect blood pressure.

To summarize, in the coming years changes in lifestyle should be encouraged to improve diets and increase the amount of exercise.

\section{How to Improve diets?}

It is a difficult task to improve diets, which is a collective responsibility of companies, the government and consumers. The possible role of companies has already been demonstrated for the intake of trans fatty acids, which has been reduced due to changes in food processing. In addition, food products reduced in fat, saturated fatty acids and/or energy contents are widely available, like light soft drinks, light chips, skimmed milk, low fat cheese etc. The role of food companies might be further increased by the development of food products with a reduced saturated fatty acid content. Also, since $33 \%$ of dailly energy intake is consumed between meals [65], reducing energy contents of snacks is a good strategy. In addition, meal sizes could be reduced. To stimulate the consumption of fruit and vegetables, fruit and vegetables could be sold in ready-to-eat portions as snacks, for example in canteens at schools or at work, the vegetable content in ready-to-eat meals could be increased, more selling places for fruit and vegetables could be created, and prices should not be higher than those of regular snacks. Canteens in schools, but also in other institutions and companies, could increase their choice of fruit and vegetable products, while keeping 
prices low. Increasing consumption of frut and vegetables is also likely to reduce energy and fat intake. However, it will remain difficult to increase intake of these foods. During the last years more vegetables and fruits are available during all seasons and they are more ofien ready-to-use. Despite these changes, daily consumption of fruit and vegetables is only $89 \mathrm{~g}$ and $100 \mathrm{~g}$. respectively, in men and women between 19 and 30 years of age in the Netherlands.

The government could have a role in increasing knowledge of Dutch consumers about a healthy dief by funding information campaigns. In addition, since the prevalence of overweight increases dramatically in children, it is important to give information about nutrition in schools. Consumers should be able to make healthy choices in supermarkets. Therefore, information about contents of energy, saturated fatty acids, vegetables and fruit should be given in such a way that it is easy to understand. Since intake of trans fatty acids is approximately on tolerable upper intake level, the need to decrease saturated fatty acids is higher and decreasing intake of trans fatty acid intake might be achieved by additional changes in food processing. The recommended amounts of $200 \mathrm{~g}$ of vegetables and 2 fruits per day is easy to understand. Giving information such as ".. provides $100 \mathrm{~g}$ of vegetables, which is half the amount that is daily recommended." makes consumers aware of their vegetable intake. For energy and saturated fatty acids, it is more difficult to provide information to consumers that is easy to understand. Since milk and dairy products, meat and oils and fats and snacks provide a large proportion of total intakes of energy, and saturated fatty acids, these products should be focussed on to lower intakes of energy and saturated fatty acids. Furthermore, the energy and fat content should be given not only per $100 \mathrm{~g}$ of product but also per portion where relevant. This might help people to compare products.

To help people making healthy choices, the use of labelling food products with colours has been proposed [67]. Food products should contain a green label if they are believed to have beneficial effects on health, a red label if they have adverse health effects and a yellow label if the have no beneficial and no adverse health effects. Green labelled products can be consumed regularly, while red labelled products should only be consumed by exception. However, the suggestion that green labelled products can be consumed regularly does not have to be true. For example, a green labelled food product can still provide energy and saturated fatty acids. Depending on how much of this green labelled product is consumed and depending on the saturated fatty acid intake during the rest of the day "consumption of this product fits in a healthy diet for a person. Apparently, nutrition is too complicated to use colours to distinguish healthy from unhealthy products. The assumption that there is a simple answer to the question whether a food product is healthy or not is not correct. Food products have positive as well as negative aspects simultaneously, and therefore there are no healthy or unhealthy food products. There are, however, healthy and unhealthy diets. A diet that 
contains a red labelled food product every day, is not necessarily unhealthy: In addition, it might be expected that people do not compare food products only within a food product group, but also between food groups. For example, one could draw the concllusion that it is better to take orange juice (green label) at breakfast instead of half-skimmed milk (yellow). But milk not only provides saturated fatty acids, which is the reason for its yellow label; but also other nutrients. Further, it is not the breakfast alone that determines if a diet is healthy or not. This depends on the food intake during the rest of the day. Together, it is arguable to use colour labels in supermarkets. It wrongly suggests that food products can be categorized as healthy and untiealthy.

Food labels can contain a lot of information on postullated health effects, on presence or absence of certain food components and on effects of the presence of certain nutrients. Some of this information might be correct, other information might be irrelevant or even misleading. For consumers, it is not always clear which claims are really true and what the real implications of the presence or absence of certain nutrients are. An important step in helping consumers to make weighed choices is to allow only health claims that have sufficient scientific basis. In the Netherlands, the "Code of Practice for assessing the scientific evidence for health benefits stated in health claims on food and drink product $1998^{\text {" }}$ is voluntary [31]. So, it is up to the food industries to decide whether or not their food product is tested for a claim. In addition ${ }_{\|}$if there is sufficient scientific evidence for a health claim as assessed by this Code of Practice, it is not allowed to refer to this Code on the label of the food product. Thus, for consumers it is not clear at all, which products might really have a health effect. This makes it very difficult for consumers to make healthy choices. The European Committee has worked on a new Regulation on nutrition and health claims made on food. According to the proposal, only claims based on scientific evidence will be allowed in future. This would be helpful for consumers to make choices based on information that is not misleading. In addition, food producers who use claims that have sufficient scientific evidence will no longer have to compete with food producers that use claims that are not true, have not sufficient scientific basis or are misleading. In addition, only meaningful information will be allowed. Clailming that lollipops contain $0 \%$ fat might be true, but is not relevant and wrongly suggests that they are healthy. In May 2006, the European Parliament held its first reading vote on the draft legislation and made a number of amendments. The Health Claims Regulation will undergo a second reading by both the Parliament and Councill, and is expected to be adopted in early 2006 [68].

Despite all efforts to help consumers to make healthy choices, it is the consumer who finally determines what he is going to eat. For people to make healthy choices they need knowledge about recommended intakes and food composition. Knowledge is certainly not enough to change eating behaviour, but is a first step. Changing eating behaviour is a very difficult task. Therefore, strategies that need the least changes in eating behaviour, will 
probably have the greatest chance to succeed. Food products with improved nutritional values are therefore of great importance.

Since obesity is the major health problem for the coming years ${ }_{4}$ focussing on prevention of obesity is important. Weight reduction decreases the risk of well-fare diseases such as coronary heart disease and diabetes mellitus. Since the prevalence of obesity is increased by a mismatch between energy intake and expenditure, efforts should also be made to increase energy expenditure.

The dramatic increase of obesity in children makes it necessary that education, focussing on both energy intake and expenditure, starts at childhood. Schools might have an important role in this regard.

To summarize, it is a challenge for the coming years to improve lifestyle, in order to increase the number of healthy years. This requires common efforts of government and business to help consumers to make healthy choices. Strategies to improve diets that need the least changes in eating behaviour will probably be the most effective. In this regard functional foods are helpful in making the healthy choice the easy choice. 


\section{References}

1. Assmann $G_{r}$ Cullen $P$, Erbey $\mathrm{I}_{\text {s }}$ Ramey DR, Kannenberg $F$ and Schulte $H$. Plasma sitosterd elevations are associated with an increased incidence of coronary events in men: results of a nested case-control analysis of the Prospective Cariovascular Munster (PROCAM) study. Nutrition, metabolism \& cardiovascular disease 2005; in press.

2. Katan MB, Grundy SM, Jones $P$, Law $M_{3}$ Miettinen T and Paoletti R. Efficacy and safely of plant stanols and sterols in the management of bload cholesterol levels. Mayo Clin Proc 2003; 78:965-78:

3. Weststrate JA and Meijer GW. Plant sterol-enriched margarines and reduction of plasma totaland LDL-cholesterol concentrations in normocholesterolaemic and mildly hypercholesterolaemic subjects. Eur J Clin Nutr 1998; 52:334-43.

4. Normen L, Dutta $P_{1}$ Lia $A$ and Anderssan $H$. Soy sterol esters and beta-sitostanol ester as inhibitors of cholesterol absorption in human small bowel. Am J Clin Nutr 2000; 71:908-13.

5. Hallikainen MA, Sarkkinen ES, Gylling $H_{*}$, Erkkila AT and Uusitupa MIJ. Comparison of the effects of plant sterol ester and plant stanol esters-enriched margarines in lowering serum cholesterol concentrations in hypercholesterolaemic subjects on a low-fat diet. Eur J Clin Nutr $2000 ; 54: 715-25$.

6. Vanhanen HT, Kajander J, Lehtowirta $H$ and Miettinen TA. Serum levels, absorption efficiency. faecal elimination and synthesis of cholesterol during increasing doses of dietary sitostanol esters in hypercholesterolaermic subjects. Clin Sci Colch $1994 ; 87: 61-7$.

7. Maki KC, Davidson MH, Umporowicz DM, et al. Lipid responses to plant-sterol-enriched reduced-fat spreads incorporated into a National Cholesterol Education Program Step I diet. Am $J$ Clin Nutr 2001; 74:33-43.

8. Gylling $\mathrm{H}$ and Miettinen TA. Baseline intestinal absorption and synthesis of cholesterol regulate its response to hypolipidaemic treatments in coronary patients. Atherosclerosis 2002; 160:47781.

9. Nguyen TT, Dale LC, won Bergmann $\mathrm{K}$ and Croghan IT. Cholesteral-lowering effect of stanol ester in a US population of mildly hypercholesterolemic men and women: a randomized controlled trial. Mayo Clin Proc 1999; 74:1198-206.

10. Jones PJ, Raeini-Sarjaz M, Nitanios FY, Vanstone CA, Feng JY and Parsons WE. Modulation of plasma lipid levels and cholesterol kinetics by phytosterol versus phytostanol esters. J Lipid Res 2000; 41:697-705.

11. Neil HA, Meijer GW and Roe LS. Randomised controlled trial of use by hypercholesterolaemic patients of a vegetable oil sterol-enriched fat spread. Atherosclerosis 2001; 156:329-37.

12. Mussner MJ, Parhofer $K G$, Von Bergmann $K$, Schwandt $P$, Broedl $U$ and Otto $C$. Effects of phytosterol ester-enriched margarine on plasma lipoproteins in mild to moderate hypercholesterolemia are related to basal cholesterol and fat intake. Metabolism 2002; $51: 189$ 94. 
13. Ketomaki A, Gylling $H$ and Miettinen TA. Non-cholesterol sterols in serum, lipoproteins, and red cells in statin-treated FH subjects off and on plant stanol and sterol ester spread. Clin Chim Actat 2005; 353:75-86.

14. Ostlund RE, Jr., McGill JB, Zeng CM, et al. Gastrointestinal absorption and plasma kinetics of soy Delta(5)- phytosterols and phytostanois in humans. Am J Physiol Endocrinol Metab 2002; 282:E911-6.

15. Salen G, Patel S and Batta AK. Sitosterolemia. Cardiovasc Drug Rev 2002; 20:255-70.

16. Sudthop T, Gottwald BM and Von Bergmann $K$. Serum plant sterols as a potential risk factor for coronary heart disease. Metabolism 2002; 51:1519-21.

17. Rajaratnam RA, Gylling $H$ and Miettinen TA. Independent association of serum squalene and noncholesterol sterols with coronary artery disease in postmenopausal women. J Am Coll Cardiol 2000; 35:1185-91.

18. Wilund $K R_{1}, Y_{u} L_{n}, X_{u} F_{n}$ et al. No association between piasma levels of plant sterols and atherosclerosis in mice and men. Arterioscler Thromb Vasc Biol 2004; 24:2326-32.

19. Moghadasian $M H_{1}$, McManus $B M_{8}$ Pritchard $\mathrm{PH}$ and Frohlich JJ. "Tall oil"-derived phytosterols reduce atherosclerosis in ApoE- deficient mice. Arterioscler Thromb Vasc Biol 1997:17:119-26.

20. Moghadasian MH, McManus BM, Godin DV, Rodrigues B and Frohlich JJ. Proatherogenic and antiatherogenic effects of probucol and phytosterols in apolipoprotein E-deficient mice: possible mechanisms of action. Circulation 1999; 99:1733-9.

21. Moghadasian MH, Godin DV, McManus BM and Frohlich JJ. Lack of regression of atherasclerotic lesions in phytosterol-treated apo E-deficient mice. Life Sci 1999; 64:1029-36.

22. Volger OL, Mensink RP, Plat J, Hornstra G, Havekes LM and Princen HMG. Dietary vegetable oil and wood derived plant stanol esters reduce atherosclerotic lesion size and severity in apoE ${ }^{\star 3} 3$-Leiden transgenic mice. Atherosclerosis 2001; 157:375-81.

23. Plat $\mathrm{J}$ and Mensink RP. Plant stanol and sterol esters in the control of blood cholesterol levels: mechanism and safety aspects. Am J Cardiol 2005; 96 (suppl):15D-22D.

24. Thompson GR and Grundy SM. History and development of plant sterols and stanol esters for cholesterol-Howering purposes. 2005 2005; 95 (supp)):3D-9D.

25. Tammi A, Ronnemaa $T$, Rask-Nissila L, et al. Apolipoprotein E phenotype regulates cholesterol absorption in healthy 13-month-old children-The STRIP Study. Pediatr Res 2001; 50:688-91.

26. Turnbull D, Whittaker MH, Frankos VH and Jonker D. 13-week oral toxicity study with stanol esters in rats. Regul Toxicol Pharmacol 1999; 29:216-26.

27. Davidson MH, Maki KC, Umporowicz DM, et al. Safety and tolerability of esterified phytosterols administered in reduced-fat spread and salad dressing to healthy adult men and women. J Am Coll Nutr 2001: $20: 307-19$.

28. De Jong N, Pijpers L, Bleeker JK and Ocke MC. Potential intake of phytosterols/-stanols: results of a simulation study. Eur J Clin Nutr 2004; 58:907-19.

29. Plat $J$, Kerckhoffs DA and Mensink RP. Therapeutic potential of plant sterols and stanols. Curr Opin Lipidol 2000; 11:571-6. 
30. Kerckhoffs DA Hornstra $G$ and Mensink RP. Cholesterol-lowering effect of beta-glucan from oat bran in mildly hypercholesterolemic subjects may decrease when beta-glucan is incorporated into bread and cookies. Am J Clin Nutr 2003; 78:221-7.

31. Stichting Voedingscentrum Nederland: Gedragscode Wetenschappelijke onderbouwing Gezondheidseffecten ten behoeve van Gezondheidsclaims voor Eet- en drinkwaren 1998. Den Haag: Stichting Voedingscentrum Nederland, 2003.

32. Available at: http:/www woedingscentrum.nl/NR/rdonlyres/69A98772-DC6D-4057-9D34 F2B90B152836/0/beoordelingsrapportPróFIT,pdf, 2005.

33. Delaney $B$, de Vogel $\mathbb{N}$ and Krul $C A$. Evaluation of the in vivo genetic toxicity of concentrated barley beta-glucan. Food Chem Toxicol 2004; 42:155-6.

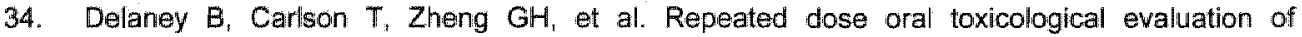
concentrated barley beta-glucan in CD-1 mice including a recovery phase. Food Chem Toxicol 2003; 41:1089-102.

35. Tappy $L$, Gugolz $E$ and Wursch $P$. Effects of breakfast cereals containing various amounts of beta-glucan fibers on plasma glucose and insulin responses in NIDDM subjects. Diabetes Care 1996; $19: 831-4$.

36. Braaten JT, Scott FW, Wood PJ, et al. High beta-glucan oat bran and oat gum reduce postprandial blood glucose and insulin in subjects with and without type 2 diabetes. Diabet Med $1994 ; 11: 312-8$.

37. Battlana $\mathrm{P}$, Ornstein $\mathrm{K}$, Minehira $\mathrm{K}$, et al. Mechanisms of action of beta-glucan in postprandial glucose metabolism in healthy men. Eur J Clin Nutr 2001; 55:327-33.

38. Belury MA. Dietary conjugated linoleic acid in health: physiological effects and mechanisms of action. Annu Rev Nutr 2002; 22:505-31.

39. Lee KN, Kritchevsky D and Pariza MW. Conjugated linolleic acid and atherosclerosis in rabbits. Atherosclerosis 1994; 108:19-25.

40. Wilson T, Nicolosi RJ, Chrysam M and Kritchevsky D. Conjugated linoleic acid reduces early aortic atherosclerosis greater than linleic acid in hypercholesterolemic hamsters. Nutr Res 2000; 20:1795-805.

41. Thomas Yeung $\mathrm{CH}$, Yang $L$, Huang $Y$, Wang $J$ and Chen $Z Y$. Dietary conjugated linolelc acid mixture affects the activity of intestinal acyl coenzyme $A$ : cholesterol acyltransferase in hamsters. Br J Nutr 2000; 84:935 41.

42. Nicolosi RJ, Rogers EJ Kritchevsky D, Scimeca JA and Huth PJ. Dietary conjugated linoleic acid reduces plasma lipoproteins and early aortic atherosclerosis in hypercholesterolemic hamsters. Artery 1997; 22:266-77.

43. Pariza MW. Perspective on the safety and effectiveness of conjugated linoleic acid. Am $J$ Clin Nutr 2004; 79:1132S-36S.

44. Mensink RP. Metabolic and health effects of isomeric fatty acids. Curr Opin Lipidol 2005; 16:2730 .

45. Gaullier JM, Halse J, Hoye $\mathrm{K}_{3}$ et al. Conjugated linoleic acid supplementation for 1 y reduces body fat mass in healthy overweight humans. Am J Clin Nutr 2004; 79:1118-25. 
46. Wang $Y$ and Jones PJ. Dietary conjugated linoleic acid and body composition. Am $J$ Clin Nutr 2004; 79:1153S-58S.

47. Berven $G$, Bye A. Hals $O$, el al. Safety of conjugated linoleic acid (CLA) in ovenweight or obese human volunteers. Eur J Lipid Sci Technol 2000; 102:455-62.

48. Gauller $\mathrm{JM}$, Halse $J$, Hoye $K$, et al: Supplementation wit conjugated linoleic acid for 24 months is well tolerated by and reduces body fat mass in healthy, overweight humans. $J$ Nutr 2005: 135:778-84.

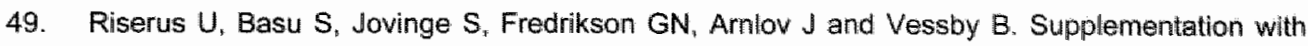
conjugated linoleic acid causes isomer-dependent oxidative stress and elevated Cureactive protein: a potential link to fatty acid-induced insulin resistance. Circulation 2002; 106:1925-9.

50. Clement $L$, Poirier $H$, Niot $I$, et al. Dietary trans-10,cis-12 conjugated linoleic acid induces hyperinsulinemia and fatty liver in the mouse. J Lipid Res 2002; 43:1400-9.

51. Warren $J M$, Simon VA, Bartolini G, Erickson KL, Mackey BE and Kelley DS. Trans-10, cis-12 $C L A$ increases liver and decreases adipose tissue lipids in mice: possible roles of specific lipid metabolism genes. Lipids $2003 ; 38: 497-504$

52. Degrace $P$, Demizieux $L$, Gresti $ل$, Chardigny JM, Sebedio JL and Clouet P. Association of liver steatosis with lipid oversecretion and hypotriglyceridaemia in C57BL/6j mice fed trans-10,cis-12 linoleic acid. FEBS Lett 2003; 546:335-9.

53. Fishbein $M$, Miner $M$, Mogren $C$ and Chalekson J. The spectrum of fatty liver in obese children and the relationship of senum aminotransferases to severity of steatosis. J Pediatr Gastroenterol Nutr 2003: 36:54-61.

54. Bellentani $S$, Saccoccio $G$, Masutti $F$, et al. Prevalence of and risk factors for hepatic steatosis in northern Italy. Ann Intern Med 2000; 132:112-7.

55. van Hoek B. Non-alcoholic fatty liver disease: a brief review. Scand J Gastroenterol 2004; Suppl 241:56-9.

56. Neuschwander-Tetri BA, Brunt EM, Wehmeier KR, Oliver D and Bacon BR. Improved nonalcoholic steatohepatitis after 48 weeks of treatment with the PPAR-g ligand Rosiglitazone. Hepatology 2003; 38:1008-17.

57. Riserus $U$, Arner $P$, Brismar $K$ and Vessby $B$. Treatment with dietary trans 10cis 12 conjugated linoleic acid causes isomer-specific insulin resistance in obese men with the metabollc syndrome. Diabetes Care 2002; 25:1516-21.

58. Jenkins DJ, Kendall CW, Marchie $A_{u}$ et al. Effects of a dietary portfolio of cholesterol-lowering foods vs lovastatin on serum lipids and C-reactive protein. Jama 2003; 290:502-10.

59. Jenkins DJ, Kendall CW, Marchie A, et al. The effect of combining plant sterols, soy protein, viscous fibers, and almonds in treating hypercholesterolemia. Metabolism 2003; 52:1478-83.

60. Simons LA. Additive effect of plant sterol-ester margarine and cerivastatin in lowering lowdensity lipoprotein cholesterol in primary hypercholesterolemia. Am J Cardiol 2002; 90:737-40.

61. Vuorio AF, Gylling $H_{*}$ Turtola $H_{*}$ Kontula $K$, Kelonen $P$ and Miettinen TA. Stanol ester margarine alone and with simvastatin lowers serum cholesterol in families with familial 
hypercholesterolemia caused by the FH-North Karelia mutation. Arterioscler Thromb Vasc Biol 2000; 20:500-6.

62. Blair SN, Capuzzi DM, Gottlieb SO, Nguyen T, Morgan JM and Cater NB. Incremental reduction of serum total cholesterol and low-density lipoprotein cholesterol with the addition of plant stanol ester-containing spread to statin therapy. Am J Cardiol 2000 86:46-52:

63. Rijksinstifuut voor Volksgezondheid en Milieu. Ons eten gemeten. Gezonde voeding en veilig woedsel in Nederland. Bithowen: Rijksinstituut voor Volksgezondheid en Milieu, 2004.

64. Voedingscentrum. Zo eet Nederland 1998. Resultaten van de Voedselconsumptiepeiling 1998. Den Haag: Voedingscentrum, 1998.

65. Voedingscentrum. Zo eten jongvolwassenen in Nederland. Resultaten wan de Voedselconsumptiepeiling 2003. Den Haag: Voedingscentrum, 2004.

66. Gezondheidsraad. Voedingsnormen. Energie, eiwitten, vetten en verteerbare kaolhydraten., in publicatie nr 2001/19R (gecorrigeerde editie: juni 2002). Den Haag: Gezondheidsraad, 2001.

67. Consumentenbond. Dikke problemen, magere aanpak. Consumentengids 2004; nowember:501.

68. Avallable at:

http://www.bma.org.uk/ap.nsf/Content/Eurobrief1 12005\#CouncilSideswithCommissionove, 2005. 


\section{Summary}




\section{Summary}

High serum concentrations of total and LDL cholesterol and of triacylcglycerol, as well as low serum concentrations of HDL cholesterol are risk factors for cardiovascular disease. Changing the composition of the diet can positively affect this lipoprotein profile. A lot of people in the Netherlands, however, consume a diet that contains too many saturated fatty acids. Although a diet in accordance with the dietary reference intakes should be recommended, functional foods are helpful to further improve the serum lipoprotein profile. This thesis describes three human intervention studies and a meta-analysis on effects of plant stanols, $\beta$-glucan and conjugated linoleic acid as possible: functional food components on cardiovascular risk markers.

Many studies have already demonstrated that plant sterols and stanols lower serum concentrations of total and LDL cholesterol by reducing cholesteral absorption (Chapter 2). In addition, it has been shown that serum concentrations of plant sterols increase during consumption of plant sterol enriched products. Although the same is true for plant stanols, only for plant sterols there are indications that high serum concentrations of plant sterols are positively associated with cardiovascular disease. As consumption of plant stanols reduces

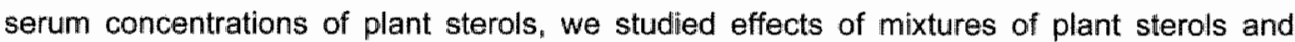
stanols on serum concentrations of plant sterols (Chapter 3 ). In a cross-over design healthy men $(n=15)$ and women $(n=29)$ daily consumed for three weeks $1.5 \mathrm{~g}$ of plant sterols plus 0.6 $\mathrm{g}$ of plant stanols (high sterol margarine), $1.0 \mathrm{~g}$ of each (low sterol margarine) or control margarine. Compared to the control period, serum cholesterol-standardized concentrations of campesterol and sitosterol increased. These increases were proportional to intakes. When expressed per $g$ of daily plant sterol intake, they did not differ during the low sterol or high sterol period. Therefore, we concluded that the change in serum concentrations of plant sterols is proportional to plant sterol intake and not affected by the simultaneous intake of plant stanols. In addition, the high and low sterol margarine were equally effective in reducing serum concentrations of LDL cholesteral, but to a lesser extent than expected from previous studies. We speculated that this smaller decrease was due to the low mean baseline serum LDL cholesterol concentrations of the subjects and decided to carry out a meta-analysis, based on five studies carried out before at our Department. The aim of the meta-analysis was to study effects of subjects' baseline characteristics that may be related to the cholesterol-lowering effects of plant stanols (Chapter 4). The results showed that decreases in LDL cholesterol and the ratio of total to HDL cholesterol during plant stanol consumption were most pronounced in subjects with the highest baseline levels of these cardiovascular risk markers ( $p<0.001)$. In addition, plant stanols may decrease serum concentrations of triacylglycerol especially in people with high baseline serum concentrations of triacylglycerol $(p<0.001)$. Together, these results indicated that functional foods with plant stanols are of 
benefit for most people with high serum concentrations of LDL cholesterol and triacylglycerol and a high total to $\mathrm{HDL}$ cholesterol ratio.

Another component that might have beneficial effects on the serum lipoprotein profile is $\beta$. glucan, but results of placebo-controlled intervention studies are less consistent than those of studies with plant sterols and stanols. At the moment, it is hard to predict the cholesterollowering effect of a $\beta$-glucan enriched product. Further, the mechanism of action is still not completely elucidated. We therefore examined effects of a $\beta$-glucan enriched fruil juice on serum lipids and lipoproteins and on markers of cholesterol absorption and cholesterol synthesis (Chapter 5). In a parallel design, subjects consumed daily a fruit juice with $5 \mathrm{~g}$ of rice starch (placebo, $n=22$ ) or $\beta$-glucan from oat $(n=25)$ for five weeks. Compared with the placebo group, serum concentrations of total and LDL cholesterol decreased by $4.8 \%$ $(p<0.05)$ and $7.7 \%(p<0.01)$, respectively. A proposed mechanism of action of $\beta$-glucan is a decreased absorption and an increased excretion of bile acids. Our study showed that also reduced cholesterol absorption contributes to the cholesterol-lowering effects of $\beta$-glucan, without affecting plasma concentrations of lipid soluble anti-oxidants.

A multi-center pilot study suggested that cis-9, trans-11 conjugated linoleic acid (CLA) lowers small dense LDL cholesterol concentrations in moderately overweight subjects, especially in subjects with LDL phenotype B. This phenotype, characterized by high proportions of small dense LDL, is related to an approximately threefold increase in risk of coronary heart disease. Initiated by the results of the pillot study, we studied effects of CLA on the serum lipoprotein profile in a larger number of subjects with LDL phenotype B (Chapter 6). Volunteers were divided into three groups consuming daily a drinkable dairy product not enriched with CLA (placebo, $n=34$ ), the same product enriched with $3 \mathrm{~g}$ of cis-9, trans- 11 CLA $(n=34)$, or the dairy product enriched with $3 \mathrm{~g}$ of trans-10, cis-12 CLA $(n=19)$ for 13 weeks. Unfortunately, both CLA isomers did not lower small dense LDL cholesterol concentrations.

Taken together, plant stanols are useful for lowering serum concentrations of LDL cholesterol and the ratio of total to HDL cholesterol, especially at higher baseline serum concentrations of $\mathrm{LDL}$ and the ratio of total to $\mathrm{HDL}$ cholesterol. Effects on serum triacylglycerol concentrations need to be examined in future trials in subjects with elevated serum concentrations of triacylglycerol. $\beta$-glucan incorporated in a fruit juice reduced serum concentrations of total and LDL cholesterol in part by lowering cholesterol absorption. Finally, cis-9, trans-11 CLA and trans-10, cis-12 CLA isomers do not favourably affect the serum lipoprotein profile and should therefore not be recommended to reduce the risk of cardiovascular disease. 
Samenvatting 


\section{Samenvatting}

Hoge serum concentraties van totaal cholesterol, LDL cholesterol en triacylglycerol, en lage concentraties van HDL cholesterol zijn risicofactoren voor hart- en vaatziekten. Deze risicofactoren kunnen positief worden beïnvloed door de voeding. Veel mensen in Nederland gebruiken echter een voeding die teveel verzadigd vet bevat. Hoewel een voeding volgens de Voedingsnormen aanbevolen wordt kunnen daarnaast functionele voedingsmiddelen helpen om het serumlipoproteinenprofiel te verbeteren. Dit proefschrift beschrijft drie humane interventiestudies en een meta-analyse naar effecten op risicofactoren voor hart-en vaatziekten van plantenstanolen, $\beta$-glucan en geconjugeerd linolzuur (CLA) als mogelijke componenten van functionele voedingsmiddelen.

Veel studies hebben laten zien dat plantensterolen en -stanolen serum concentraties van totaal en LDL cholesterol verlagen door de absorptie van cholesterol te verminderen (Hoofdstuk 2). Serum concentraties van plantensterolen stijgen tijdens consumptie van voedingsmiddelen verrijkt met plantensterolen. Hoewel dit ook geldt voor plantenstanolen, zijn er alleen voor plantensterolen aanwijzingen dat een hoge serum concentratie positief geassocieerd is met hart- en vaatziekten. Omdat consumptie van plantenstanolen serum concentraties van plantensterolen verlaagt, hebben wij de effecten van mengsels van plantensterolen en -stanolen op serum plantensterolconcentraties bestudeerd (Hoofdstuk 3). In een cross-over studie consumeerden gezonde mannen $(n=15)$ en vrouwen $(n=29)$ gedurende drie weken $1,5 \mathrm{~g}$ plantensterolen plus $0,5 \mathrm{~g}$ plantenstanolen (hoog sterol margarine), 1,0 g plantensteralen plus 1,0 g plantenstanolen (laag sterol margarine) of een contrale margarine. Ten opzichte van de controle groep stegen de serum cholesterolgestandaardiseerde concentraties van campesterol en sitosterol. Deze stijgingen waren gerelateerd aan de inname. Wanneer de stijging werd uitgedrukt per gram plantensterol inname per dag, werd geen verschil gevonden tussen de hoog en laag sterol margarine. Wij hebben daarom geconcludeerd dat de verandering in serum concentraties van plantensterolen gerelateerd is aan de inname en niet beïnvloed wordt door een gellifktijdige inname van plantenstanolen. Verder werd gevonden dat de hoog en laag sterol margarine even effectief waren in het verlagen van het LDL cholesterol gehalte, maar dat de gevonden dalingen lager waren dan op grond van eerdere studies werd verwacht. Wij speculeerden dat deze geringere daling een gevolg zou kunnen zijn van lage serum LDL cholesterol concentraties van de proefpersonen bij aanvang van de studie. Om dit verder te bestuderen werd een meta-analyse uitgevoerd, waarbij gebruik werd gemaakt van vijf eerder door ons uitgevoerde studies. Het doel van deze meta-analyse was om na te gaan of kenmerken van de proefpersonen bij aanvang van de studies gerelateerd waren aan het cholesterolverlagende effect van plantenstamolen (Hoofdstuk 4). De resultaten lieten zien dat de dalingen in LDL cholesterol en in de ratio totaal / HDL cholesterol tijdens consumptie van plantenstanolen het meest uitgesproken waren bil proefpersonen met hoge waarden van 
deze risicofactoren voor hart- en vaatziekten $(p<0,001)$. Bovendien verlaagden plantenstamolen serum concentraties van triacylglycerol, met name bij mensen met een hoge triacylglycerol concentratie bij aanvang van plant stanol consumptie $(p<0,001)$. Deze resultaten laten dus zien dat functionele voedingsmiddelen met plantenstanolen positieve effecten hebben voor de meeste mensen met hoge serum LDL en triacylglycerol concentraties en een hoge totaal / HDL cholesterol ratio.

Een andere component met mogelijk gunstige effecten op het serumiipoproteinenprofiel is $\beta$ glucan, maar resultaten van placebo-gecontroleerde interventie studies zijn minder eenduidig dan die voor plantensterolen en -stanolen. Op dit moment is moeilijk te voorspellen of een product verrijkt met $\beta$ glucan cholesterolverlagend werkt. Bovendien is het mechanisme achter deze cholesterolverlaging nog steeds niet geheel opgehelderd. Wij bestudeerden daarom de effecten van een vruchtendrank verrijkt met $\beta$-glucan op serum lipiden en lipoproteinen en op markers voor cholesterolabsorptie en cholesterolsynthese (Hoofdstuk 5). In een parallel design consumeerden proefpersonen dagelijks gedurende vijf weken een vruchtendrank met $5 \mathrm{~g}$ rijstzetmeel (placebo, $n=22$ ) of $\beta$-glucan afkomstig uit haver ( $n=25$ ). Ten opzichte van de placebo groep daalden de serum concentraties van totaal en LDL cholesterol met respectievelijk $4,8 \% \quad(p<0,05)$ en $7,7 \% \quad(p<0,01)$. Een mogelijk werkingsmechanisme van $\beta$-glucan is een verminderde absorptie en verhoogde excretie van galzuren. Onze studie liet zien dat ook een verminderde absorptie van cholesterol bijdraagt aan het cholesterolverlagende effect van $\beta$-glucan. Er werd geen effect gevonden van $\beta$ glucan op plasma concentraties van vetoplosbare anti-oxidanten.

Resultaten van een pilot studie suggereerden dat cis-9, trans-11 geconjugeerd linolzuur (CLA) de concentratie van small dense LDL cholesterol verlaagde bij proefpersonen met matig overgewicht. Dit effect werd met name gevonden bij personen met LDL fenotype B. Dit fenotype, dat gekarakteriseerd wordt door hoge concentraties small dense LDL "geeft een verdrievoudiging van het risico op hart- en vaatziekten. Gebaseerd op de uitkomsten van deze pilot studie, hebben wij vervolgens de effecten van CLA op het serumlipoproteïnenprofiel bestudeerd in een grotere groep proefpersonen met LDL fenotype $B$ (Hoofdstuk 6). Vrijwilligers werden verdeeld over drie groepen die gedurende 13 weken dagelijks een zuivelproduct dronken dat niet verrijkt was met CLA (controle groep, $n=34$ ), hetzelfde product verrijkt met $3 \mathrm{~g}$ cis-9, trans-11 CLA (n=34) of het zuivelproduct verrijkt met $3 \mathrm{~g}$ trans-10, cis-12 CLA $(n=19)$. Helaas veranderde geen van beide CLA isomeren lets aan de concentratie van small dense LDL cholesteral.

Samenvattend concluderen wij dat plantenstanolen de serum concentraties van LDL cholesterol en de ratio totaal/ HDL cholesterol meer verlagen naarmate de aanvangswaarden van LDL cholesterol en de ratio totaal/ HDL cholesterol hoger zijn. De effecten op serum triacylglycerolconcentraties dienen in toekomstige studies met proefpersonen met een verhoogd triacylglycerolgehalte verder onderzocht te worden. \$- 
glucar toegevoegd aan een vruchtendrank verlaagt de serum concentraties van totaal en LDL cholesterol, deels door een verminderde absorptie van cholesterol. Cis-9, trans-11 CLA en trans-10, cis-12 CLA tenslotte hebben geen positieve effecten op het serumlipoproteinenprofiel en zouden daarom niet aanbevolen moeten worden om het risico op hart-en vaatziekten te verlagen. 


\section{Dankwoord}




\section{Dankwoord}

Zoals velen al voor mij in hun dankwoord hebben geschreven "kan ook ik niet anders dan constateren dat je niet op eigen houtje kunt promoveren. De hulp en steun van heel veel mensen hebben entoe bijgedragen dat dit boekje tot stand is gekomen.

Als eerste wil ik op deze plaats mijn promotor Ronald Mensink bedanken. Ronald, jij hebt mij de mogelijkheid gegeven om te promoveren. lk heb onze samenwerking altijd als erg prettig ervaren en ik heb veel van je geleerd.

Op de tweede plaats een woord van dank aan mijn co-promotor. Jogchum, het is alweer heel wat jaren gelleden dat iij mijn tutor was tijdens het blok Voeding. Je vertelde dat je iets deed met plant stanolen en functional foods. Nou, dat leek me wel wat. En dus ging ik stage lopen en werd jij mijn begeleider. Vanuit Bonn woor een belangrijk deel, maar dat leverde geen problemen op. Jogchum, bedankt voor je enthousiasme en de fijne samenwerking!

De beoordelingscommissie, bestaande uit Prof. Dr. Ir. W.H.M. Saris, Prof. Dr. M.H. Hofker, Prof. Dr. Em. G. Hornstra, Prof. Dr. A.M.W.J. Schols en Dr. Ir. P.L. Zock, will ik bedanken voor het beoordelen van dit proefschrift. Prof. Dr. Em. G. Hornstra wil ik bovendien bedanken voor het bespreken van het manuscript.

Tijdens de uitvoering van de studies kon ik altijd rekenen op de hulp van een aantal analisten: Frank, Maurice, Sjoerd en Hasibe, dank jullie well voor het helpen uitvullen van de oneindige rijen epjes en analyseren van de monsters! Om de epjes te vullen was er bloed nodig van de proefpersonen: bedankt allemaal! Anita, Lucie, Edith, Frank, Angelina, Marco en Joan en verder iedereen die zo nu en dan eens inviel als dat nodig was (Ariënne, Myriam en Elke), allemaal heel erg bedankt voor alle bloedafnames! Verder wil ik op deze plaats ook Angelina en Cathelijne bedanken, die een groot aandeel hebben gehad bij de uitvoering van respectievelijk de $\beta$-glucan studie en de CLA studie. Ook de diëtisten Heidi, Imke, Marlouke, Mirjam en Kirsten: bedankt voor de hulp in de "winkel". Nu we afhankelijk zijn van het gebruik van computers, zlin we ook afhankelijk van een paar mensen die echt verstand hebben van deze apparaten; Loek en Paul, ook mijn Mac deed soms niet wat "ie moest doen. Na een bezoekje aan een van jullie kwam het altijd toch weer goed. Geweldig! Ook alle medewerkers en ex-medewerkers van het secretarlaat wil ik bij deze bedanken voor hun hullp.

Terugkijkend op die vier jaar bij Humane Biologie , concludeer ik dat ik er met plezier heb gewerkt. Dat kwam niet in de laatste plaats door leuke collega's! Als eerste wil ilk mijn excollega's en tevens paranimfen bedanken: Ariënne, ik vond het super om jouw als kamergenote te hebben! $\mathrm{k}$ geloof dat we een beetje gezien werden als een soort Jut en Jul die altijd samen koffie gingen halen. We hadden ook discussies over plant stanolen, ook al geloofde Ronald dat misschien niet altijd als hij ons zag zitten praten. Julian, tijdens de studie hebben we heel wat verslagen samen geschreven. Ik vond het dan ook erg leuk dat we later collega"s werden! Ariënne en Julian, jullie begrijpen wel dat ik erg blij ben dat jullie willen optreden als paranimfen! Dank jullie wel voor allie hulp. 
Verder ben ik alle lunches, spelavonden, fotokijkavonden etc. nog niet vergeten. Kirsten (tof om jou als kamergenote te hebben en de uitdrukking "Ik schud me" zal ik nooil meer vergeten!), Elke, Marjolijn, Frank. Pascal, Stefan, Jacquelien, Julia, Myriam, Petra, Mirjam, Daniëlle "Maurice, Sjoerd, Angelina, Annemarie, Wilhelmine en Susan; dank jullie wel voor de leuke tijd! Humane Biologie is natuurlijk meer dan de middenlob. Ook al die andere (ex-)collega's will ik bedanken voor de leuke tijd, de vakgroepuitstapjes, kerstdiners, Carnavalsvrijdagen in de Perroen, en al die andere dingen die het werken bij Humane Biologie gezelig maakten.

Maarten en Mario, bedankt voor jullie creatieve bijdragen!

Op deze plek wil ik verder graag mijn ouders bedanken. Pap en mam, dank jullie wel voor alle steun en relativerende woorden ("neem ook wat rust in de vakantie, dan komt dat proefschrift maar wat later af"). En mam, nu het proefschrift af is, gaan we gauw weer eens een dagje winkelen.

De laatste regels van dit dankwoord zijn gewijd aan degene die de meeste last heeft ondervonden van mijn promotieperikelen. Lieve Roeland, misschien komt het wel door jou dat dit boekje uiteindelijk is afgekomen. Jij weet als geen ander dat het afronden van het proefschrift in combinatie met een drukke baan in Nijmegen, het vele reizen "het door de week uit een weekendtas leven en de vakanties die opgingen aan het schrijven, me soms zwaar viel. Jij bent degene geweest die me dan weer moed insprak om het toch af te maken. $\mathrm{Nu}$ is het dan eindelijk zover. Ik denk nog hard na over hoe ik je kan bedanken voor al die bemoedigende woordien en alle hulp. 


\section{List of publications}




\section{List of publications}

- Elke Naumann, Jogchum Plat and Ronald P. Mensink. Plant sterols and plant stanols, fipoprotein metabolism, and cardiovascular disease. Nutrition and Heart disease. Causation and prevention. Chapter 15 . Editors R.R. Watson and V.R. Preedy. CRC Press LLC, Florida, USA, 2004.

- Elke Naumann, Jogchum Plat and Ronald P. Mensink. Changes in serum concentrations of non-cholesterol sterols and lipoproteins in healthy subjects do not depend on the ratio of plant sterols to stanols in the diet. Journall of Nutrition 133: $2741-2747,2003$.

- Elke Naumann, Jogchum Plat, Arnold D.M. Kester, and Ronald P. Mensink. The baseline serum lipoprotein profile is related to plant stanol induced changes in serum lipids and lipoproteins. Submitted

- Elke Naumann, Angelina B. van Rees, Gunilla Önning, Rickard Öste, Markus Wydra and Ronald P. Mensink. $\beta$-Glucan incorporated into a fruit drink effectively lowers serum LDL cholesterol concentrations. In press

- Elke Naumann, Yvon A. Carpentier, Asgeir Saebo, Taous S. Lassel, Jean-Michell Chardigny, Jean-Louis Sébédio and Ronald P. Mensink. Cis-9, trans- 11 and trans10 , cis-12 conjugated linoleic acid (CLA) do not affect the plasma lipoprotein profile in moderately overweight subjects with LDL phenotype B. Atherosclerosis, 2005: In press

- E. Naumann, Y.A. Carpentier, A. Saebo, T.S. Lassel, I.E. Dupont, R.P. Mensink and J-L. Sébédio. Conjugated linoleic acid (CLA) does not improve LDL phenotype in moderately overweight subjects with LDL phenotype B. Abstract

- E. Naumann, Y.C. Luiking, J. Plat, D.A.J.M. Kerckhoffs and R.P. Mensink. Effects of different ratios of palmitic and linoleic acids in the diet on palmtic acid oxidation. Abstract

- E. Naumann, J. Plat and R.P. Mensink. Adding plant stanols to plant sterols does not prevent the increase in serum plant sterol concentrations. Abstract 
- E. Naumann and R.P. Mensink. $\beta$-Glucan: een cholesterolveriager? Wateroplosbare voedingsvezels en de preventie van hart- en vaatziekten. Voeding Nu: 5: 9-11, 2003. 


\section{Curriculum Vitae}


on July 7,1976 , in Tegelen. After finishing secondary school at the lenlo, she studied Nutrition and Dietetics at the Hogeschool van ere she graduated in 1998. In the same year she started her laastricht University, where she studied Biological Heaith Sciences sciences. Her internship was performed at the Department of Human id effects of plant sterols and stanols on serum lipids and ting in 2000 , she worked at the Department of Human Biology as a ant and PhD-student. She conducted human dietary intervention ary fatty acids, plant sterols and stanols, $\beta$-glucan and CLA on ers ${ }_{n}$ especially the serum lipoprotein profile. Since August 2004 , she van Arnhem en Nijmegen at the Department of Nutrition and 